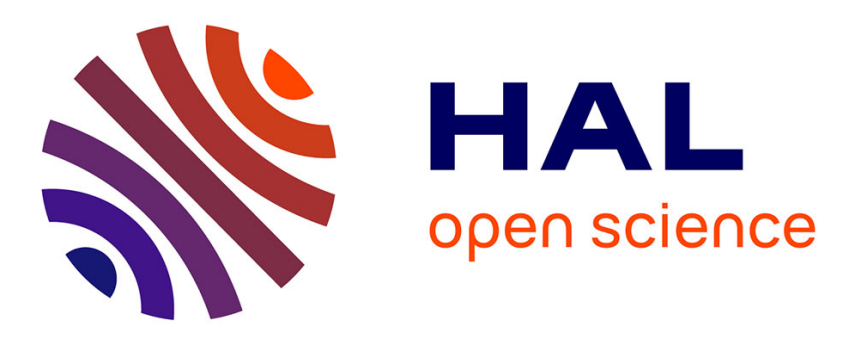

\title{
The chemistry of mavacurane alkaloids: a rich source of bis-indole alkaloids
}

Audrey Mauger, Maxime Jarret, Cyrille Kouklovsky, Erwan Poupon, Laurent Evanno, Guillaume Vincent

\section{- To cite this version:}

Audrey Mauger, Maxime Jarret, Cyrille Kouklovsky, Erwan Poupon, Laurent Evanno, et al.. The chemistry of mavacurane alkaloids: a rich source of bis-indole alkaloids. Natural Product Reports, 2021, 30 (10), pp.1852-1886. 10.1039/D0NP00088D . hal-03186969

\section{HAL Id: hal-03186969 \\ https://hal.science/hal-03186969}

Submitted on 31 Mar 2021

HAL is a multi-disciplinary open access archive for the deposit and dissemination of scientific research documents, whether they are published or not. The documents may come from teaching and research institutions in France or abroad, or from public or private research centers.
L'archive ouverte pluridisciplinaire HAL, est destinée au dépôt et à la diffusion de documents scientifiques de niveau recherche, publiés ou non, émanant des établissements d'enseignement et de recherche français ou étrangers, des laboratoires publics ou privés. 


\title{
The Chemistry of Mavacurane Alkaloids: A rich source of Bis-indole Alkaloids
}

\author{
Audrey Mauger, ${ }^{a}$ Maxime Jarret, ${ }^{a}$ Cyrille Kouklovsky, ${ }^{a}$ \\ Erwan Poupon, ${ }^{\mathrm{b} *}$ Laurent Evanno, ${ }^{\mathrm{b} *}$ Guillaume Vincent ${ }^{\mathrm{a} *}$ \\ a Institut de Chimie Moléculaire et des Matériaux d'Orsay (ICMMO) \\ Université Paris-Saclay, CNRS \\ 91405 Orsay, France
}

b Biomolécules: Conception, Isolement et Synthèse (BioCIS)

Université Paris-Saclay, CNRS

92290 Châtenay-Malabry, France

erwan.poupon@universite-paris-saclay.fr

laurent.evanno@universite-paris-saclay.fr

guillaume.vincent@universite-paris-saclay.fr

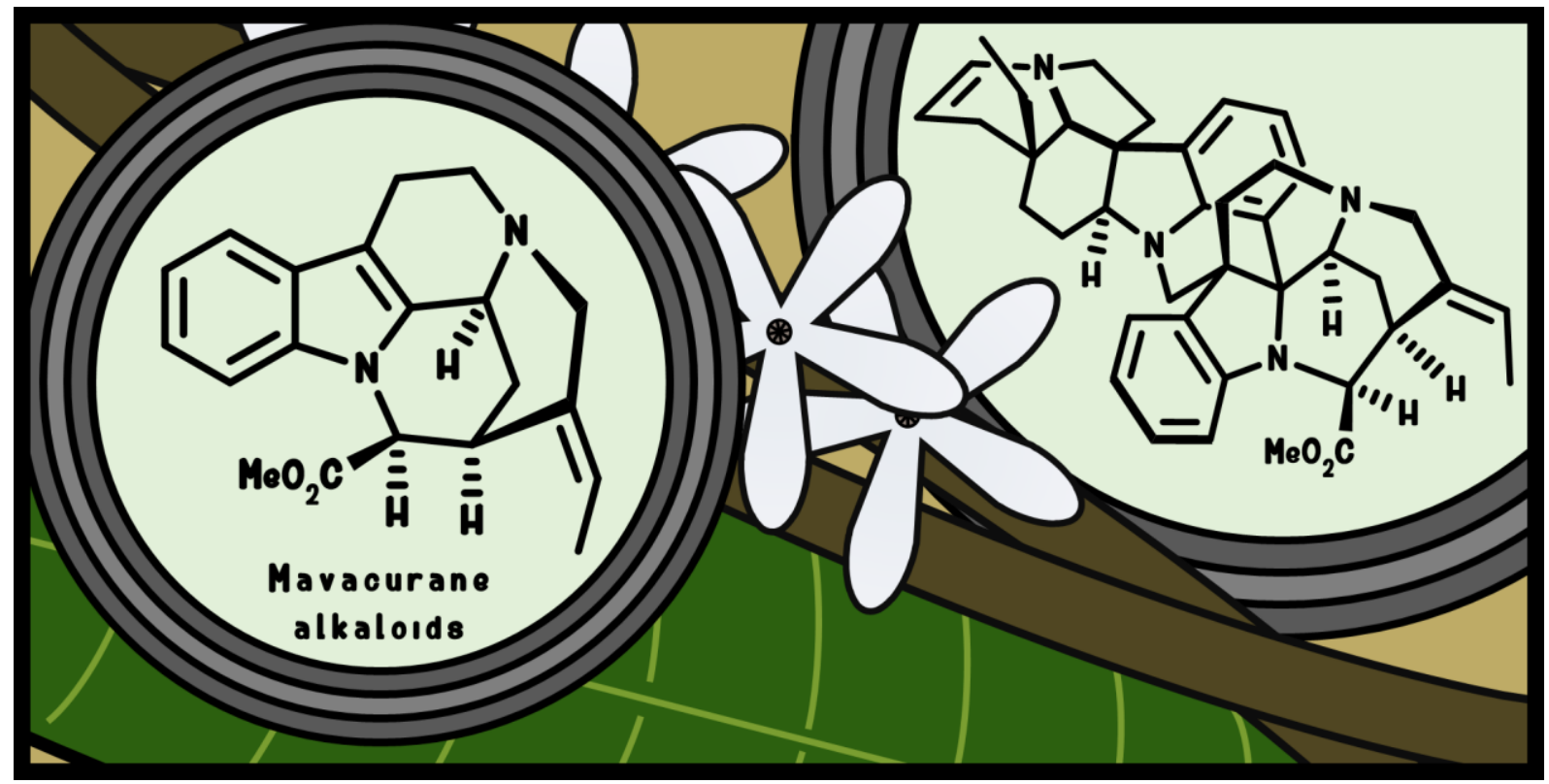

This review presents a complete coverage of the mavacuranes alkaloids since the early reports to date. Mavacuranes alkaloids are a restrictive sub-group of monoterpene indole alkaloids (MIA) represented by its two emblematic congeners C-mavacurine and pleiocarpamine. Their skeleton is defined by a bond between the indolic N1 nitrogen and the C16 carbon of the tetracyclic scaffold of the corynanthe group of MIA. A limited number of congeners is known, as this skeleton can be considered as a cul-desac in the main MIA biosynthetic routes. Thanks to an exalted enamine-type reactivity, mavacuranes are frequently involved in the formation of multimeric MIA scaffolds. This review cover isolation aspects and synthetic approaches toward the mavacurane core and bisindoles assemblies. To access the mavacurane core, only few strategies are reported, and the main synthetic difficulties usually originate from the important rigidity of the pentacyclic system. For the bisindoles assemblies, biomimetic routes were privileged and delivered the complex structures using smooth conditions. 


\section{Introduction}

\section{Structure and biosynthesis of the mavacuranes}

2.1 Structural elucidation of the mavacurane skeleton

2.2 Diversity of the mavacurane alkaloids

2.3 Biosynthesis of the mavacurane alkaloids

\section{Total synthesis of the mavacurane alkaloids}

3.1 Boekelheide and co-workers: total synthesis of ( \pm )-19,20-dihydro-norfluorocurine (unnatural) and ( \pm )-19,20-dihydro-normvacaurine (unnatural) via formation of the E ring and the N1-C16 bond as the last stage

3.2 Sakai and co-workers: hemisynthesis of (+)-16-epi-pleiocarpamine via formation of the C/D ring junction and the C3-N4 bond as the last stage

3.3 Harley-Mason and co-workers: total synthesis of ( \pm )-16-epi-pleiocarpamine, ( \pm )-16-epipleiocarpamine-N-oxide, ( \pm )-normavacurine and ( \pm )-C-mavacurine via formation of the $C / D$ ring junction and the C3-N4 bond as the last stage.

3.4 Bosch and co-workers: total synthesis of $(-)$ and ( \pm )-vinoxine via formation of the C2-C3 and C15-C16 bonds of the $E$ ring.

3.5 Bosch and co-workers: total synthesis of ( \pm )-2,7-dihydropleiocarpamine via formation of the C6-C7 bond of the $C$ ring as the last stage.

3.6 Poupon, Evanno, Vincent and co-workers: total synthesis of (+)-16-hydroxymethyl-pleiocarpamine, $(+)$-16-epi-pleiocarpamine and (+)-taberdivarine $\mathrm{H}$ via formation of the $\mathrm{E}$ ring and the N1-C16 bond as the last stage.

3.7 Takayama and co-workers: total synthesis of ( \pm )-pleiocarpamine, ( \pm )-16-epi-pleiocarpamine ( \pm )normavacurine and ( \pm )-C-mavacurine via formation of the E ring and the N1-C16 bond as the last stage.

\section{Mavacurane-containing bis-indole alkaloids}

4.1 Reactivity of pleiocarpamine

4.2 Macrolane-mavacurane bis-indoles

4.3 Sarpagane-mavacurane bis-indole

4.4 Aspidospermane-mavacurane bis-indoles

4.5 Akuammilane-mavacurane bis-indoles

4.6 Adducts of mavacuranes with non-indolic species

4.7 Comments upon "biosynthesis" of pleiocarpamine-based bis-indoles

5. Conclusion 


\section{Introduction}

The mavacurane alkaloids are part of the Monoterpene Indole Alkaloids (MIA) which compose a large family of plant metabolites with exceptional structural diversity and complexity isolated mainly from 3 families of species of tropical plants: Apocynaceae, Rubiaceae and Loganiaceae. MIA are divided in several groups and sub-groups of compounds which aroused from skeletal diversification of strictosidine (1), their common biosynthetic precursor. ${ }^{1}$

Corynanthe alkaloids are one of the most important group among the MIA since their tetracyclic structure give birth to several pentacyclic skeletons via formation of an additional bond such as for the heteroyohimbane ((C17)O-C19), yohimbane (C17-C18), excelsinidine (N4-C16), akuammilane (C7-C16), sarpagane (C5-C16) and mavacurane (N1-C16) alkaloids sub-groups (Scheme 1). Further skeletal rearrangement of some of these sub-groups produces other sub-families of MIA such as the strychnane, macrolane, secocurane, ibogane, aspidospermane, pseudo-aspidospermane or eburnane alkaloids. The presence of a bond between the indolic N1 nitrogen and the C16 carbon of the corynanthe architecture is characteristic of the mavacurane scaffold, a restrictive sub-family of the corynanthe alkaloid group.

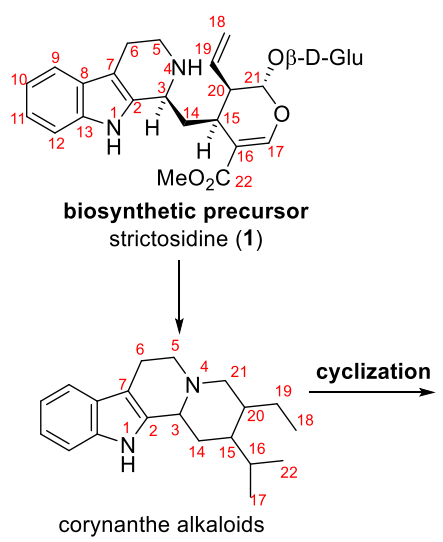

corynanthe alkaloids

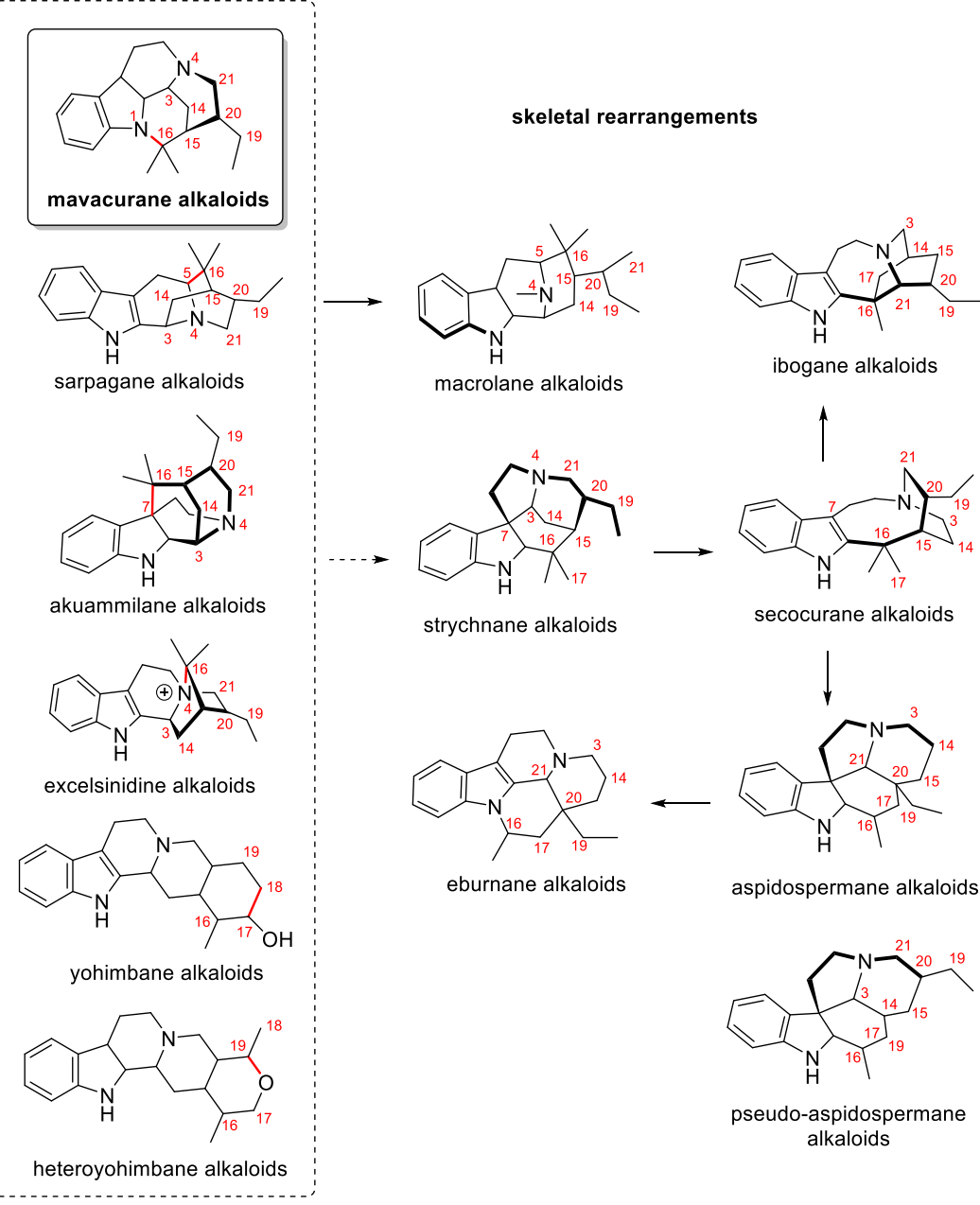

Scheme 1 Position of the mavacurane alkaloids among corynanthe-derived monoterpene indole alkaloids

Several of these sub-groups have been targets of choice in the context of total synthesis. It is particularly the case of the sarpagane, ${ }^{2}$ akuammilane ${ }^{3}$ strychnane $^{4}$ or aspidospermane ${ }^{4,5}$ alkaloids and their respective chemistries have been reviewed.

In contrast and until recently, less attention has been paid to the synthesis of members of the mavacurane family such as C-mavacurine (2) and pleiocarpamine (3), its emblematic members maybe due to the absence of any reported important biological activity (Scheme 2). Its unique exalted 
enamine-type reactivity gave to pleiocarpamine the ability to assemble with various MIA units to form highly intricate bisindole alkaloids such as villalstonine (4), bipleiophylline (5) or pycnanthinine (6). After several pioneering synthetic studies between the seventies and the nineties, the mavaruranes were abandoned as targets in total synthesis. However, a recent renaissance of synthetic works towards and from the mavacurane alkaloids is observed. Moreover, the diversity of their bis-indole alkaloids isolated is increasing. Therefore, we would like to present in this review the very rich chemistry of this family of natural products which was somehow forgotten for two decades.

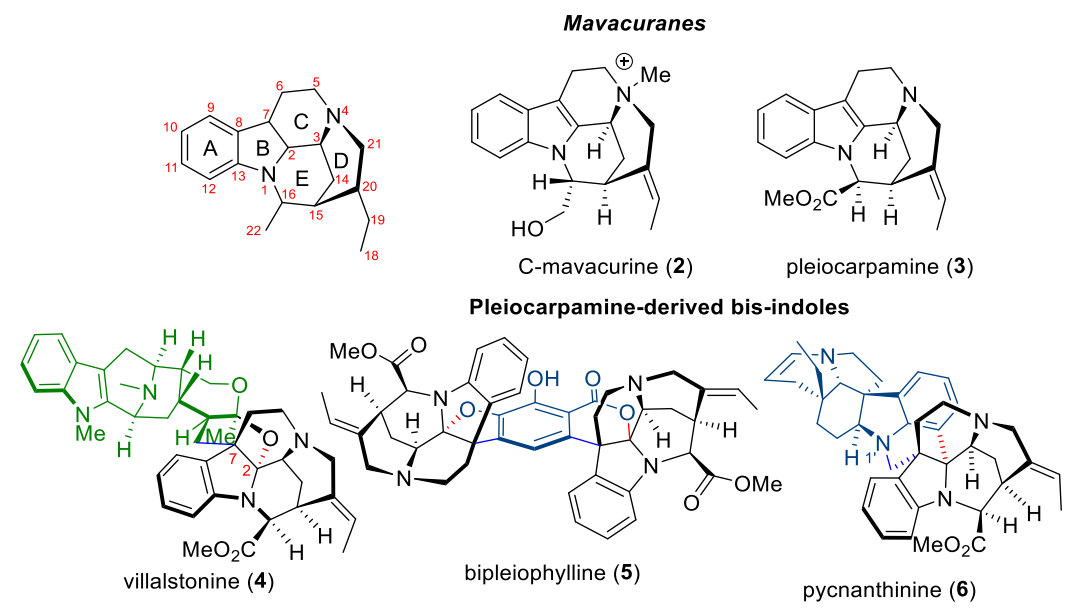

Scheme 2 Structures of C-mavacurine, pleiocarpamine and some important pleiocarpamine-derived bisindole alkaloids

\section{Structure and biosynthesis of the mavacuranes}

\subsection{Structural elucidation of the mavacurane skeleton}

C-Mavacurine, isolated from calabash curare (historically prepared from Strychnos sp.) in 1952 by Wieland and Merz, ${ }^{6}$ was named in reference to its presence in a drug called "mavacure" used for the preparation of arrow poisons in Venezuela. The structure of C-mavacurine, which gave its name to this family, was somehow related to C-fluorocurine which was discovered earlier in 1947 by Schmid and Karrer also from calabash curare. ${ }^{7}$ Preliminary structural studies allowed Schmid, Karrer and coworkers to propose the pentacyclic structures $\mathbf{8}$ and $\mathbf{1 0}$ for these two natural products (Scheme 3$).^{8}$ It was determined that $\mathrm{C}$-mavacurine possess the tetracyclic $A B C D$ framework of the corynanthe skeleton with a N4-methylated nitrogen. It was proposed that an additional ring would link the N1indolic nitrogen and the $\mathrm{C} 15$ carbon via a two-carbon linker (C16 and C17 carbons) in 8. The position of an extra hydroxy group was left open. The proposed structure $\mathbf{1 0}$ of C-fluorocurine displayed a spirooxindole scaffold in which the C6-carbon of the proposed structure 8 of C-mavacurine would have migrated from the $\mathrm{C} 7$ to the $\mathrm{C} 2$ indolic positions. In 1958 , it was proven ${ }^{9}$ that $\mathrm{C}$-alkaloid- $Y$, isolated in 1954 from calabash curare, $^{10}$ (also later named C-profluorocurine) ${ }^{11}$ was in fact 2,7dihydroxymavacurine (9) and may be an intermediate in the conversion of C-mavacurine into fluorocurine. The erroneously attributed pentacyclic skeleton which contains a 7-membered $\mathrm{E}$ ring was related to apogeissoschizine (7), a hydrolysis product of the bis-indole alkaloid geissospermine. The $\mathrm{N} 1-\mathrm{C} 17$ bond results from the condensation of the N1-indolic nitrogen and $\mathrm{C} 17$-aldehyde of the released corynanthe alkaloid geissoschizine. ${ }^{12}$

Later on, pleiocarpamine (3) (Scheme 3), was isolated from two species of Apocyanaceae: Pleiocapa Mutica Benth in 1961 by Kump and Hess ${ }^{13}$ and from Hunteria eburnea Pichon in 1963 by Taylor and co-workers. ${ }^{14}$

In an important report, the structures of C-mavacurine, C-alkaloid $\mathrm{Y}$ and $\mathrm{C}$-fluorocurine were revised by Hesse, Taylor, Schmid, Karrer and co-workers in $1996 .{ }^{15}$ The E ring is actually closed by only a onecarbon linker (C16 carbon) instead of a two-carbon linker. The C22 carbon is therefore an oxygenated functional group, outside the E-ring: a primary alcohol in the cases of C-mavacurine (2), C-alkaloid-Y (11) and fluorocurine (12) while it is a carboxylic methyl ester in the case of pleiocarpamine. 


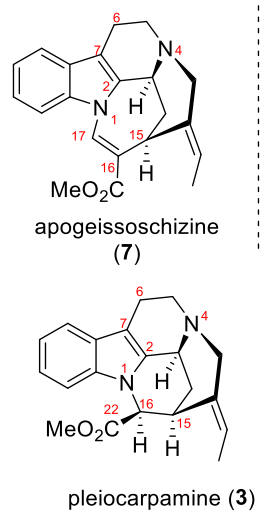

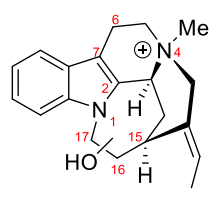

misassigned structure of C-mavacurine (8)

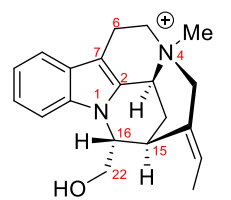

revised structure of C-mavacurine (2)

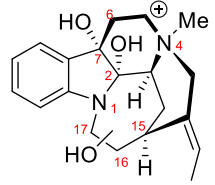

misassigned structure of C-alkaloid Y (9)

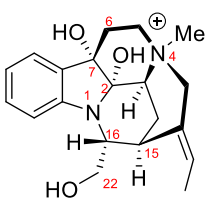

revised structure of C-alkaloid Y (11) (C-profluorocurine)

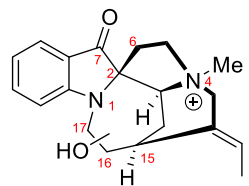

misassigned structure of C-fluorocurine (10)

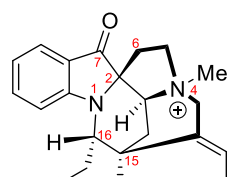

$\mathrm{HO}^{-22} \overline{\overline{\mathrm{H}}}$

revised structure of C-fluorocurine (12)

Scheme 3 Originally misassigned and reassigned structures of C-mavacurine, C-fluorocurine, C-alkaloid Y and pleiocarpamine

These structure elucidation studies were assisted by several synthetic transformations of the natural products (Scheme 4). The relationship between C-mavacurine and C-fluorocurine was demonstrated before the determination of their revised structures $\mathbf{2}$ and 12. The transformation of the latter into the former was performed directly with zinc in sulphuric acid or via reduction of the oxindole-carbonyl with $\mathrm{NaBH}_{4}$ followed by acidic rearrangement of the resulting hydroxyl-spiroindoline motif of dihydrofluorocurine (13). ${ }^{8 a}$ Upon heating, C-fluorocurine (12) could be N4-demethylated into norfluorocurine (14) which could then be converted into normavacurine (16) through the previous sequence $\left(\mathrm{NaBH}_{4}\right.$, $\mathrm{H}_{2} \mathrm{SO}_{4}$ ) via dihydro-norfluorocurine (15). Quaternization of the tertiary amine of normavacurine (16) with methyl iodide delivered C-mavacurine (2).

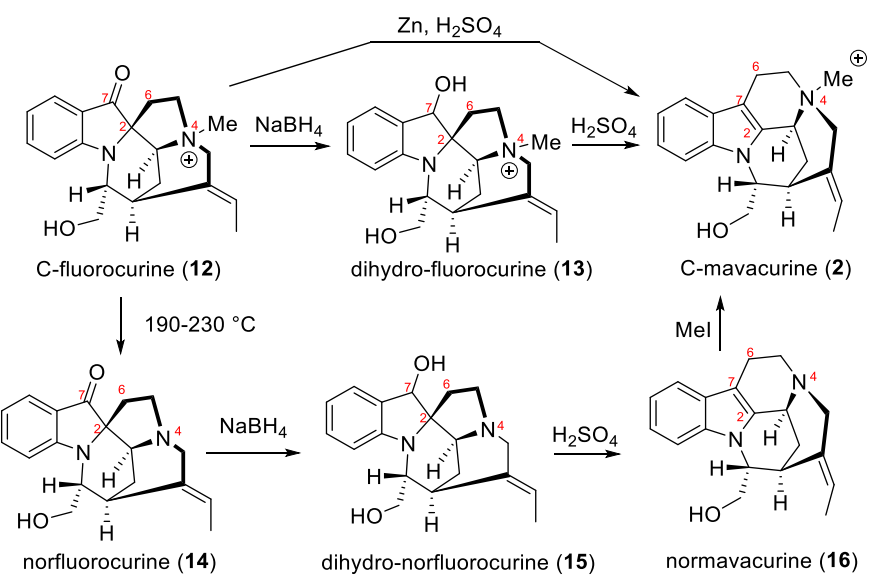

Scheme 4 Conversion of $C$-fluorocurine to $C$-mavacurine to prove their relationship

The stereochemistry at C16 proved to be opposite between pleiocarpamine (3) and C-mavacurine (2) or C-fluorocurine (12) (Scheme 5). Reduction of the methyl ester of pleiocarpamine (3) delivered pleiocarpaminol (17) which spectral properties differed from normavacurine (16). ${ }^{15}$ On the other hand, pleiocarpamine (3) could be epimerized into 16-epi-pleiocarpamine (18) under thermodynamic conditions with $t$-BuOK in methanol. Reduction of 16-epi-pleiocarpamine (18) delivered normavacurine (16) and then methylation of the tertiary amine furnished C-mavacurine (2). ${ }^{15}$ 


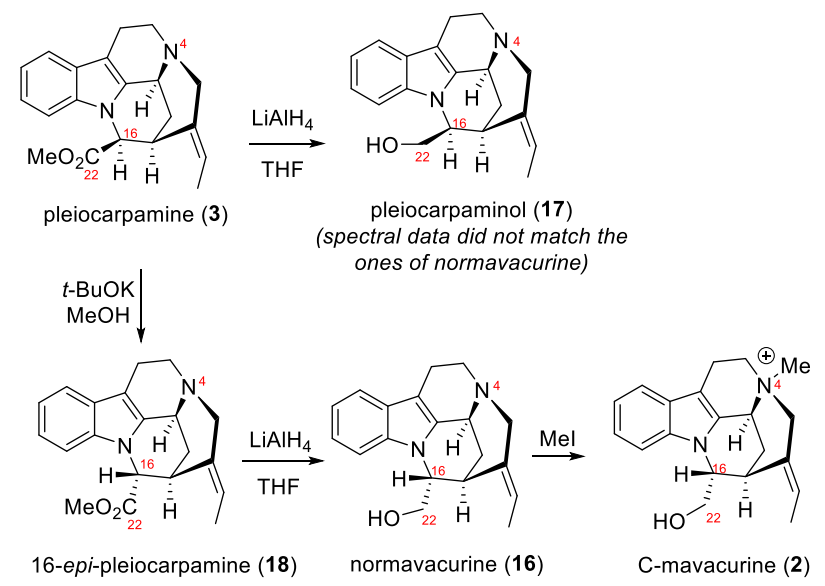

Scheme 5 Epimerisation of pleiocarpamine to prove its opposite stereochemistry at C16 with C-mavacurine.

Reduction reactions of the mavacurane skeleton were also performed during these studies (Scheme 6). Hydrogenation of pleiocarpamine (3) resulted in the highly diastereoselective reduction of the enamine part of the indole into 2,7-dihydropleiocarpamine (19), while the ethylidene was untouched. ${ }^{15}$ It could probably be explained by the sulfuric acid-mediated isomerization of the enamine into an iminium which is then reduced in an easier manner. In contrast, the ethylidene could be diastereoselectively hydrogenated in the case of norfluorocurine (14) or dihydro-norfluorocurine (15) into $\mathbf{2 0}$ and 21. Acidic rearrangement of tetrahydro-norfluorocurine (21) yielded 19,20-dihydronormavacurine (22). ${ }^{8 b}$

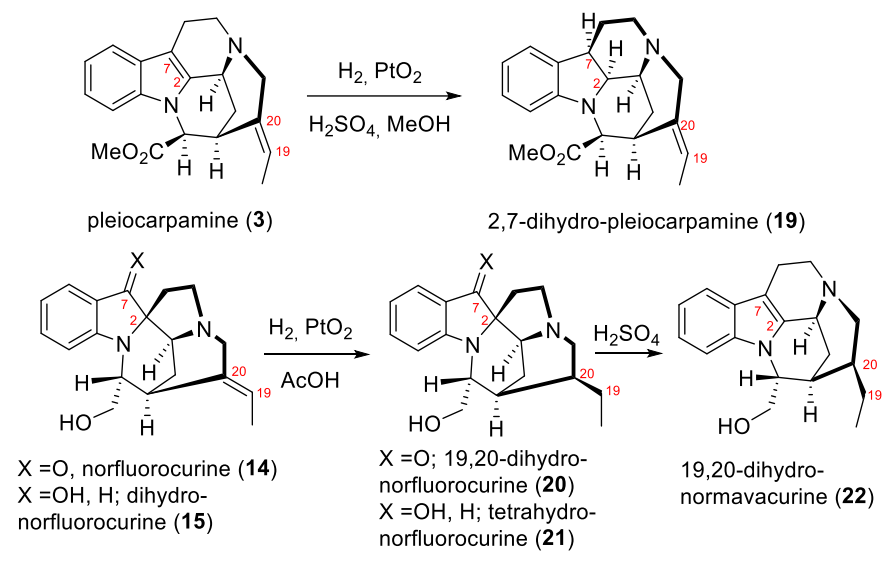

Scheme 6 Reduction of pleiocarpamine and norfluorocurine.

Overall, the N1-C16 bond and the resulting 6-membered $\mathrm{E}$ ring, signatures of the mavacurane alkaloids, induce an important rigidity to the pentacyclic system which adopts a hemispheric shape with a convex face and a concave face. Consequently, the functional groups inside this cage are involved in strong transannular interactions. This is particularly true for the methyl ester of pleiocarpamine (3) which lies in the concave face. The release of this transannular strain is the driving force of the epimerisation of pleiocarpamine at $\mathrm{C} 16$ in thermodynamic basic condition ( $t-\mathrm{BuOK}, \mathrm{MeOH})$. Indeed, only the convex face is accessible to reagents, which explains the diastereoselective reduction of the $\mathrm{C} 2=\mathrm{C} 7$ indolic bond of 3 to access 2,7-dihydro-pleiocarpamine (19) or of the ethylidene C19-C20 bond in $\mathbf{1 4}$ or $\mathbf{1 5}$ to obtain 19,20-dihydro-norfluorocurine (20) or tetrahydro-norfluorocurine (21).

Interestingly, some of these compounds obtained synthetically were later isolated from plants (normavacurine (16), ${ }^{16}$ 16-epi-pleiocarpamine (18), ${ }^{17}$ or 2,7-dihydro-pleiocarpamine (19). ${ }^{18}$

\subsection{Diversity of the mavacurane alkaloids}

Since the elucidation of the structure of the mavacurane skeleton in 1964, several natural congeners have been discovered from various plant species. It is worth to mention that C-mavacurine (2), pleiocarpamine (3), or C-fluorocurine (12) were often co-isolated in these occasions. 
Apart from the strained pentacyclic architecture, most of the mavacuranes possess a C18-C19 side chain in the form of an E-configured ethylene group. They also possess an oxygenated C22 carbon, either as an ester or a primary alcohol.

The main differences between the mavacuranes are observed at the $\mathrm{C} 16$ carbon, the N4 quinolizidine nitrogen, as well as the oxidation level of the indole ring (Scheme 7).

Different substitution patterns are possible at C16: 16-hydroxymethyl-pleiocarpamine (23, Kopsia deverrei Lucile Allorge, Kopsia dasyrachis Ridl., Kopsia fruticose (William Roxburgh) A.DC, Kopsia singapurensis Ridl., Melodinus yunnanensis Tsiang \& P.T.Li) is the only mavacurane isolated to have a tetrasubstituted $\mathrm{C} 16$ carbon with the presence of a methyl ester on the concave face and a primary alcohol on the convex face. ${ }^{19}$ As already mentioned, pleiocarpamine (3) possesses a methyl ester in the cage, ${ }^{15}$ while 16 -epi-pleiocarpamine (18), its thermodynamic isomer, is a less abundant natural product (Catharanthus ovalis Markgr., Anartia meyeri (G.Don) Miers, Ochrosia borbonica J.F.Gmel). ${ }^{17}$ In a related manner, normavacurine $(\mathbf{1 6}$, Strychnos minfiensis, Strychnos potatorum L.f., Strychnos longicaudata Gilg) presents a primary alcohol on the open face. ${ }^{16}$

The quinolizidinic N4-nitrogen is quaternized in several natural products of this family in the form of an $\mathrm{N}$-methyl ammonium as it is the case of $\mathrm{C}$-mavacurine $\mathbf{2}$, calabash curare $)^{15}$ or taberdivarine $\mathrm{H}$ (24, Tabernaemontana officinalis (Tsiang) P.T.Li), ${ }^{20}$ which exists as a zwitterion form with a carboxylate at C16, or C-alkaloid Y $(\mathbf{1 1})^{15}$ or pleiocarpamine methochloride (25, Pleiocarpa mutica Benth., Hunteria eburnea, Kopsia officinalis). ${ }^{21}$ In these three first compounds, the C16-substituent is outside the cage. $\mathrm{N} 4$-oxides are also encountered such as in 16-epi-pleiocarpamine $\mathrm{N}$-oxide (26, Vinca minor L.). ${ }^{22}$

The $\mathrm{C} 2=\mathrm{C} 7$ enamine double bond of the indole is oxidized for a few compounds: $\mathrm{C}$-alkaloid $\mathrm{Y}^{15}$ (11, calabash curare) also named C-profluorocurine (Strychnos guianensis (J.B. Aublet) Martius) ${ }^{11}$ and 2,7dihydroxy-pleiococarpamine (27, Alstonia plumosa Labill. $)^{23}$ are notably dihydroxylated while 7hydroxy-pleicocarpamine (28, Alstonia angustifolia Wall. ex A.DC) ${ }^{24}$ is the product of a formal hydration of pleiocarpamine. Uncommonly, a cyclic carbamate is embedded in pleiomalicine (29, Alstonia angustifolia). ${ }^{25}$

A classical feature in indole alkaloids is the oxygenation of the benzene ring as in 10-methoxypleiocarpamine (30, Rauvolfia volkensii (K.Schum.) Stapf, Rauvolfia oreogiton Markgr.) ${ }^{26}$ and $10-$ methoxy-pleiocarpamine $\mathrm{N}$-oxide (31, Rauvolfia volkensii). ${ }^{26 a}$ Compounds which were at first believed to be 10-hydroxy and 11-hydroxy-pleiocarpamine ${ }^{27}$ were latter reassigned to 10-hydroxy-strictamine and 11-hydroxy-strictamine (Vinca erecta Regel \& Schmalh). ${ }^{28}$

Other positions of the mavacurane scaffold are prone to oxidation: 6-oxopleiocarpamine $(32$, Alstonia angustifolia) ${ }^{24}$ displays a ketone in $\alpha$ to the indole and normavacurin-21-one (33, Alstonia scholaris (L.) R. Br.) features an $\alpha, \beta$-unsaturated N4-lactam whose carbonyl is attached to the C18-C19ethylidene. ${ }^{29}$ Strictine (34, Rhazya stricta Decne.) is an isomer of the latter in which the positions of the carbonyl and the double bond have been inverted thus displaying a 21,20-vinylogous-19-amide. ${ }^{30}$ Very interestingly, the $\mathrm{C} 2=\mathrm{C} 7$ bond is reduced in 2,7-dihydro-pleiocarpamine (19, Alstonia muelleriana Domin $)^{18}$ and 10-methoxy-2,7-dihydro-pleiocarpamine $(35, \text { Rauvolfia volkensii })^{26 a}$ with the presence of an indoline moiety. 


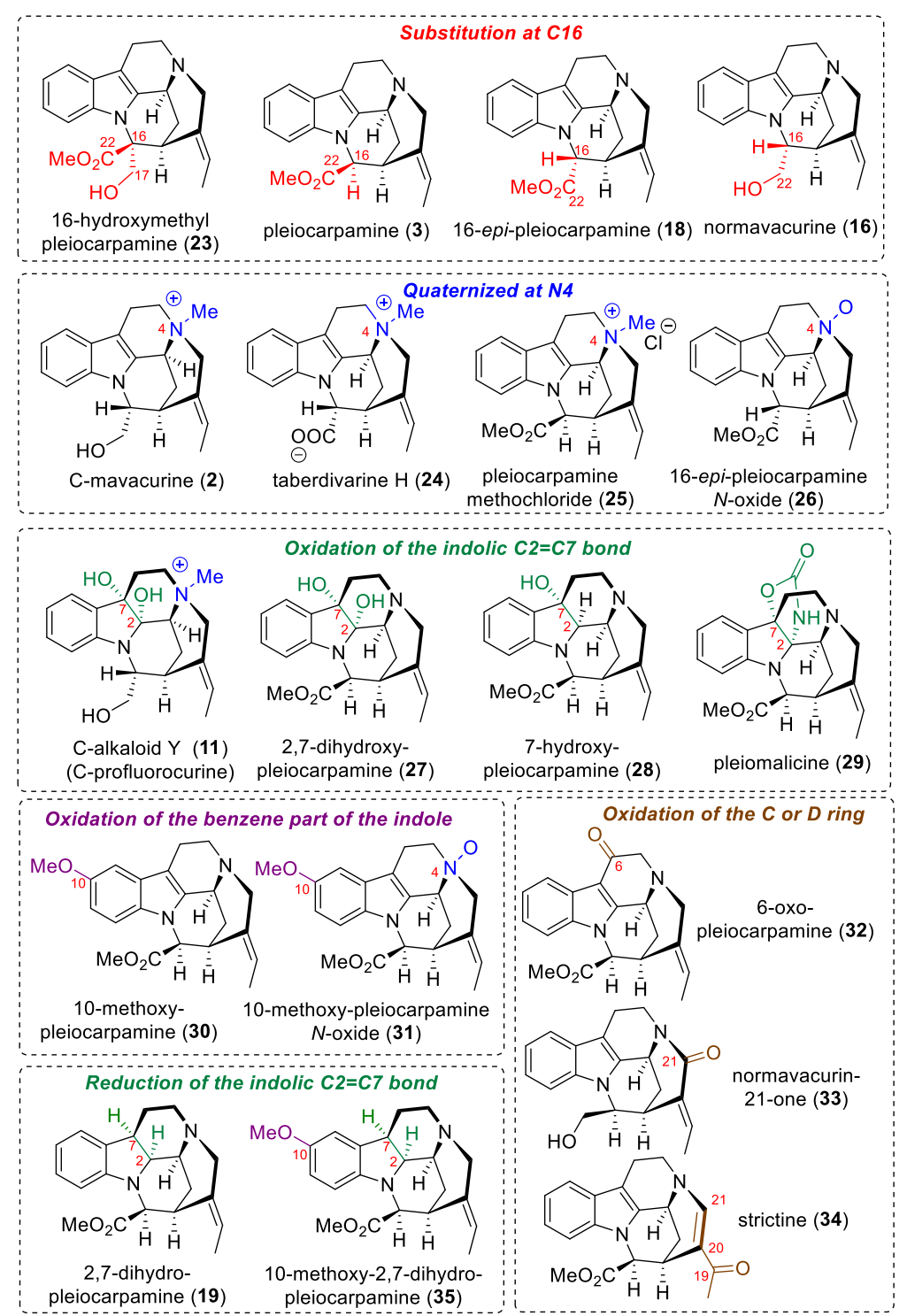

Scheme 7 Diversity of the mavacurane alkaloids.

There are a few particular cases of natural products that could be considered part of the mavacurane family while their scaffolds, somehow, differ from the general one.

As already mentioned, C-fluorocurine (12, calabash curare and other species) ${ }^{7,31}$ was discovered before C-mavacurine, the name-giver of the mavacuranes, and these two compounds were rapidly recognized to be directly related. ${ }^{10,15} \mathrm{C}$-fluorocurine (12), fluorocarpamine (36, Gonioma kamassi E.Mey., Alstonia plumosa, Catharanthus roseus(L.) G.Don among other species) ${ }^{23,32}$ and fluorocarpamine $\mathrm{N}$-oxide (37, Catharanthus roseus) ${ }^{32 \mathrm{~b}}$ have a rearranged mavacurane skeleton (Scheme 8). Rather than having an indole, they have a 2,2-spirocyclic indolin-7-one motif and consequently, the $\mathrm{C}$ ring is a five-membered ring instead of a six-membered ring: the carbon $\mathrm{C} 6$ is connected to the $\mathrm{C} 2$ position instead of the $\mathrm{C} 7$ position. They all possess the C16-stereochemistry of C-mavacurine with as a substituent at this position: a primary alcohol for C-fluorocurine (12) and a methyl ester for fluorocarpamine (36) and fluorocarpamine $\mathrm{N}$-oxide (37). Similarly, to the mavacuranes, the $\mathrm{N} 4$ nitrogen could be a tertiary amine (fluorocarpamine 36), a $\mathrm{N}$-methyl ammonium (C-fluorocurine 12) or a $\mathrm{N}$-oxide (fluorocarpamine $\mathrm{N}$ oxide 37). 


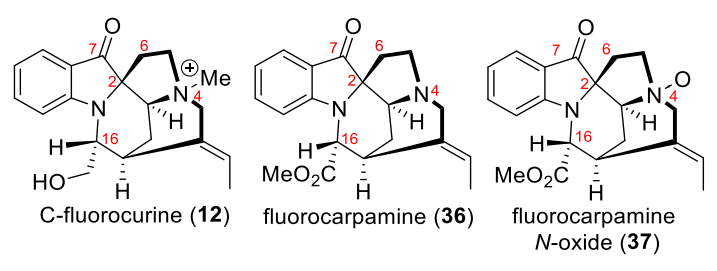

Scheme 8 Rearranged mavacurane skeleton.

In addition, a few compounds lack one of the ring of the mavacurane scaffold but still exhibit the signature N1-C16 bond and could therefore be considered associated with this family (Scheme 9).

As for C-fluorocurine (12) and its congeners, vinoxine (38) exhibits a C6-C7 cleaved tryptamine unit. Vinoxine was isolated in 1966 (Vinca minor) ${ }^{33}$ and its structure 38 was elucidated in 1974 by Potier and co-workers and possesses the complete ABDE ring system. ${ }^{34}$ The $\mathrm{C} 6-\mathrm{C} 7$ bond, which originated from tryptamine, has been cleaved and this 6,7-seco-mavacurane is missing the $C$ ring with a N4ethanolamine side chain instead.

In a related manner, talbotine (39) is considered as a 4,21-seco-mavacurane and was discovered from Pleiocarpa talbotii Wernham by Pinar, Schmid, Hesse and co-workers in $1971 .{ }^{35} \mathrm{It}$ possesses the ABCE system but lacks the N4-C21 bond and therefore the D ring. Instead, talbotine (39) possesses a lactol formed from an alcohol at C21 and an aldehyde at C17 (Scheme 8). Three derivatives were reported two years later from the same source. ${ }^{36}$ The secondary amine, resulting from the absence of the N4C21 bond, could be oxidized as in didehydro-talbotine (40) and tetradehydro-talbotine (41). Desformyltalbotinic acid methyl ester (42) is formally the product of the $\mathrm{C} 17$ aldehyde removal from talbotine. It was not excluded by the authors that the latter was an artefact produced during the isolation process. Desformyl-talbotine lactone (43) was isolated as a natural product, ${ }^{37}$ years after it was synthetically obtained by desformylation of talbotine. ${ }^{35}$

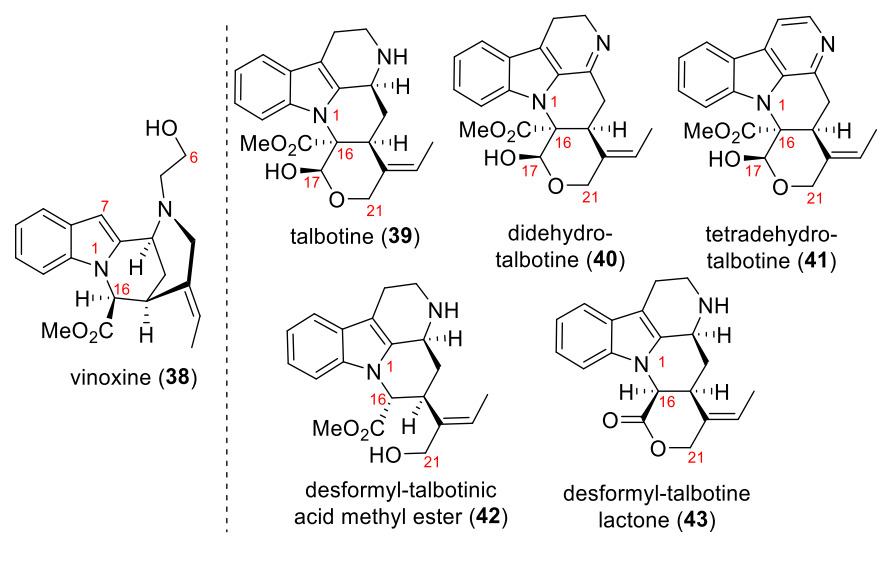

Scheme 9 Ring-opened mavacurane skeletons

\subsection{Biosynthesis of the mavacurane alkaloids}

Geissoschizine (51) is considered to be a pivotal intermediate in the biosynthesis of several sub-families of MIA, including the mavacurane alkaloids.

The corynanthe skeleton of geissoschizine as well as all MIA are biosynthetically formed from strictosidine (1) via a biosynthetic pathway which is now of basic knowledge (Scheme 10). ${ }^{1}$ In one hand, tryptophan (44) is transformed into tryptamine (45) thanks to tryptophan decarboxylase. On the other hand, secologanin (47), a secoiridoid monoterpene, is produced from geranyl-diphosphate (46). Then, an enzymatic Pictet-Spengler reaction between tryptamine (45) and secologanin (47), catalysed by strictosidine synthase, enables the formation of strictosidine (1). Strictosidine glucosidase then induces the deglucosylation of strictosidine (1) into strictosidine aglycone $\mathbf{4 8}$, a highly reactive hemiacetal. Opening of this intermediate produces 17,21-dialdehyde 49 and intramolecular condensation between the most reactive C21-aldehyde with the N4-secondary amine allows to form 4,21dehydrogeissoschizine (50). Geissoschizine (51) is finally obtained after reduction of the iminium function by a NADPH reductase. ${ }^{38}$ 


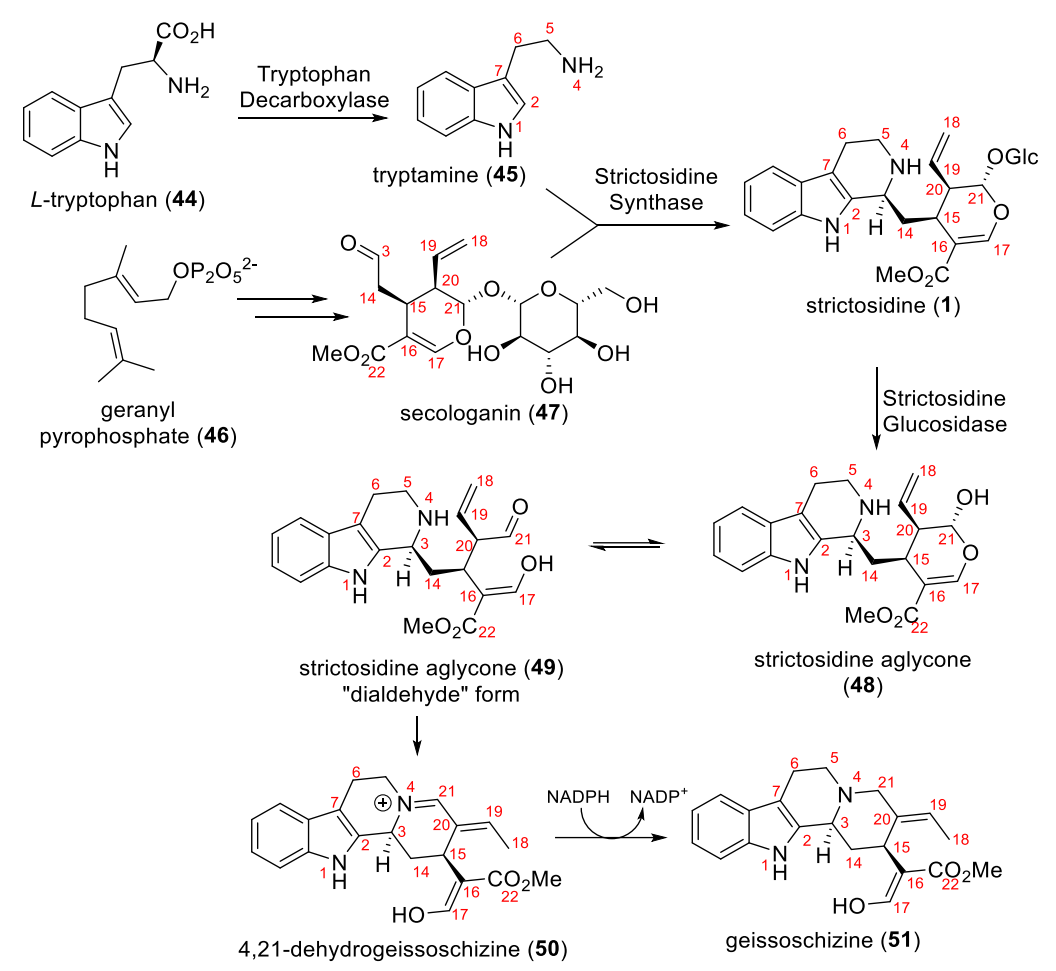

Scheme 10 Biosynthesis of geissoschizine

Over the years, several hypotheses for the biosynthesis of the mavacurane family have been postulated but they yet have to be proven via feeding experiments and/or, today, identification of the enzymes involved.

The first and most acknowledged hypothesis was proposed in 1965 by Wenkert ${ }^{39}$ who suggested that the mavacurane skeleton would arise directly from the oxidative cyclization of geissoschizine (51) (Scheme 11). More precisely, he hypothesized divergent intramolecular couplings between the C16 formyl ester and the indole nucleus towards the mavacurane and akuammilane alkaloids via an umpolung process as two nucleophilic entities are coupled together. To perform such a transformation, Wenkert postulated that oxidation of geissoschizine (51) produces a radical-containing intermediate such as $\mathbf{5 2}$ via single electron transfer (SET). This highly reactive intermediate could possess a radical at $\mathrm{C} 16$ stabilized by the aldehyde and ester functions and a radical delocalized on the $\mathrm{N} 1-\mathrm{C} 2=\mathrm{C} 7$ enamine moiety of the indole ring. Coupling of the $\mathrm{C} 16$-radical with the $\mathrm{C} 7$ position of the indole would deliver a C-C bond and the akuammilane skeleton of rhazimal (53) while the coupling with the N1-indolic nitrogen would deliver the characteristic N1-C16 bond of 16-formylpleiocarpamine (54), which could be considered to be the biosynthetic precursor of all the mavacuranes but has not been isolated yet from natural sources. The epimer $\mathbf{5 5}$ at C16 might be formed, based on the observed stereochemistry at C16 of talbotine (39) which might raise from the cleavage of the N4-C21 bond.

It could indeed also be envisioned that such oxidative cyclization might proceed through ionic pathways via formation of electrophilic intermediates at the enamine of the indole ring or the C16formyl ester.

The C16-formyl ester of geissoschizine (51) is obviously also involved in other oxidative cyclizations of geissoschizine (with $\mathrm{C} 5$ for the sarpaganes ${ }^{40}$ and $\mathrm{N} 4$ for the excelsinidines ${ }^{41}$ ). Thus, it is interesting to take into consideration the potential influence of the conformation of geissoschizine (51) in these cyclization processes (Scheme 12). In fact, the conformation of geissoschizine has been the subject of debates. For instance, according to NMR analysis, Sakai and co-workers believed that in solution in $\mathrm{CDCl}_{3}$, geissoschizine adopts a trans-quinolizidinic conformation (51-A) in which the C16 formyl ester and the N4-tertiary amine are in close proximity thanks to a hydrogen bond between the proton of the C17-enol and N4. ${ }^{42}$ This proximity is coherent with the direct formation of the N4-C16 bond and the excelsinidines from geissoschizine. In contrast, a more recent study by Eckermann and Gaich 
advocated for a cis-quinolizidinic conformation of geissoschizine (51-B) which is more favourable for a cyclization between the C16-formyl ester and the indole nucleus leading to the mavacuranes or the akuammilanes. ${ }^{43}$ Cyclisation of an ammonium salt (51-C, by protonation or alkylation) at N4 into $\mathbf{5 4}$ or 53 could not be excluded since it would lock the required cis-conformation as shown by Eckermann and Gaich by an X-ray structure. Moreover, we have reported that such an oxidative cyclization from a quaternized N4-amine is favourable synthetically (see later part 3.6). Anyway, the conformation of geissoschizine in a NMR tube may be barely relevant to explain the divergent secondary cyclizations since they are obviously governed by enzymes.

After the isolation of talbotine (39) in 1971 by Pinar, Hesse and Schmid, ${ }^{35}$ an alternative biosynthetic hypothesis was proposed by these authors (Scheme 11). It involves the formation of the key N1-C16 bond and $\mathrm{E}$ ring before the formation of geissoschizine (51) and its $\mathrm{D}$ ring. In this case, the dialdehyde form 49 of strictosidine aglycone, would be oxidised in bis-radical $\mathbf{5 6}$ to give, after divergent recombination, either the C7-C16 bond of the akuammilanes or the N1-C16 bond of dialdehyde 57 . The latter would then lead either to talbotine (39) via reduction of the C21 aldehyde or to the complete mavacurane template via formation of the N4-C21 bond and the D ring through a reductive amination (Scheme 11). However, based on the stereochemistry at C16 of talbotine (39), it is likely that 16-epiformyl-pleiocarpamine (55) would be formed which does not correspond to the stereochemistry of 16hydroxymethyl-pleiocarpamine. It is also possible that both epimers of $\mathbf{5 7}$ at C16 could be formed and that only the stereochemistry corresponding to 16 -formyl-pleiocarpamine $\mathbf{5 4}$ could undergo D-ring cyclisation via formation of the N4-C21 bond.

Finally, the akuammilane scaffold has been postulated in few cases to be a biosynthetic intermediate towards other pentacyclic MIA (excelsinidines, ${ }^{41}$ strychnanes ${ }^{39,44}$ ). This assumption has also been considered by Hugel for the mavacuranes. ${ }^{45}$ It implies that the oxidative cyclisation of geissoschizine (51) only leads to rhazimal (53), which would be the true biosynthetic precursor of the mavacurane (Scheme 11). The mavacurane skeleton would be obtained via two [1,5] sigmatropic transpositions of $\mathrm{C} 16$ from $\mathrm{C} 7$ to $\mathrm{C} 2$ to give $\mathbf{5 8}^{39,44}$ and then from C2 to N1 in order to obtain 16-formyl-pleiocarpamine 54. Despite several attempts it has never been possible to mimic such a transformation in a laboratory.
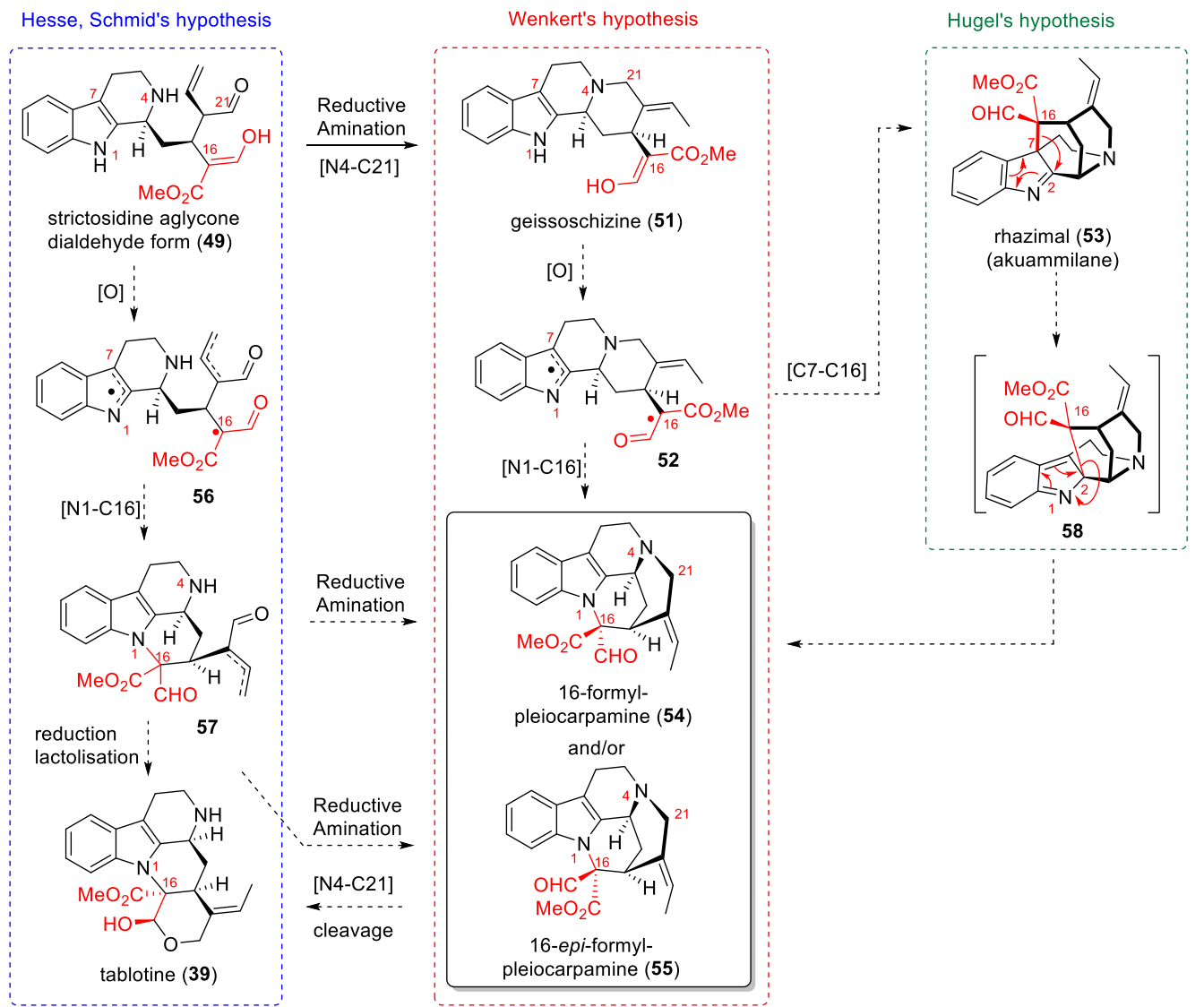


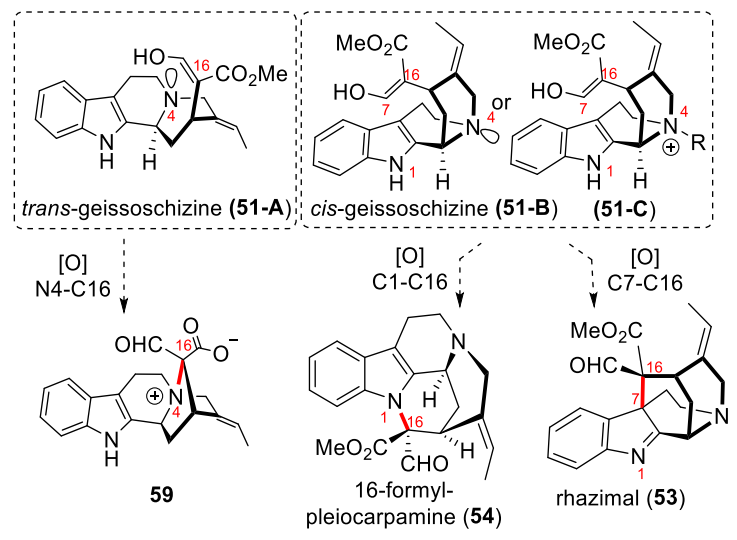

Scheme 12 Influence of the conformation of geissoschizine on its divergent oxidative cyclizations

From 16-formyl-pleiocarpamine, most of the steps to access all the other members of the mavacuranes seem evident despite the fact that no experimental proofs are reported. The order in which these transformations are orchestrated are sometimes less obvious.

Only the reduction of the aldehyde of 16-formyl-pleiocarpamine (54) could produce 16hydroxymethyl-pleiocarpamine (23) with the correct stereochemistry at C16 (Scheme 13). Pleiocarpamine (3), the emblematic compound of the mavacuranes, could result from the desformylation of 16-hydroxymethyl-pleiocarpamine (23). It could also derive from 16-formylpleiocarpamine (54) or its epimer (55) via the release of formic acid. In the course of this extrusion of the $\mathrm{C} 17$ carbon, the enol form $\mathbf{6 0}$ of the ester might be produced and protonation of the C16 carbon should happen from the convex face leading to pleiocarpamine (3), the kinetic product. Formation of 16-epi-pleiocarpamine (18) is also possible from $\mathbf{6 0}$ since it is the most stable epimer (thermodynamic product). Reduction of the $\mathrm{C} 22$ ester of $\mathbf{1 8}$ should then produce normavacurine (16). Methylation of the N4-tertiary amine of pleiocarpamine (3) and/or 16-epi-pleiocarpamine (18) and/or normavacurine (16) could produce pleiocarpamine methochloride (25), taberdivarine $\mathrm{H}$ (24) and C-mavacurine (2). On the other hand, oxidation of the N4-tertiary amine should lead to 16-epi-pleiocarpamine $\mathrm{N}$-oxide (26).

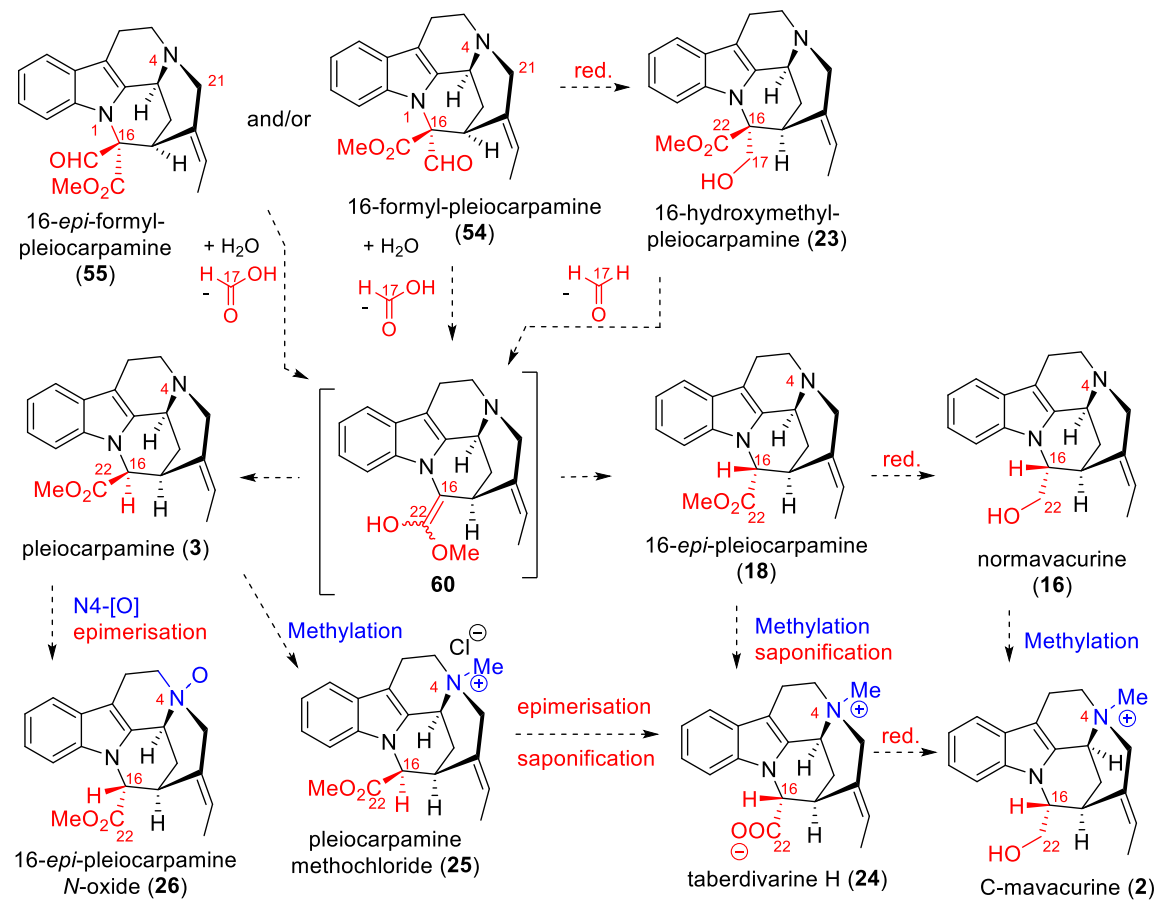

Scheme 13 Substitution at C16 and N4-quaternization of the mavacuranes 
Diverse oxidized indoline natural products are obtained via oxidation of the $\mathrm{N} 1-\mathrm{C} 2=\mathrm{C} 7$ enamine part of the indole into presumably a 7-hydroxy-indolenium intermediate 61 (Scheme 14). The iminium could be reduced into 7-hydroxy-pleiocarpamine (28) or trapped by water to lead to 2,7-dihydroxypleiocarpamine (28) or C-alkaloid Y (11, C-profluorocurine). Putative reaction of the 7-hydroxy of $\mathbf{6 1}$ or $\mathbf{2 7}$ with carbamoyl phosphate $\mathbf{6 2}$ (known from urea cycle) lead to carbamate $\mathbf{6 3}$ which would cyclize onto the iminium to deliver pleiomalicine (29). ${ }^{25}$

The 2,2-spirocyclic-7-oxindole framework of fluorocarpamine (36), its N4-oxide congener (37) and Cfluorocurine (12) would be produced via a pinacol-type ring contraction of the $\mathrm{C}$ ring of 7-hydroxy indolenium $\mathbf{6 1}$ with the migration of the $\mathrm{C} 6$ carbon from the $\mathrm{C} 7$-position to the $\mathrm{C2}$-position.

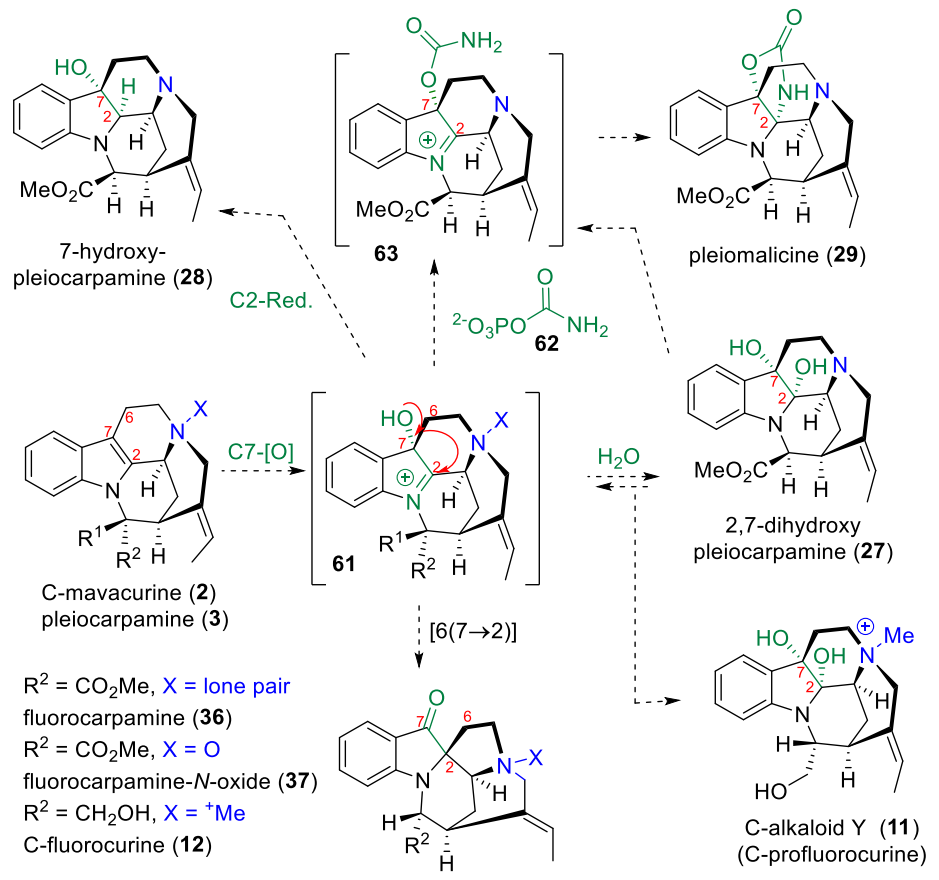

Scheme 14 Oxidation of the indole ring and ring rearrangement of the mavacuranes

Other activated $\mathrm{CH}_{2}$ positions of pleiocarpamine are oxidizable into carbonyls to lead to 6-oxopleiocarpamine (32) or normavacurin-21-one (33) (Scheme 15). Strictine (34) formally results from the oxidation of the $\mathrm{C} 19$ position of the exocyclic ethylidene into a ketone accompanied with unsaturation of the $\mathrm{C} 20=\mathrm{C} 21$ bond leading to a vinylogous amide. The benzene ring could also be oxidized at the C10-position to introduce a methoxy group as in 10-methoxy-pleiocarpamine (30) or its $\mathrm{N}$-oxide $\mathbf{3 1}$.

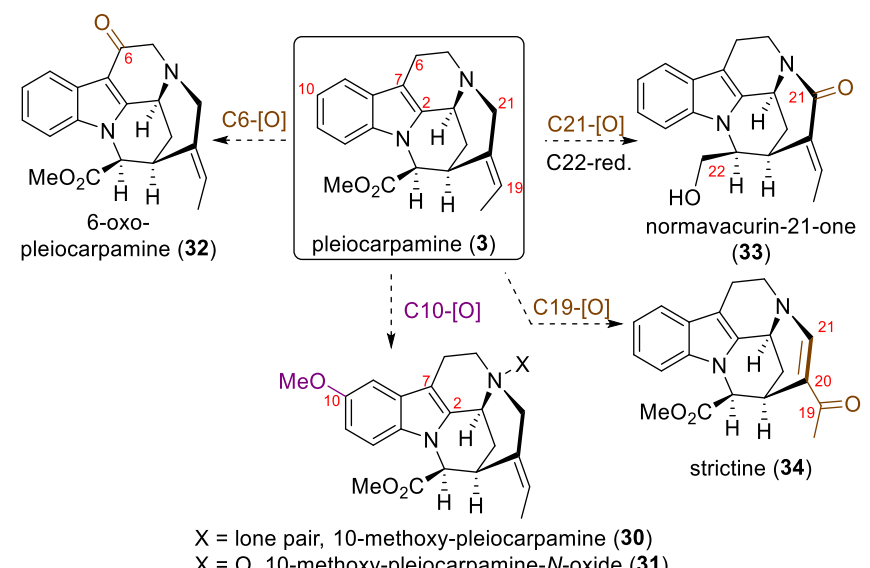

Scheme 15 Other oxidations of pleiocarpamine 
On the other hand, reduction of the indole ring is also possible (Scheme 16). Protonation of pleiocarpamine (3) or 10-methoxy-pleiocarpamine (30) would form indolenium 64 that could be reduce into 2,7-dihydo-pleiocarpamine (19) and 10-methoxy-2,7-dihydro-pleiocarpamine (35).
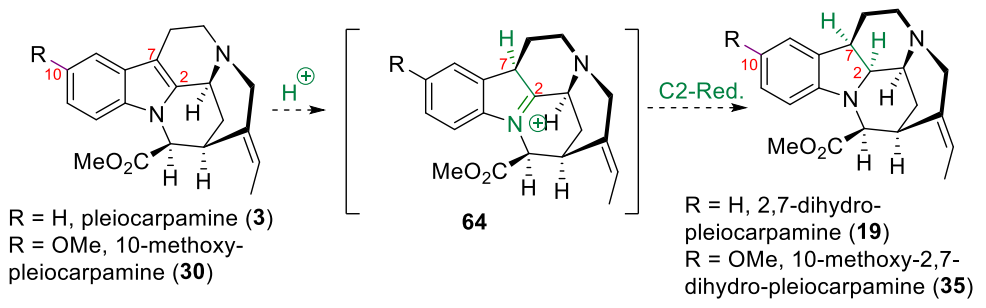

Scheme 16 Reduction of the indole ring of the mavacuranes

Finally, the absence of the $\mathrm{C} 6-\mathrm{C} 7$ bond in vinoxine is quite unique among the MIA. It is conceivable that vinoxine (38) would arise from the cleavage of the $\mathrm{C} 6-\mathrm{C} 7$ bond of the strained structure of pleiocarpamine (3) to form a primary alcohol at C6 (Scheme 17). A similar N4-C21 hydrolysis of 16-epiformyl-pleiocarpamine (55) followed by acetalisation might also explain the biosynthesis of tablotine (39) as already depicted in Scheme 11.

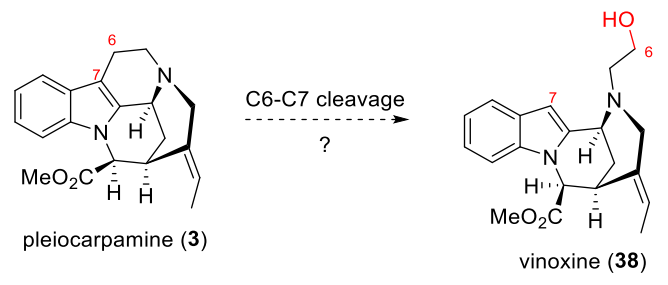

Scheme 17 Proposed origin of vinoxine

\section{Total synthesis of the mavacurane alkaloids}

The compact and highly tensed pentacyclic structure of the mavacurane alkaloids makes pleiocarpamine and its congeners much more difficult synthetic targets that they look like at first sight. The choice of the last ring and bond to construct when planning a total synthesis of these compounds is crucial for the success of this endeavor.

It should be mentioned that early synthetic investigations toward the 7-membered E-ring-containing early misassigned structure (Scheme 3 ) of the mavacuranes have been conducted by Tolkachev et $a l$ in 1967. ${ }^{46}$ Moreover, few syntheses of related 7-membered E-ring pentacyclic compounds have been reported such as lactams ${ }^{47}$ or apogeissoschizine derivatives. ${ }^{48}$

3.1 Boekelheide and co-workers: total synthesis of ( \pm )-19,20-dihydro-norfluorocurine (unnatural) and ( \pm )-19,20-dihydro-normavacurine (unnatural) via formation of the E ring and the N1C16 bond as the last stage

The mavacurane skeleton was assembled for the first time by Boekelheide and co-workers in 1972 with the racemic synthesis of ( \pm )-19,20-dihydro-normavacurine (22) and ( \pm )-19,20-dihydronorfluorocurine (20) which are unnatural saturated analogs of the mavacurane alkaloids. ${ }^{49}$ Their strategy relied on a base-mediated intramolecular attack of the indolic nitrogen onto epoxide ( \pm )-65 to form the E ring and the hydroxymethyl group at C16 (Scheme 18). Epoxide ( \pm )-65 would be obtained via an annulation reaction of 3,4-dihydro- $\beta$-carboline 66.

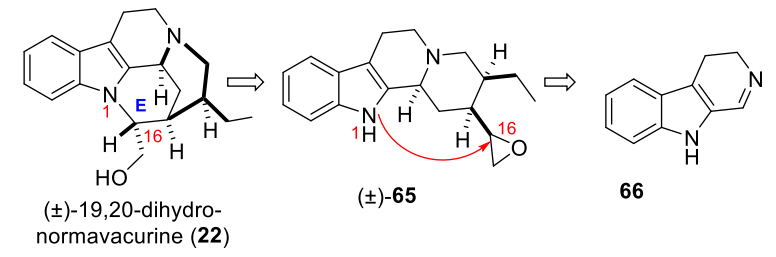

Scheme 18 Boekelheide's retrosynthetic strategy: E ring formation via epoxide opening 
The tetracyclic $A B C D$ system was constructed via the reaction between 3,4-dihydro- $\beta$-carboline 66 and ethyl-2-ethyl-3-oxobutanoate $\mathbf{6 7}$ in the presence of formaldehyde leading, after acidic decarboxylation of the resulting ketoester, to ketone ( \pm )-68 (Scheme 19). Then, ketone ( \pm )-68 was homologated via a Wittig reaction with 69 a. The reaction proceeded with epimerisation of the stereocenter bearing the ethyl group. Hydroboration of the exocyclic alkene $( \pm)-70 a$ and oxidation of the resulting alcohol led to aldehyde ( \pm )-71. In order to improve the access to the latter, the Wittig reaction was performed with methoxymethylene-triphenylphosphorane $69 \mathrm{~b}$ to deliver methyl enol ether $( \pm)-\mathbf{7 0 b}$ which was hydrolysed into aldehyde ( \pm )-71. The latter was converted into epoxide ( \pm )-65 via a Corey-Chaykovsky reaction with dimethyloxosulfonium methylide obtained from $\mathbf{7 2}$. Unfortunately, deprotonation of the indolic nitrogen with sodium hydride under nitrogen atmosphere could not convert $( \pm)$-65 into $( \pm)$ 19,20-dihydronormavacurine (22). Intramolecular addition of the nitrogen nucleophile and opening of the epoxide proceeded on the less substituted carbon and only led to compound ( \pm )-73 with a sevenmembered $\mathrm{E}$ ring which corresponds to the formerly misassigned framework of the mavacuranes (cf Scheme 3).

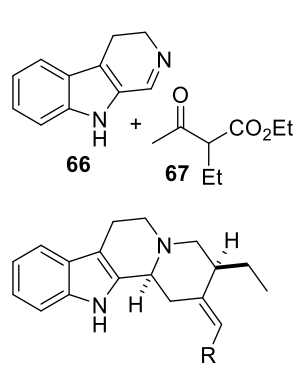

$( \pm)-70 a, R=H($ from $69 a), 80 \%$

$( \pm)-70 b, R=O M e($ from $69 b), 66 \%$

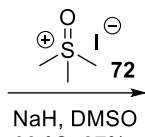

$60^{\circ} \mathrm{C}, 87 \%$

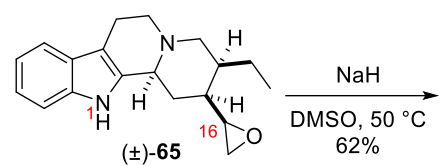

$( \pm)-65$

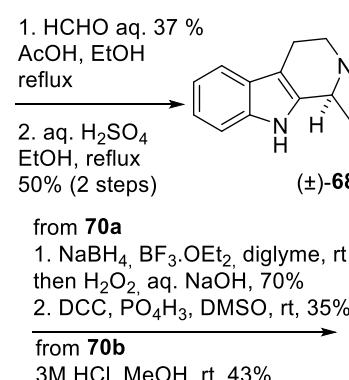

$3 \mathrm{M} \mathrm{HCl}, \mathrm{MeOH}, \mathrm{rt}, 43 \%$

Scheme 19 First attempt toward the synthesis of ( \pm )-19,20-dihydronormavacurine

However, the desired 6-exo cyclization selectively took place over the 7-endo cyclization by conducting the base-mediated reaction under an oxygen atmosphere (Scheme 20). In addition to the formation of the 6-membered $\mathrm{E}$ ring, the oxidative ring contraction of the $\mathrm{C}$ ring was observed leading to the formation of the 2,2-spiro-7-oxindole core of ( \pm )-19,20-dihydro-norfluorocurine (20). In presence of oxygen under basic condition, the indole nucleus is oxidized into 7-hydroxy-indolenine ( \pm )-74 which could be the subject of a pinacol-type rearrangement with migration of the $\mathrm{C} 6$ carbon from the $\mathrm{C} 7$ to the $\mathrm{C} 2$ carbon of the indole as already observed from natural C-alkaloid $Y .{ }^{9}$ The skeletal transposition would then favour the addition of the indolic nitrogen of $( \pm)-\mathbf{7 5}$ onto the more substituted carbon of the epoxide.

As previously achieved during structural determination studies, ${ }^{15}$ it is possible to restore the indolic mavacurane scaffold from the spirocyclic oxindole motif. Thus, ( \pm )-19,20-dihydro-normavacurine (22) was obtained in two steps from ( \pm )-19,20-dihydro-norfluorocurine (20), via reduction of the carbonyl followed by an acidic treatment to induce the ring expansion of the C-ring via migration of the C6carbon from the $\mathrm{C} 2$ to the $\mathrm{C} 7$ positions $(( \pm)-76$ to $( \pm)-77)$. 


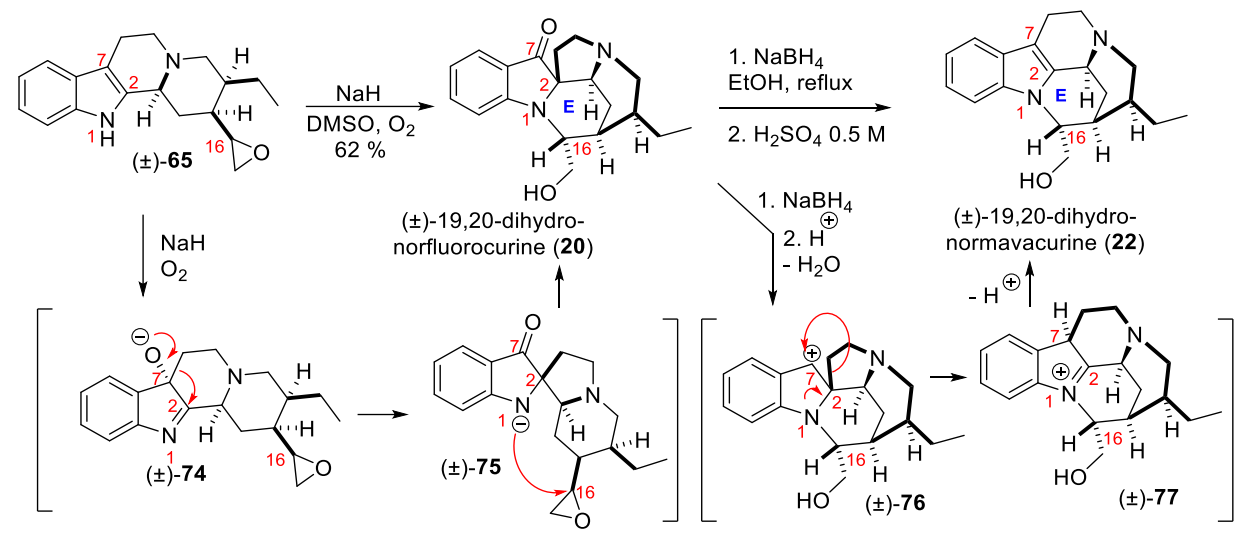

Scheme 20 Synthesis of ( \pm )-19,20-dihydronorfluorocurine and ( \pm )-19,20-dihydronormavacurine

\subsection{Sakai and co-workers: hemisynthesis of (+)-16-epi-pleiocarpamine via formation of the C/D ring junction and the C3-N4 bond as the last stage}

Soon after (1976) the first assembly of the mavacurane skeleton, Sakai was interested in the biomimetic transformation of geissoschizine (51) to pleiocarpamine (3). ${ }^{50}$ Its strategy was based on the formation of the $\mathrm{E}$ ring, via an intramolecular alkylation of the indolic nitrogen with a chloroester moiety. The direct cyclization of the complete tetracyclic system of geissoschizine (51) appeared to be difficult due to conformational restriction. Therefore, the authors reasoned that the opening of the C/D rings via cleavage of the C3-N4 bond would give more flexibility to scaffold $\mathbf{7 8}$ in order to form the E ring (Scheme 21). ${ }^{51}$

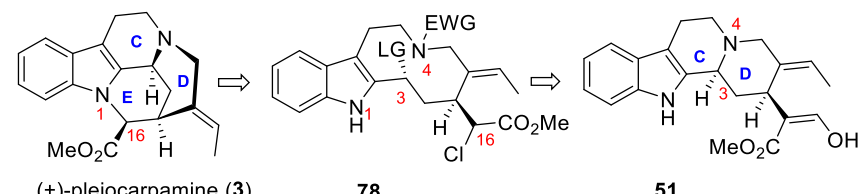

(+)-pleiocarpamine (3)

78

51

Scheme 21 Sakai's retrosynthetic strategy: temporary C/D ring cleavage for the N1-C16 bond formation via nucleophilic substitution

The synthesis started from geissoschizine methyl ether $\mathbf{7 9}$ which was obtained from natural sources. Demethylation using hydrochloric acid was followed by protection of the enol function as an ethyl carbonate (Scheme 22). The C3-N4 bond at the junction of the C/D rings, was then cleaved via a Von Braun reaction using cyanogen bromide in presence of ethanol in basic conditions to deliver 3-(R)ethoxy derivative $\mathbf{8 0}$ as the main product after addition of $\mathrm{NaOH}$. The C16-formyl ester was then chlorinated with $t$-BuOCl leading to 16 -chloroester $\mathbf{7 8}$ as a mixture of epimers after spontaneous desformylation. The desired formation of the E cycle was performed by intramolecular nucleophilic substitution of the $\mathrm{C} 16$ chloride by the N1-indolic nitrogen in the presence of sodium hydride. (+)-16epi-Pleiocarpamine (18) was finally obtained after restoration of the C3-N4 bond and of the C/D ring junction with inversion of configuration at $\mathrm{C} 3$ of $\mathbf{8 1}$ by hydrolysis with acetic acid and ammonium acetate.

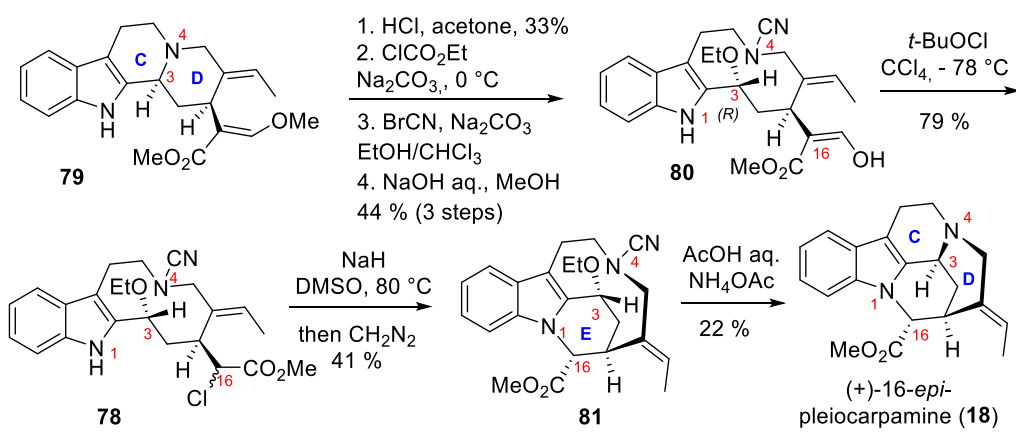

Scheme 22 Hemi-synthesis of (+)-16-epi-pleiocarpamine 
The stereochemistry at the $C 3$ position proved to be important for the reformation of the C/D ring junction during the synthesis of 19,20-dihydro-16-epi-pleiocarpamine (85), a saturated unnatural analogue (Scheme 23). ${ }^{52}$ For instance, a mixture of C3-epimers (83 and $\mathbf{8 4}$ ) is obtained after the C3-N4 bond cleavage of hirsutine (82), for which the stereochemistry is inverted at C3 in comparison with geissoschizine. After formation of the N1-C16 bond of both epimers, restoration of the C/D ring junction was attempted by acidic treatment. Only the 3-(R)-epimer 83 delivers 18,19-dihydro-16-epipleiocarpamine, while the 3-(S)-epimer 84 resulted in the intramolecular C2-hydroamination of the indole ring by the liberated N4-secondary amine leading to 86 .

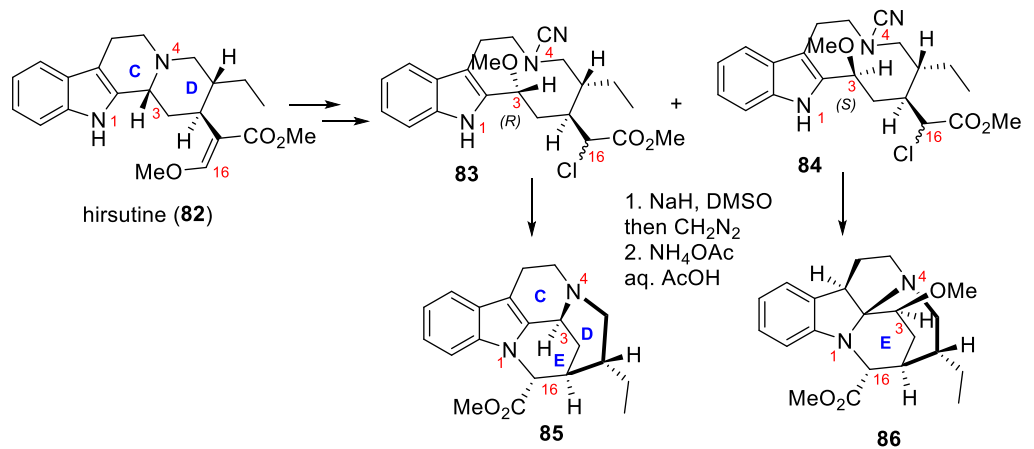

Scheme 23 Importance of the stereochemistry at C3 for the restauration of the C/D ring junction

3.3 Harley-Mason and co-workers: total synthesis of $( \pm)$-16-epi-pleiocarpamine, $( \pm)-16-e p i-$ pleiocarpamine- $N$-oxide, ( \pm )-normavacurine and ( \pm )-C-mavacurine via formation of the $C / D$ ring junction and the C3-N4 bond as the last stage

Later on, in 1981, Harley-Mason used the strategy previously described by Sakai, i.e. breaking the C/D ring junction to give more flexibility to the molecule, in order to complete the first total synthesis of ( \pm )-16-epi-pleiocarpamine (18), ( \pm )-16-epi-pleiocarpamine- $N$-oxide (26), $( \pm)$-normavacurine (16) and ( \pm -C-mavacurine (2). ${ }^{53}$ The difference with Sakai's approach, is the use of a reductive cleavage of the C3-N4 bond of tetracyclic compound ( \pm )-88, resulting in the generation of an achiral C3-carbon in $( \pm)$ 87 (Scheme 24). The regeneration of this bond is thus effected under oxidative conditions and is not dependent of the C3-stereochemistry as for the aforementioned route.

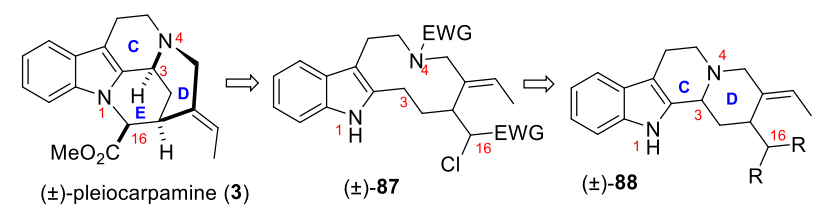

Scheme 24 Harley-Mason's retrosynthetic strategy: temporary C/D ring cleavage for the N1-C16 bond formation via nucleophilic substitution

The synthesis of the tetracyclic $A B C D$ framework related to geissoschizine ${ }^{54}$ began with a peptide coupling between tryptamine (45) and carboxylic acid $\mathbf{8 9}$ followed by a Bischler-Napieralski reaction in order to form the $\mathrm{C}$ ring (Scheme 25 ). The N4-secondary amine of ( \pm )-90 was acylated with ( \pm )-91 into $( \pm)-92$ and the $D$ ring of ( \pm )-93 was obtained after an intramolecular nucleophilic substitution. Selective saponification, decarboxylation, ester reduction and elimination of methanol allowed to install the ethylene part on lactam ( \pm )-94. After oxidation of the $\mathrm{C22}$-alcohol and protection of the resulting aldehyde into a dithiolane, the N4-C21 lactam was reduced into ( \pm )-88. The reductive opening of C/D ring junction was performed with phenyl chloroformate and sodium cyanoborohydride. Macrocycle ( \pm )-95 was transformed into the chloro-cyanide intermediate ( \pm )-87 after 4 steps via hydrolysis of the dithiolane with methyl iodide, formation of a cyanohydrin, mesylation of the latter and nucleophilic substitution with a chloride. 


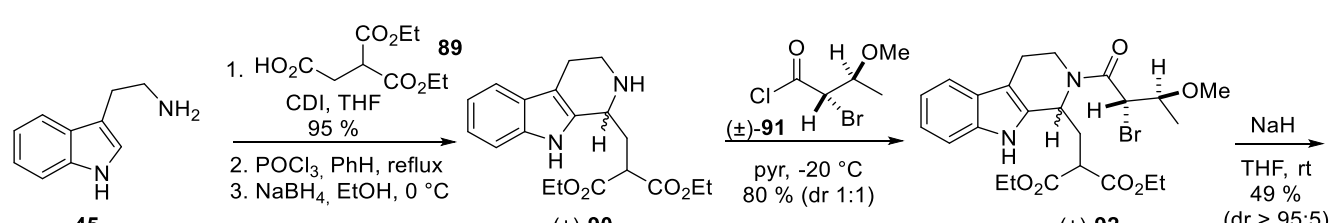

45

$( \pm)-90$
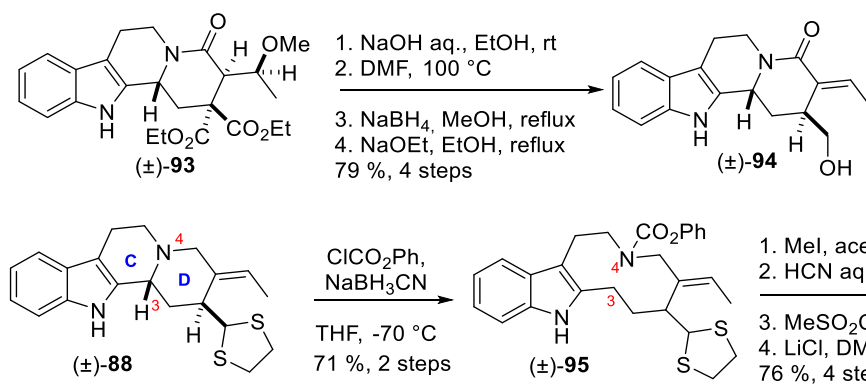

( \pm -92

$(d r>95: 5)$

1. DCC, DMSO, $\mathrm{H}_{3} \mathrm{PO}_{4}$

2. $\mathrm{HSCH}_{2} \mathrm{CH}_{2} \mathrm{SH}$

$\mathrm{BH}_{3}$. THF, $\mathrm{CH}_{2} \mathrm{Cl}_{2}, 0^{\circ} \mathrm{C}$

$60 \%, 2$ steps

3. DIBAL-H, DME, $-55^{\circ} \mathrm{C}$

Scheme 25 Synthesis of the $A B C D$ tetracyclic system and cleavage of the $C / D$ ring junction

Similarly to Sakai's work, the key N1-C16 bond and E ring were obtained via an intramolecular nucleophilic substitution where only the diastereoisomer $( \pm)-96$ was obtained with the relative configuration at C16 corresponding to 16-epi-pleiocarpamine (Scheme 26). The C/D ring junction was restored by oxidation with $N$-chlorobenzotriazole and triethylamine giving pentacycle $( \pm)-97$. We could presume that 7-chloroindolenium ( \pm )-98 is formed which would isomerize into enamine ( \pm )-99. Addition of the N4-nitrogen to the C3 position would induce formation of the C3-N4 bond, expulsion of chloride and rearomatisation. Hydrolysis and esterification of $( \pm)-97$ delivered ( \pm )-16-epipleiocarpamine (18). Reduction of the ester of the latter with $\mathrm{LiAlH}_{4}$ yielded ( \pm )-normavacurine (16), which could be converted into ( \pm )-C-mavacurine (3) with methyl iodide. Finally, oxidation of ( \pm )-16-epipleiocarpamine (18) with $m$-CPBA afforded ( \pm )-16-epi-pleiocarpamine- $N$-oxide (26).

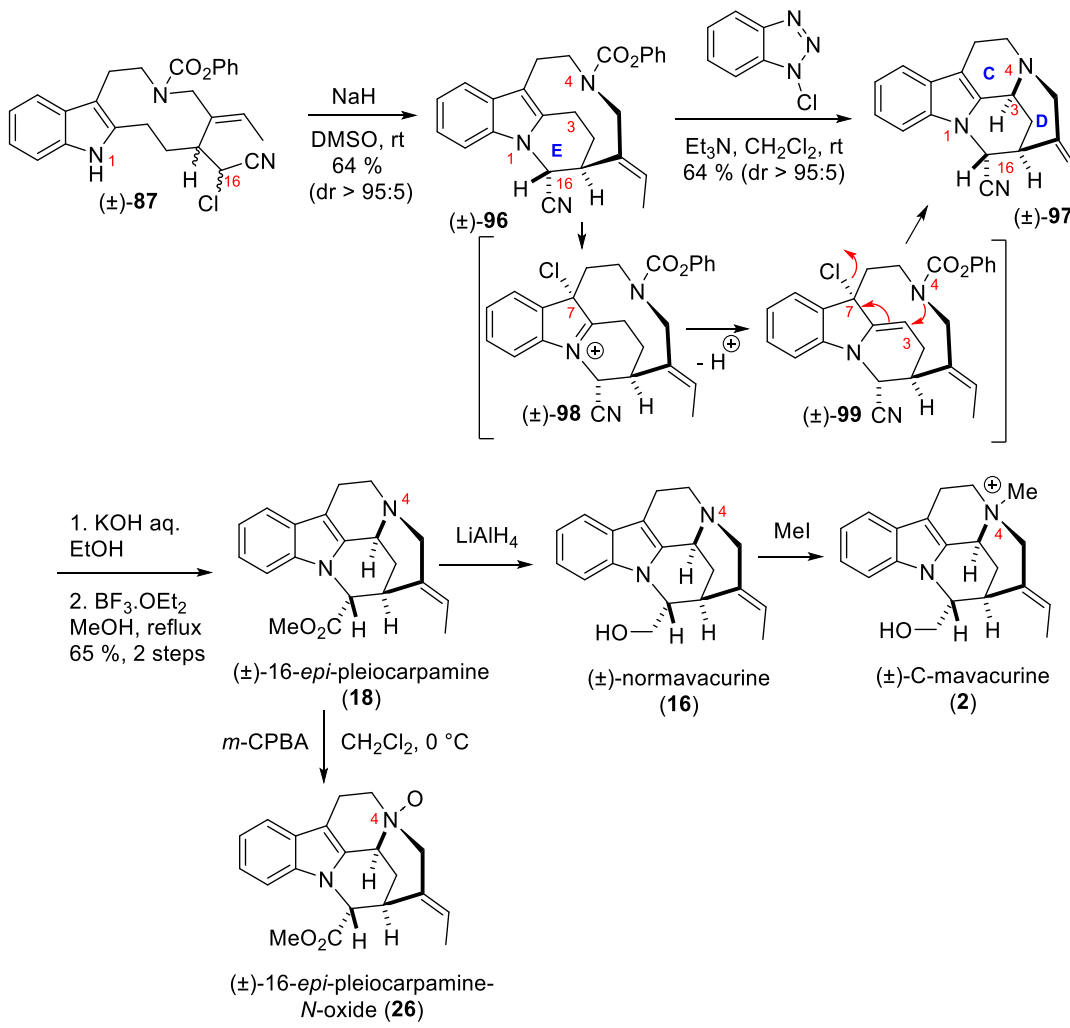

Scheme 26 Total synthesis of ( \pm )-16-epi-pleiocarpamine, ( \pm )-16-epi-pleiocarpamine- $N$-oxide, $( \pm)$-normavacurine and ( \pm )-Cmavacurine

Very interestingly, during preliminary synthetic studies, the group of Harley-Mason did form the N1C16 bond and the mavacurane skeleton without having to cleave the C/D ring junction (Scheme 27). ${ }^{55}$ 
This was accomplished on a substrate lacking the exocyclic C20-ethylidene and the methyl ester attached at $\mathrm{C} 16$ and in which the N4-nitrogen is embedded in a C21-lactam. Formation of primary mesylate ( \pm )-101 from ( \pm -100 is followed by a nucleophilic substitution in presence of $\mathrm{NaH}$ to yield pentacyclic compound $( \pm)$-102. Reduction of the lactam moiety with $\mathrm{LiAlH}_{4}$ delivered $( \pm)-\mathbf{1 0 3}$. Dihydroxylation of the indolic $\mathrm{C} 2=\mathrm{C} 7$ double bond into $( \pm)-104$ could be effected with the Adams catalyst in presence of $\mathrm{O}_{2}$ and subsequent acidic treatment initiated the pinacol-type rearrangement leading to spirocyclic oxindole $( \pm)-\mathbf{1 0 5}$ related to norfluorocurine. The latter could be converted back to mavacurane-type compound $( \pm)$-103 through reduction of the C7-carbonyl and acidic-induced migration of the $\mathrm{C} 6$ carbon from the $\mathrm{C} 2$ to the $\mathrm{C} 7$ position.

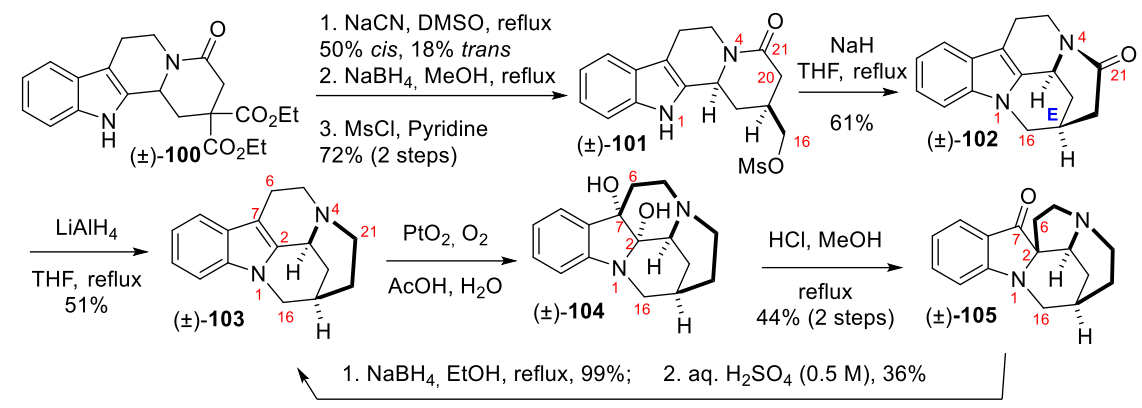

Scheme 27 Formation of the mavacurane skeleton without cleavage of the $C / D$ ring junction

\subsection{Bosch and co-workers: total synthesis of (-) and ( \pm )-vinoxine via formation of the C2-C3 and C15-C16 bonds of the $E$ ring.}

The first total synthesis of ( \pm )-vinoxine (38) was reported by Bosch and co-workers in $1984 .{ }^{56}$ The strategy in place relied on the formation of the $\mathrm{C} 15-\mathrm{C} 16$ and $\mathrm{C2}-\mathrm{C} 3$ bonds of the $\mathrm{E}$ ring via an annulation reaction between pyridinium salt 107 and indolylacetate 106 (Scheme 28). This approach could also lead to pleiocarpamine (3) via closing of the D ring from ( \pm )-vinoxine (38) through the $\mathrm{C} 6-\mathrm{C} 7$ bond formation. At the outset of this study, the stereochemistry of vinoxine at C16 was not clearly attributed.

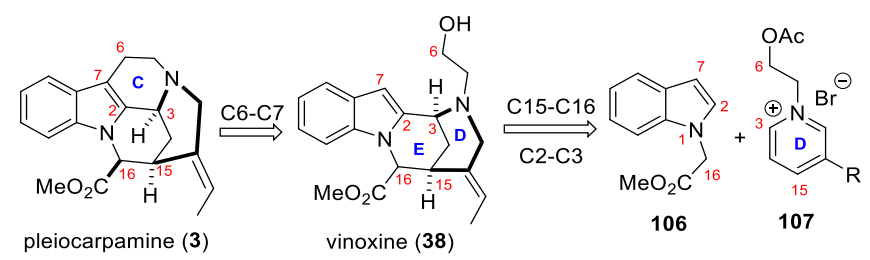

Scheme 28 Bosch's retrosynthesis of vinoxine via an annulation reaction to form the $E$ ring

The first step of the synthesis was a nucleophilic addition of the enolate of indolylacetate 106 generated with LDA to the C15 position of the pyridinium salt 107a (Scheme 29). Acidic treatment of the non-isolated intermediate $( \pm)-\mathbf{1 0 8}$ allowed cyclization of the $\mathrm{C} 2$ position of the indole to iminium $( \pm)$-109 leading to tetracyclic compound $( \pm)-\mathbf{1 1 0}$ as a $5: 1$ mixture of epimers $(\mathbf{1 1 0 a} / \mathbf{1 1 0 b})$ at $\mathrm{C16}$ in favour of the stereochemistry of 16-epi-vinoxine. A second acidic treatment in refluxing hydrochloric acid resulted in hydrolysis of the two methyl ester with decarboxylation of the acrylic acid moiety and migration of the double bond to form the E ethylidene substituent. ( \pm )-Vinoxine (38) and ( \pm )-16-epivinoxine (112) were obtained after acidic esterification with methanol and reduction of iminium ( \pm )111. The relative stereochemistry of vinoxine at C16 was attributed to the one of pleiocarpamine.

In 1990, the group of Bosch reported an alternative synthesis of ( \pm )-vinoxine (38) based on a very similar general strategy. ${ }^{57}$ It differs by the fact that the pyridinium salt $107 \mathrm{~b}$ was substituted by an acetyl group instead of an acrylate as the electron-withdrawing group and ethylidene precursor (Scheme 29). The first two steps and the stereochemical outcome leading to the formation of the ABDE systems are identical to the first approach. This time, the ethylidene was obtained after treatment of the epimeric vinylogous enamides $( \pm)-\mathbf{1 1 3} \mathbf{a} / \mathbf{b}$ with trimethyloxonium tetrafluoroborate and the $1,4-$ 
addition of sodium borohydride to conjugated iminium ( \pm )-114. ( \pm )-Vinoxine (38) and $( \pm)-16-e p i-$ vinoxine (112) were obtained after a methanolysis of the acetate at $\mathrm{C6}$.
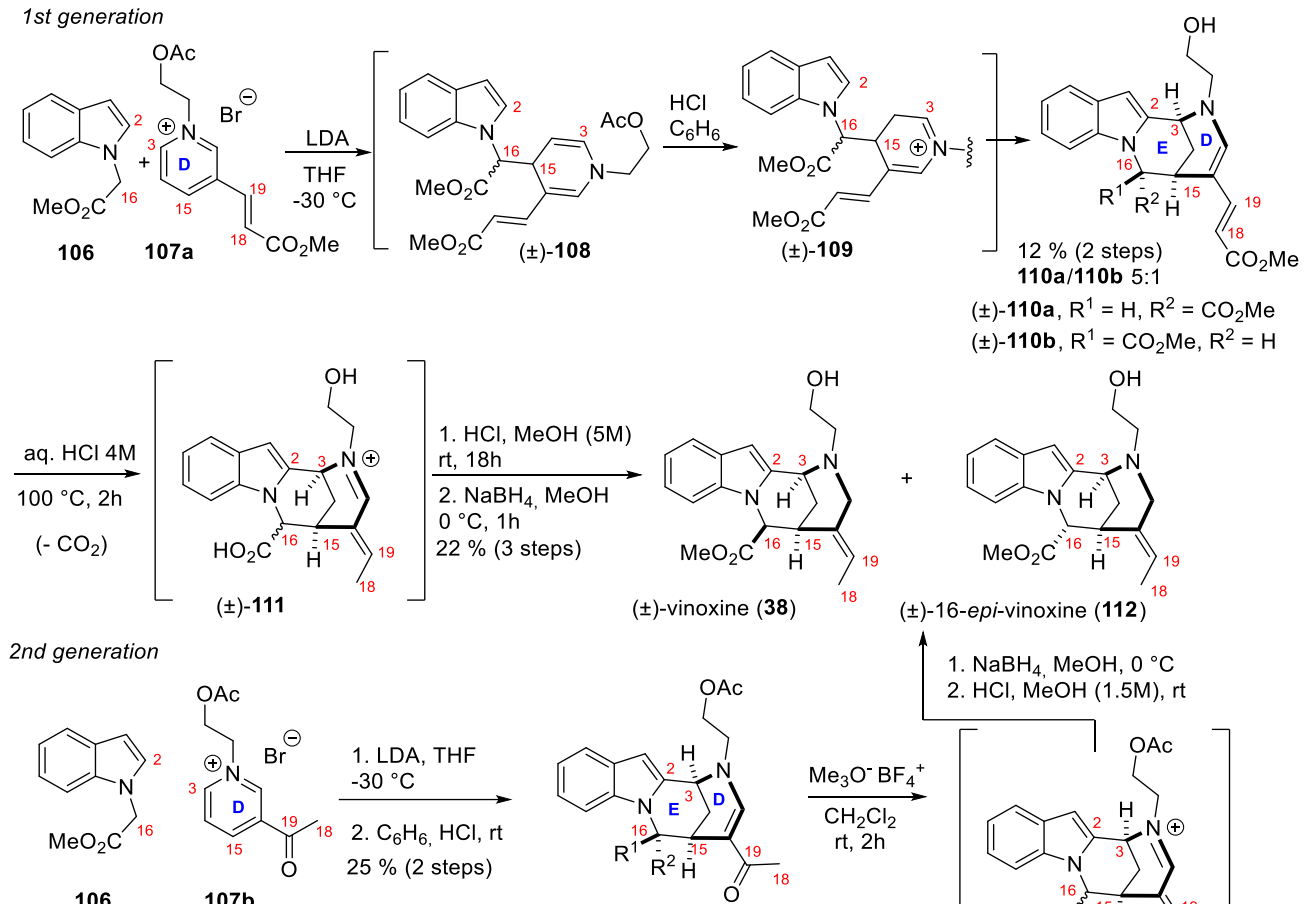

( \pm )-vinoxine (38)

( \pm )-16-epi-vinoxine (112)

d generation

$107 \mathrm{~b}$

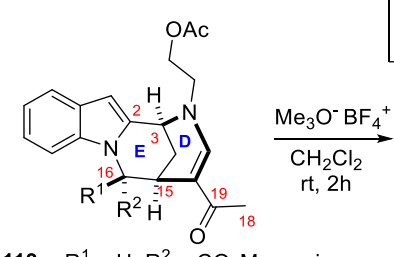

$( \pm)-113 a, R^{1}=\mathrm{H}, \mathrm{R}^{2}=\mathrm{CO}_{2} \mathrm{Me}$, major $( \pm)-113 b, R^{1}=\mathrm{CO}_{2} \mathrm{Me}, \mathrm{R}^{2}=\mathrm{H}$, minor
1. $\mathrm{NaBH}_{4}, \mathrm{MeOH}, \mathrm{O}^{\circ} \mathrm{C}$ 2. $\mathrm{HCl}, \mathrm{MeOH}(1.5 \mathrm{M}), \mathrm{rt}$

Scheme 29 Total synthesis of ( \pm )-vinoxine and ( \pm )-16-epi-vinoxine

The use of a chiral auxiliary on the indolylacetyl moiety allowed the same research group to implement in 2002, the above racemic synthesis into an enantioselective version (Scheme 30). ${ }^{58}$ Among the different chiral groups evaluated (menthol derivatives and oxazolidinones), (S)-prolinol in indolylacetamide $\mathbf{1 1 5}$ showed the optimal results with a 3:1 diastereoselectivity and the ease of separation of the diastereoisomers albeit a modest yield.

The synthesis was carried on with an acidic treatment of the major diastereoisomer $\mathbf{1 1 6}$ followed by a reduction step to give the allyl amine moiety of $\mathbf{1 1 7}$ and the prolinol was involved in an intramolecular $\mathrm{O}$-acylation. The latter went through a transesterification with $\mathrm{MeOMgBr}$ to get rid of the chiral auxiliary and gave (+)-16-epivinoxine (38). Epimerisation by treatment with $t$-BuOK in $\mathrm{MeOH}$ at reflux allowed to obtain a 1:2 mixture of (-)-vinoxine (38) and (+)-16-epivinoxine (112) which evolved to 6:1 after column chromatography on silica gel.
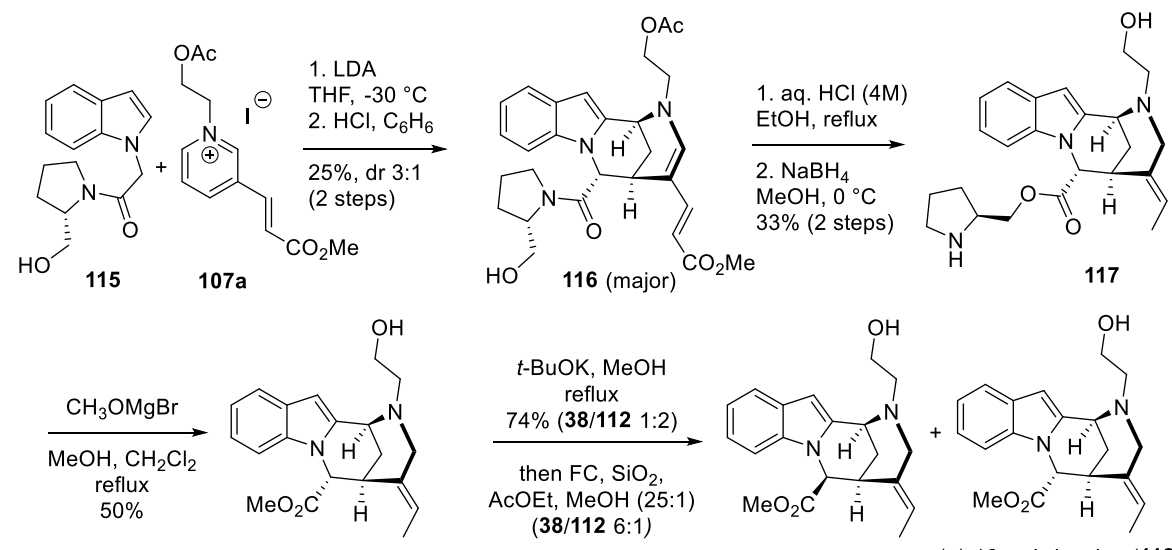

(+)-16-epi-vinoxine (112)

$(-)$-vinoxine (38)

$(+)$-16-epi-vinoxine $(112)$

Scheme 30 Total synthesis of (+)-16-epi-vinoxine and (-)-vinoxine 


\subsection{Bosch and co-workers: total synthesis of ( \pm )-2,7-dihydropleiocarpamine via formation of the C6-C7 bond of the $\mathrm{C}$ ring as the last stage.}

Bosch and co-workers wanted to take advantage of the strategy that they developed for the total synthesis of $\left( \pm\right.$ )-vinoxine (38) to access ( \pm )-pleiocarpamine (3). ${ }^{59,60}$ They desired to effect the $C$ ring closure in the final step via the C6-C7 or N4-C5 bond formation (Scheme 31). From ( \pm )-vinoxine (38), all what remained to do is to forge the $\mathrm{C} 6-\mathrm{C} 7$ bond to close the missing $\mathrm{C}$ ring. In a related manner, it seemed even more easy to close the $\mathrm{C}$ ring via a nucleophilic substitution between an N4-amine and a C5-alcohol from ( \pm )-118.

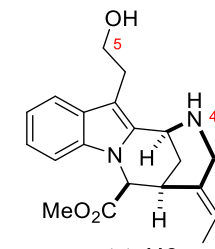

(土)-118

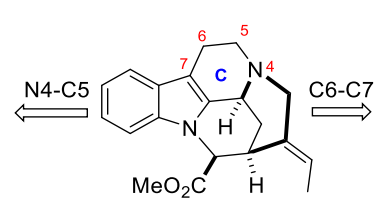

(士)-pleiocarpamine (3)

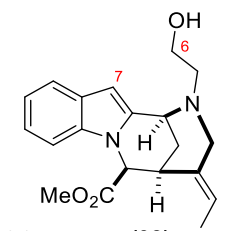

( \pm )-vinoxine (38)

Scheme 31 Bosch's retrosynthetic strategy via late stage C ring formation

Substrates ( \pm )-118 and ( \pm )-123, needed to study the $C$ ring closure, were obtained using the strategy of nucleophilic addition of the enolate of 106 or 119 to a pyridinium salt $121 \mathrm{a} / \mathrm{b}$ as previously described for the synthesis of ( \pm )-vinoxine (Scheme 32). Hydrogenolysis of the N4-benzylamine of $( \pm)$-120b and $( \pm)$-122 permitted to obtain secondary amines $( \pm)-\mathbf{1 1 8}$ and $( \pm)$-123 ready for further functionalisation.
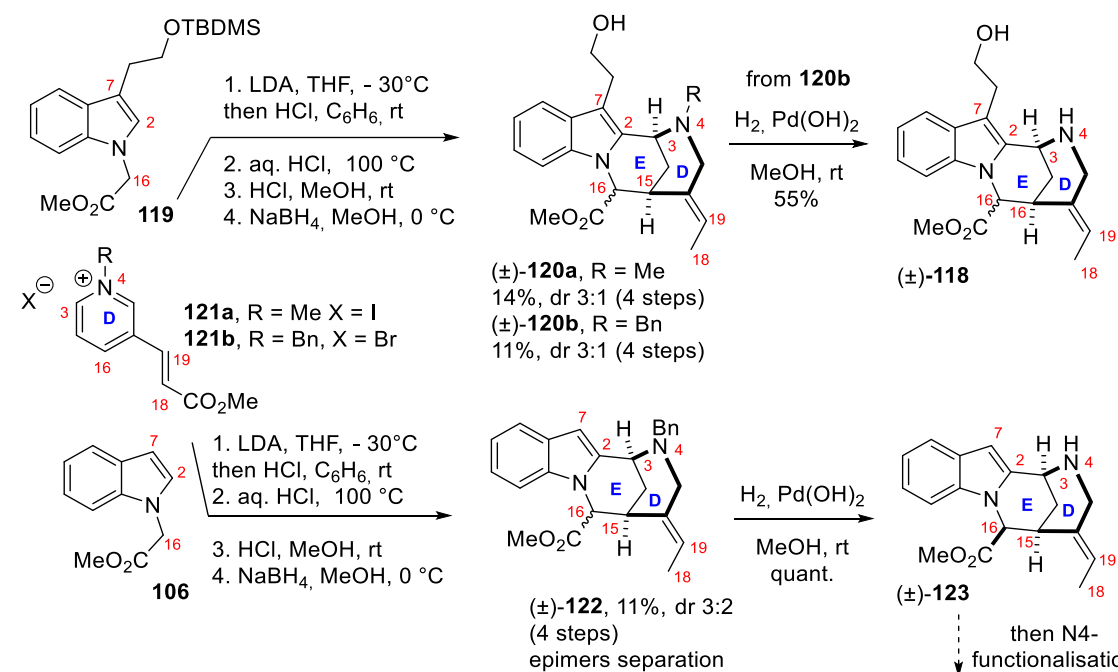

(士)-118

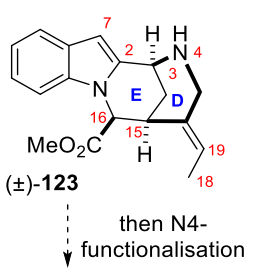

Scheme 32 General synthesis of ABDE tetracycles

Attempts toward the $\mathrm{C}$ ring closure were then undertaken (Scheme 33). Forging the N4-C5 bond via a nucleophilic substitution from alcohol ( \pm )-118 or ( \pm )-120a was investigated. Unfortunately, all attempts failed despite the formation of mesylated intermediates.

The electrophilic substitution of the indole ring of vinoxine (38) was also considered to construct the C6-C7 bond. However, direct cyclizations in acidic conditions of ( \pm )-vinoxine (38) or the corresponding aldehyde $( \pm)-\mathbf{1 2 5}$ or dithioacetal $( \pm)-\mathbf{1 2 6}$ were unsuccessful.

At this point, the authors hypothesized that the distance between $\mathrm{C} 6$ and $\mathrm{C} 7$ or $\mathrm{C} 5$ and $\mathrm{N} 4$ was not favourable for the 6-membered ring cyclization to happen. To validate this hypothesis, they decided to extend the $\mathrm{N} 4$ side chain with an extra carbon. Indeed, the formation of a 7-membered $\mathrm{C}$ ring may be more favourable because it would result in a less strained pentacycle. Intermolecular Michael addition of N4-secondary amine ( \pm )-123 to acrolein allowed to introduce three carbons. The resulting aldehyde was converted into dithioacetal $( \pm)-127$. Treatment of the latter with dimethyl(methylthio)sulfonium tetrafluoroborate (DMTSF) resulted in the desired cyclization. Finally, 
reduction of alcohol ( \pm )-128 allowed the formation of ( \pm )-6a-homo-pleiocarpamine (129), an unnatural analog of pleiocarpamine.

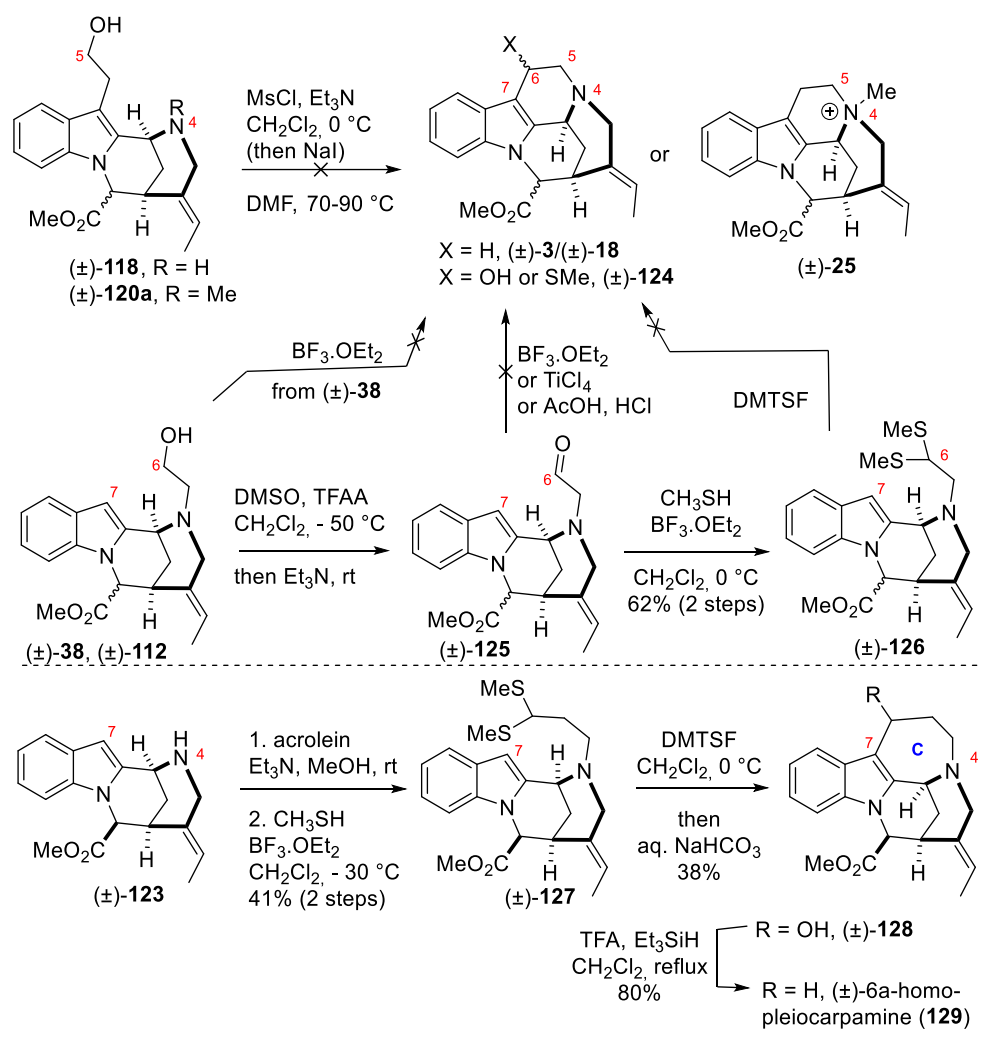

Scheme 33 Unsuccessful attempts towards the 6-membered C ring formation and synthesis of ( \pm )-6a-homo-pleiocarpamine

In order to achieve the formation of the 6-membered ring, Bosch and co-workers decided to study a strategy which would be mechanistically different from the purely ionic electrophilic and nucleophilic substitutions (Scheme 34). They focused on a photocyclization approach which implied the formation of a bis-radical intermediate (Witkop type cyclization). ${ }^{61}$ The secondary amine $( \pm)$-123 previously prepared was acylated with $\mathbf{1 3 0}$ in order to obtain choroacetamide ( \pm )-131. The latter was irradiated in presence of sodium carbonate in an aqueous methanolic solution leading to the formation of the 2hydroxy-indoline ( \pm )-132 in a modest yield. Presumably, homolytic cleavage of the C6-chloride bond induced the formation of an $\alpha$-acetamide radical and of an indolyl cation radical in ( \pm )-133 which gave birth to the $\mathrm{C} 6-\mathrm{C} 7$ bond via intramolecular radical recombination. The 2-hydroxy group, obtained by trapping of the indolenium intermediate $( \pm)$-134, with water was then reduced into 2,7-dihydroindoline ( \pm )-135. Finally, reduction of the C5 lactam into the N4-tertiary amine was effected through a thiolactam and allowed the authors to complete the first total synthesis of $( \pm)-2,7$-dihydropleiocarpamine (19). ${ }^{59,60}$ The possibility of oxidizing this compound into pleiocarpamine was not mentioned. 


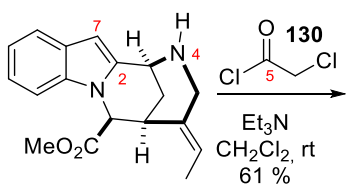

(土)-123

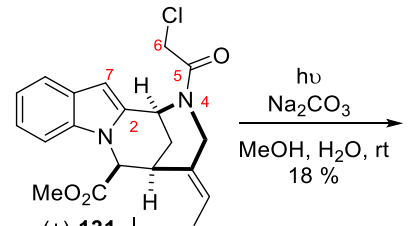

(土)-131

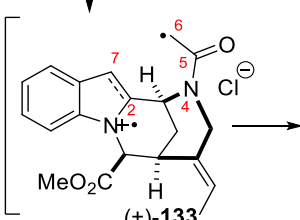

( \pm -133
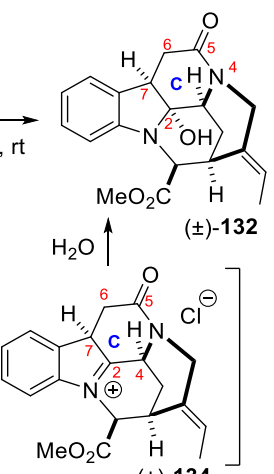

1.Lawesson toluene, reflux 2. $\mathrm{NiCl}_{2} \cdot 6 \mathrm{H}_{2} \mathrm{O}, \mathrm{NaBH}_{4}$ $\mathrm{MeOH}, \mathrm{THF},-30{ }^{\circ} \mathrm{C}$ $29 \%$ (2 steps)

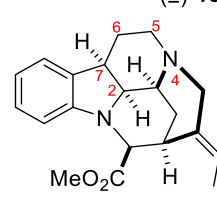

( \pm -2,7-dihydro-

pleiocarpamine (19)

Scheme 34 Total synthesis of ( \pm )-2,7-dihydro-pleiocarpamine

On a final note, Bosch also described the access to analogous pentacyclic compounds with a 7membered $\mathrm{E}$ ring via the same general strategy and a final 6 -membered $\mathrm{C}$ ring formation via either a Witkop photocyclization or an electrophilic cyclization from a dithiolane or a Pummerer reaction of a sulfoxide (not shown). ${ }^{48 c}$

3.6 Poupon, Evanno, Vincent and co-workers: total synthesis of (+)-16-hydroxymethylpleiocarpamine, (+)-16-epi-pleiocarpamine and (+)-taberdivarine $\mathrm{H}$ via formation of the $\mathrm{E}$ ring and the N1-C16 bond as the last stage.

In the framework of a collaboration, our research groups wondered if the biomimetic direct oxidative cyclization of (+)-geissoschizine (51) could lead to (+)-pleiocarpamine (3). It would be the first formation of the N1-C16 bond and E ring from the complete tetracyclic architecture with all its functional groups (Scheme 35).

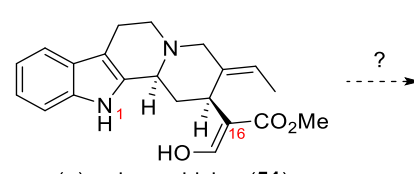

(+)-geissoschizine (51)

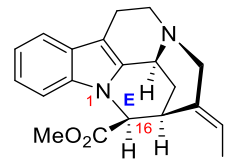

$(+)$-pleiocarpamine (3)

Scheme 35 Direct oxidative cyclization of geissoschizine towards pleiocarpamine

This idea was inspired by the report from Zhu and co-workers in 2013 of the formation of the N1-C16 bond via an oxidative cyclization of C16-malonate-containing $A B C$ tricycle ( \pm )-136 with a C16-malonate using LiHMDS $/ \mathrm{I}_{2}$ (Scheme 36). ${ }^{62}$ The authors were targeting the synthesis of the akuammilane alkaloid strictamine by deploying conditions described by $\mathrm{Ma}$ and co-workers for the formation of the C7-C16 bond of the akuammilanes. ${ }^{63}$ Deprotonation of both the malonate and the indole with LiHMDS was followed by oxidation of the resulting dianion $( \pm)-\mathbf{1 3 8}$ with $\mathrm{I}_{2}$ to obtain putative bisradical intermediate ( \pm )-139 which would lead to the formation of the N1-C16 bond of $( \pm)-137$. 


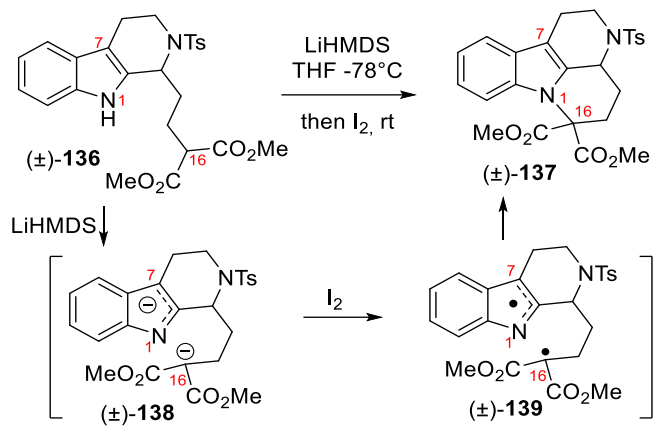

Scheme 36 Zhu's N1-C16 bond formation via oxidative cyclisation in Ma's conditions

(+)-Geissoschizine (51) and its 16-desformyl analogue were synthesized by combining two efficient already known syntheses of these compounds by Martin and Cook. ${ }^{64,65} \beta$-Dihydrocarboline 140, obtained in 2 steps from D-tryptophan, was engaged in a diastereoselective Mannich addition with silyl ketene acetal 141 as described by Martin ${ }^{66}$ followed by N4-allylation with allyl bromide 142 leading to the formation of 143 (Scheme 37). The end of the synthesis then followed Cook's work. ${ }^{67}$ Intramolecular addition of the vinyl iodide onto the unsaturated ester, leading to the formation of the $\mathrm{D}$ ring of 144, was promoted by $\mathrm{Ni}(\mathrm{COD})_{2}$ and the diastereoselectivity was controlled by the benzyl ester. In the absence of the benzyl ester, the diasteroselectivity was reversed (see later scheme 43). The latter was removed in three steps to obtain (+)-16-deformyl-gessoschizine (145) which was converted into (+)-geissoschizine (51) after a formylation step and to C16-malonate $\mathbf{1 4 6}$ via protection and deprotection of the indole nitrogen. ${ }^{65,68}$

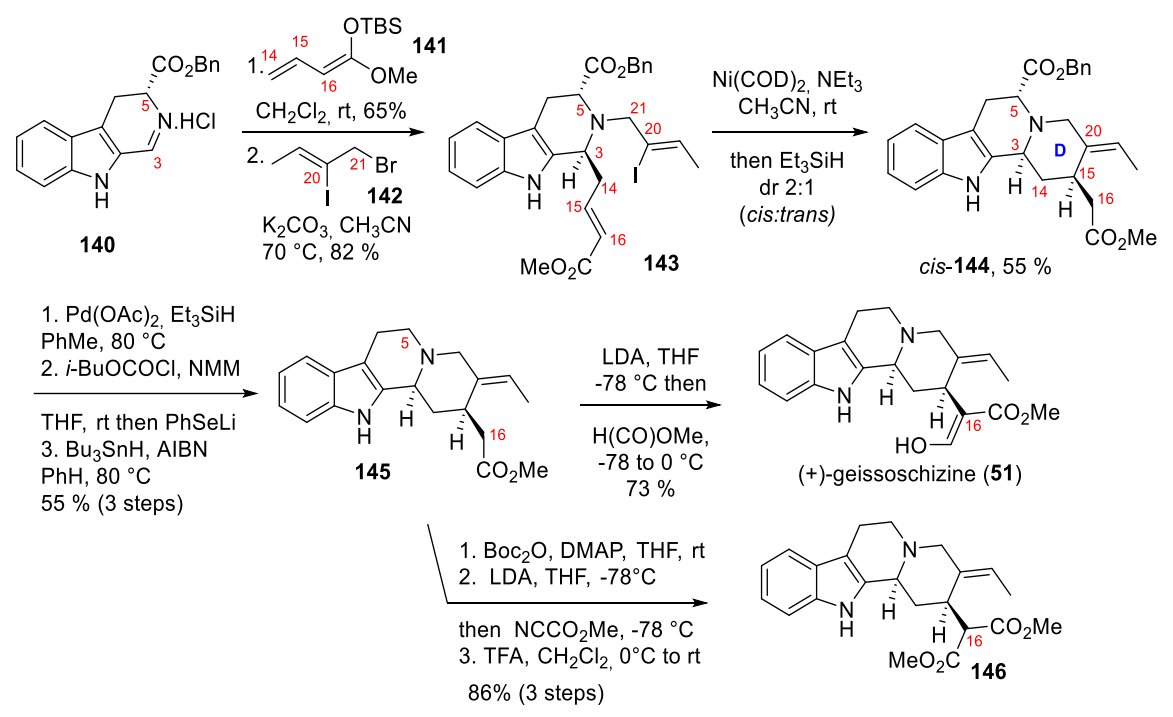

Scheme 37 Synthesis of 16-desformyl-geissoschizine, geissoschizine, and its malonate derivative

In 2018, slightly-modified Ma's conditions were applied by our groups to (+)-geissoschizine (51) itself which was deprotonated with KHMDS (instead of LiHMDS) followed by addition of $\mathrm{I}_{2}$ and it was noticed that only (-)-17-nor-excelsinidine (147) was formed (Scheme 38). ${ }^{64,65}$ Neither the N1-C16, nor the C7C16 bond formation were obtained as planned. Instead, the oxidative cyclisation happened between the N4-tertiary amine and the C16-formyl ester to yield the N4-C16 bond of the excelsinidines. Saponification of the methyl ester allowed to complete the first total synthesis of zwitterionic (-)-17nor-excelsinidine (147).

This selective N4-C16 coupling could be explained by the reactivity of the N4 tertiary amine towards the oxidant and as proposed by Sakai, the postulated trans-conformation 51-A adopted by (+)geissoschizine in solution, which is favourable to the formation of the excelsinidine core. ${ }^{42} 16$ Desformyl-geissoschizine $\mathbf{1 4 5}$ and geissoschizine-related malonate $\mathbf{1 4 6}$ did not produce any oxidative cyclization. 
In order to bring closer the $\mathrm{N} 1$ indolic nitrogen and the $\mathrm{C} 16$ carbon, a ring contraction of 7-membered ring 16-chloro-lactam 148 was envisioned. However, (-)-17-nor-excelsinidine (147) was obtained one more time due to the nucleophilicity of the N4-teriary amine. ${ }^{64,65}$

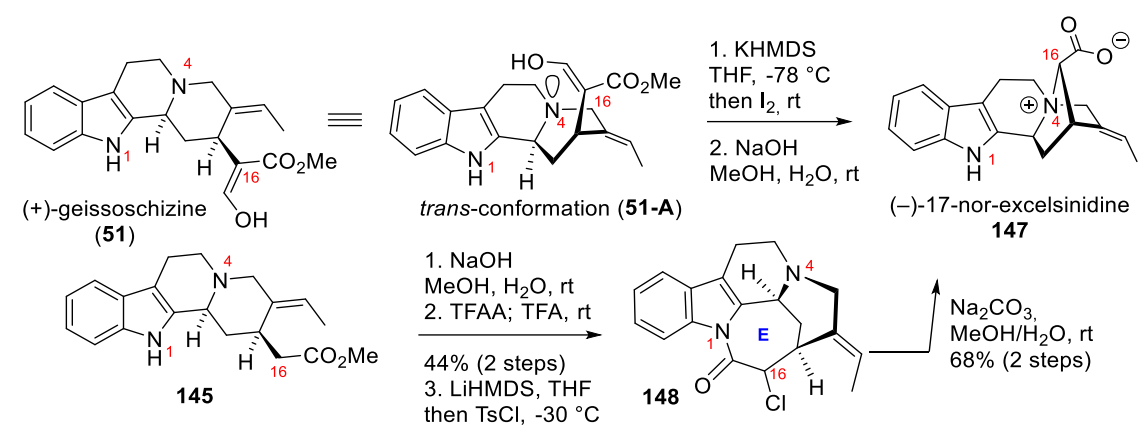

Scheme 38 Oxidative cyclization of geissoschizine for the total synthesis of (-)-17-nor-excelsinidine

In order to ensure the formation of the N1-C16 bond from geissoschizine, the molecule should probably adopt a cis-conformation 51-B. As demonstrated by the group of Gaich in 2016, ${ }^{43}$ this specific conformation can be locked by benzylation of the N4 amine. Moreover, this quaternization should also sequester the lone pair of the N4-nitrogen and hence blocks its reactivity towards oxidants. Therefore, to construct the $E$ ring of (+)-pleiocarpamine (3), it was planned to effect the oxidative cyclization from a cis-"locked" benzyl ammonium derivative 149 of geissoschizine (Scheme 39).

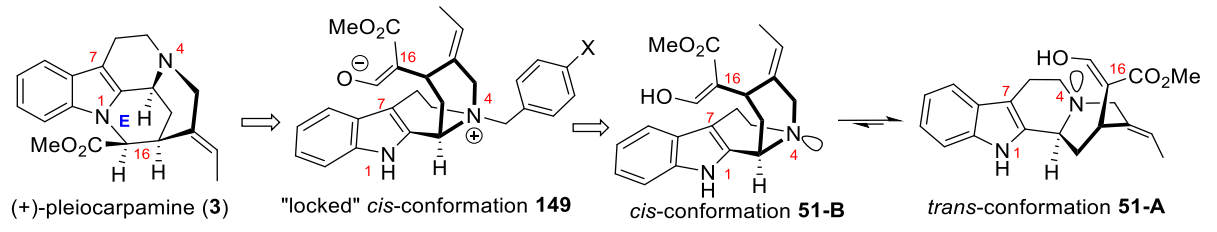

Scheme 39 Poupon, Evanno, Vincent's retrosynthesis of pleiocarpamine via quaternization of geissoschizine

Therefore, (+)-geissoschizine (51) was quaternized with para-methoxybenzylbromide and the resulting ammonium 149 was submitted to the modified Ma's conditions (KHMDS followed by the addition of $\mathrm{I}_{2}$ ). It led to the formation of the desired mavacurane skeleton and its N1-C16 bond as mixture of the PMB ammoniums 150 and 151 of 16-epi-16-formyl-pleiocarpamine (55) and 16-epi-pleiocarpamine (18) via spontaneous desformylation of the former (Scheme 40). ${ }^{68}$

This synthetic sequence was next implemented from dimethyl malonate $\mathbf{1 4 6}$ in order to desymmetrize this function at a later stage and to access the stereochemistry of pleiocarpamine at $\mathrm{C} 16$. The sequence of ammonium formation into $\mathbf{1 5 2}$ and oxidative cyclization efficiently produced the pentacyclic skeleton 153 and the N4-tertiary amine was regenerated from the N4-ammonium under the action of $\mathrm{BBr}_{3}$ on the PMB substituent. Indeed, the ester of $\mathbf{1 5 4}$ which is on the convex face is more accessible to chemical reagents. Thus, malonate $\mathbf{1 5 4}$ was selectively reduced in the presence of DIBAL-H, into 16formyl-pleiocarpamine 54, a presumed biosynthetic precursor of most of the mavacurane alkaloids. Then (+)-16-hydroxymethyl-pleiocarpamine $\mathbf{2 3}$ was accessed after the reduction of the aldehyde by sodium borohydride. Unlike what was expected, desformylation of the latter or Krapcho-type reaction of malonate $\mathbf{1 5 4}$ or thermic decarboxylation of acid 155 yielded 16-epi-pleiocarpamine (18), the thermodynamic product rather than pleiocarpamine ${ }^{68}$ To shorten the overall sequence and avoid the three steps to prepare malonate $\mathbf{1 4 6}$ and the decarboxylation step, the quaternization/N1-C16 cyclization sequence could be performed directly on 16-desformyl-geissoschizine 145 with a modest yield, ending with the synthesis of 16-epi-pleiocarpamine (18) via $\mathbf{1 5 6}$ and $\mathbf{1 5 0 .} .^{65}$ 


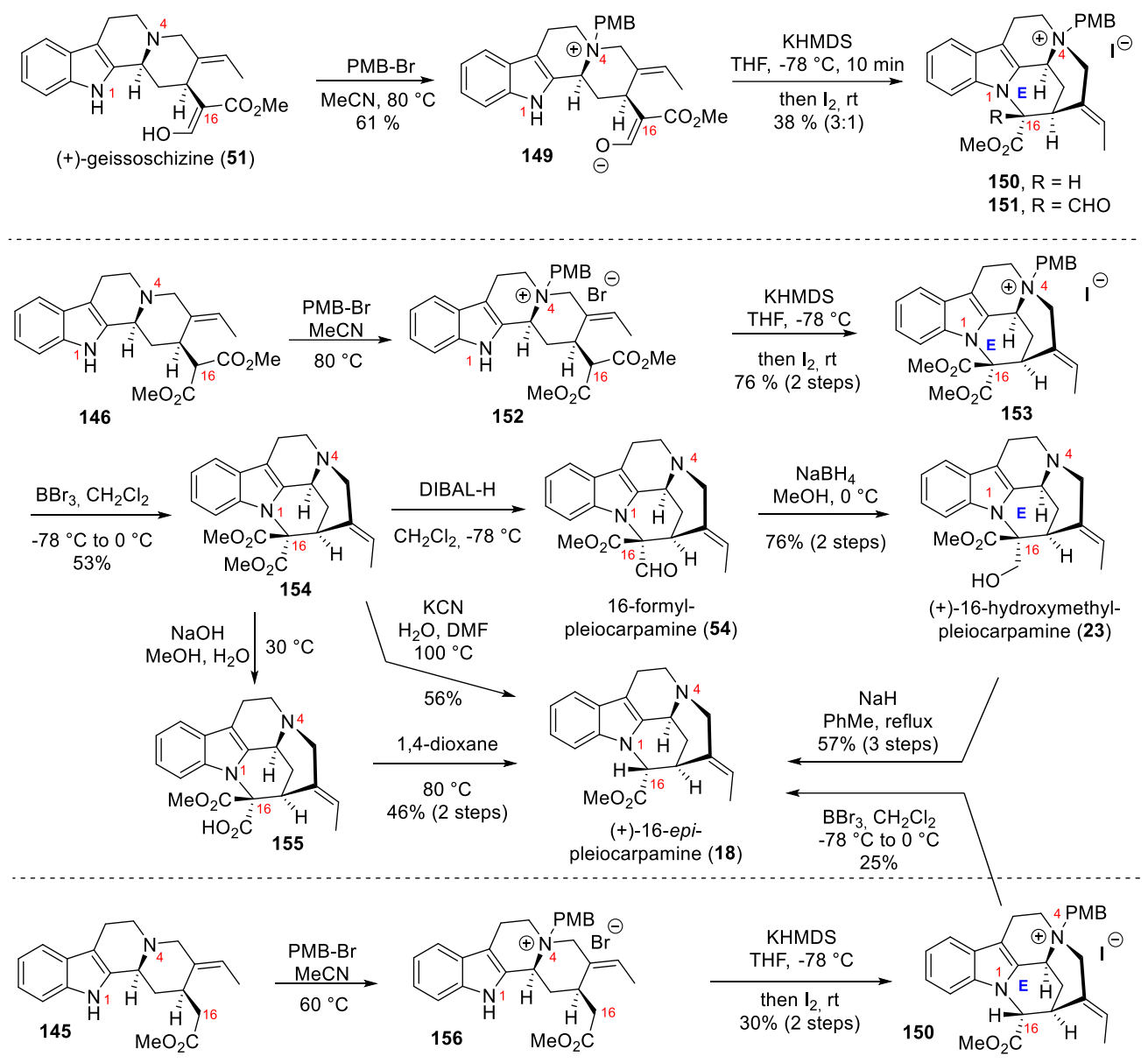

Scheme 40 Total synthesis of (+)-16-hydroxymethyl-pleiocarpamine and (+)-16-epi-pleiocarpamine

(+)-Taberdivarine $\mathrm{H} \mathrm{(24)}$ was a well-suited target for this strategy since this natural product is a N4amonium and possesses the stereochemistry of 16-epi-pleiocarpamine at C16 (Scheme 41). Therefore, dimethyl malonate $\mathbf{1 4 6}$ was engaged in a methylation step followed by the oxidative cyclization to form the N1-C16 bond. Finally, double saponification and decarboxylation of $\mathbf{1 5 7}$ led to the total synthesis of zwitterionic (+)-taberdivarine $\mathrm{H}(\mathbf{2 4})$.

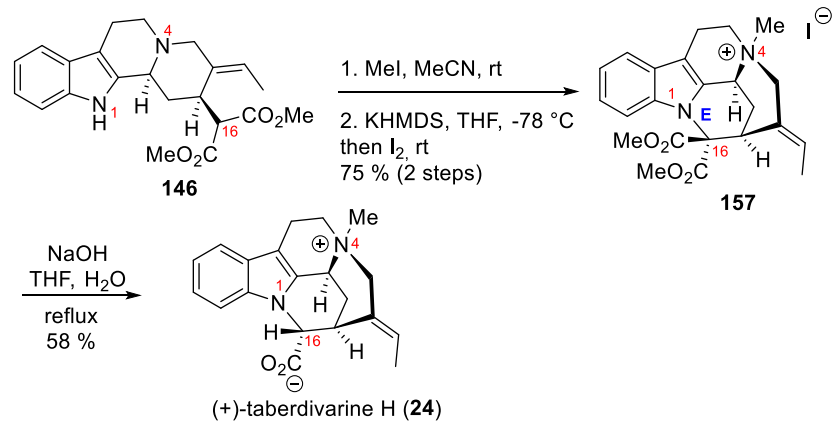

Scheme 41 Total synthesis of (+)-taberdivarine $H$

In parallel to this oxidative cyclization of the geissoschizine scaffold according to the Wenkert hypothesis, our team aimed to achieve the key oxidative cyclization at an earlier stage according to the Hesse and Schmid hypothesis (Scheme 42). ${ }^{69}$ Organocatalyzed enantioselective Michael addition of dimethyl malonate $\mathbf{1 5 8}$ to enal $\mathbf{1 5 9}$ followed by a non diastereoselective Pictet-Spengler reaction furnished strictosidine open form model $( \pm)-160 \mathrm{a}$ and its C-3 epimer ( \pm )-160b. A divergent oxidative cyclization was developed to access either the akuammilane or mavacurane frameworks by the choice of the oxidant after the double deprotonation by LiHMDS. Hexafluorophosphate ferrocenium 
$\left(\mathrm{Cp}_{2} \mathrm{FePF}_{6}\right)$ induced the formation of the $\mathrm{C7}-\mathrm{C} 16$ bond of strictamine precursor $( \pm)-161$, while bistrifluoroacetate iodobenzene (PIFA) delivered the N1-C16 bond of pleiocarpamine precursor ( \pm )162. Deprotection of the primary alcohol led to a spontaneous lactonisation and to the pentacyclic framework ( \pm )-163 of talbotine.

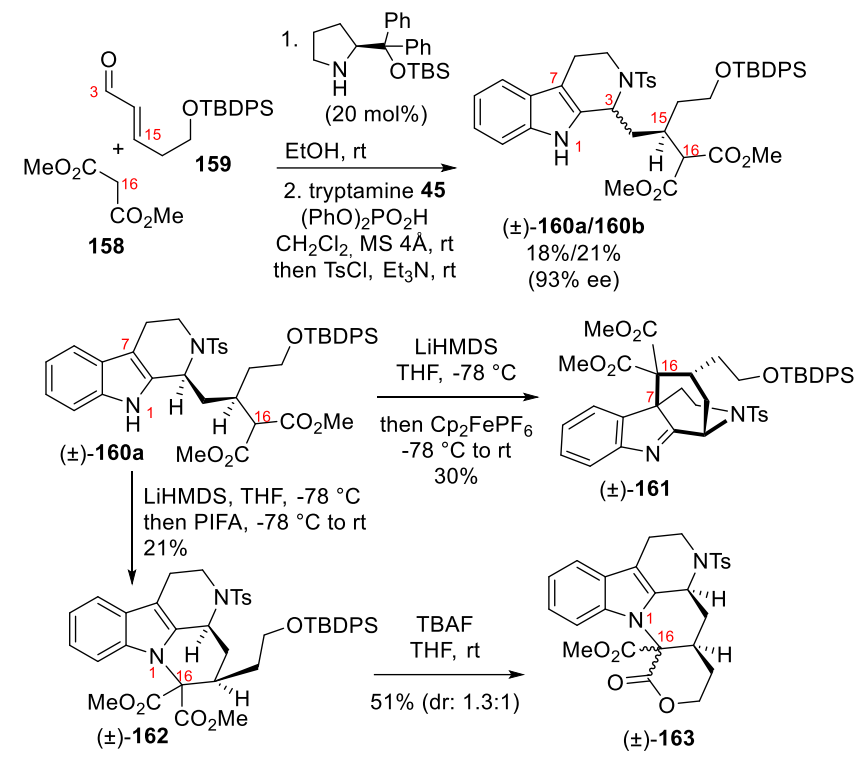

Scheme 42 Divergent oxidative cyclizations of a strictosidine model

3.7 Takayama and co-workers: total synthesis of ( \pm )-pleiocarpamine, $( \pm)$-16-epi-pleiocarpamine ( \pm )normavacurine and ( \pm )-C-mavacurine via formation of the E ring and the N1-C16 bond as the last stage.

In 2019, Takayama and co-workers reported the first total synthesis of ( \pm )-pleiocarpamine (3) as well as the synthesis of ( \pm )-16-epi-pleiocarpamine (18), $( \pm)$-normavacurine (16) and ( \pm )-C-mavacurine (2). ${ }^{70}$ This work appeared few weeks before the Poupon, Vincent and Evanno's report of the enantioselective total syntheses of (+)-16-hydroxymethyl-pleiocarpamine (23), (+)-16-epi-pleiocarpamine (18) and (+)taberdivarine $\mathrm{H}$ (24). The strategy was also based on the formation of the N1-C16 bond and the $\mathrm{E}$ ring from the complete geissoschizine framework. They planned to effect an intramolecular insertion of a geissoschizine-derived metal carbenoid ( \pm )-164 at C16 into the indolic N1-H bond (Scheme 43).

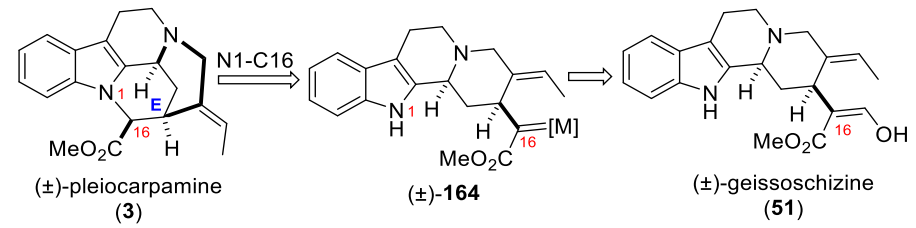

Scheme 43 Takayama's retrosynthesis of ( \pm )-pleiocarpamine

In order to access ( \pm )-16-desformyl-geissoschizine (145), the authors used the $\mathrm{Ni}(\mathrm{COD})_{2}$ mediated reductive cyclization of vinyl iodide ( \pm )-165 described by Poupon, Evanno and Vincent which afforded undesired trans-tetracyclic compound $( \pm)-\mathbf{1 6 6}$ as the major product, and its cis-isomer $( \pm)-\mathbf{1 4 5}$ as the minor and desired compound (Scheme 44). ${ }^{64,65}$ In order to limit the loss of substrate, ( \pm )-166 was epimerized to ( \pm )-145 in three steps: 1 ) oxidation into a 7-chloroindolenine; 2 ) isomerisation of the latter into $\mathrm{C} 3=\mathrm{N} 4$ iminium $( \pm)-167 ; 3)$ diastereoselective reduction of this iminium promoted by Noyori's catalyst.

( \pm )-16-Desformyl-geissoschizine (145) was formylated into ( \pm )-geissoschizine (51) and then converted into diazo compound ( \pm )-168 using Regitz diazo transfer reaction. 


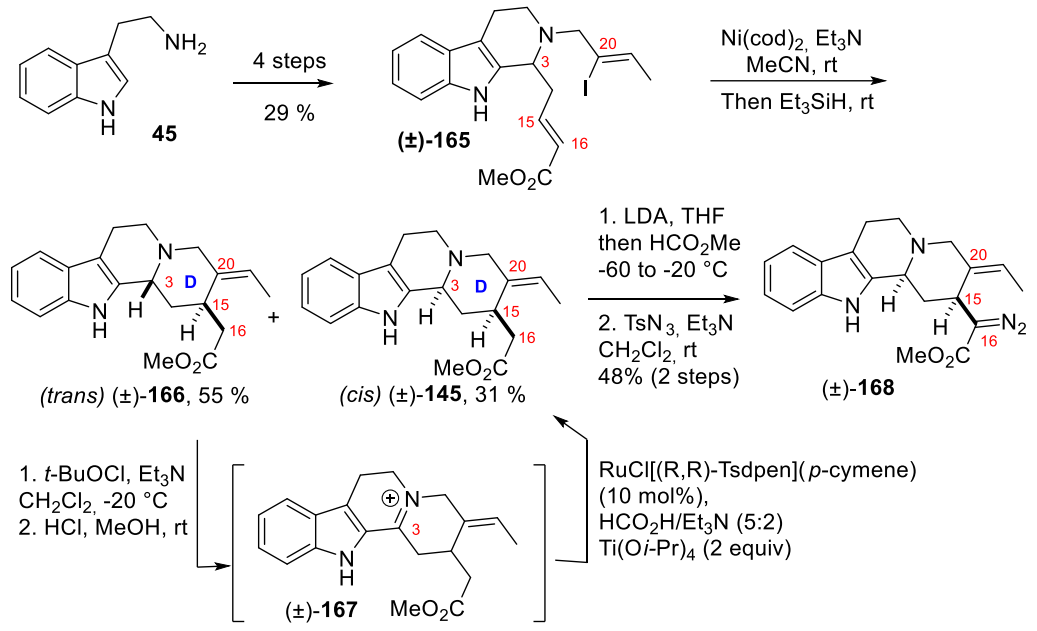

Scheme 44 Preparation of ( \pm )-16-diazo-16-desformyl-geissoschizine

( \pm )-16-Diazo-16-desformyl-geisosschizine ( \pm )-168 was next treated with a rhodium catalyst to generate a metal carbenoid intermediate ( \pm )-164 (Scheme 45). However, the obtained compound ( \pm )-169 was not the one expected. The formation of the $E$ ring was not observed but $( \pm)-169$ resulted from $D$ ring expansion with migration of the $\mathrm{C} 20$ ethylidene carbon from the $\mathrm{C} 15$-position to the C16-carbenoid position. This unexpected result could be explained by the trans-conformation adopted by the skeleton in solution. Independently and in analogy with the N4-benzylation of geissoschizine deployed by Poupon, Vincent and Evanno, ${ }^{65,68}$ Takayama and co-workers submitted the lone pair of N4-tertiary amine of $( \pm)-168$ in a reaction with the $\mathrm{BF}_{3}$-THF complex to force the geissoschizine framework of amino-borane-containing diazo ( \pm )-170 to adopt a cis-conformation. ${ }^{43}$ The latter was next engaged in the metal-carbenoid cyclisation, catalysed by $\mathrm{Rh}_{2}(\mathrm{cap})_{4}$, forging the desired $\mathrm{N1}$-C16 bond of pentacycle ( \pm )-171 with a 7:1 diastereoselectivity at C16. Regeneration of the N4-tertiary amine was done in the presence of trimethylamine oxide and gave $( \pm)$-pleiocarpamine $(3)$ for the first time and $( \pm)$-16-epipleiocarpamine (18) in $12 \%$ and $84 \%$ yield respectively.

Eventually, conditions previously employed by Harley-Mason and co-workers ${ }^{53}$ were used to easily transform ( \pm )-16-epi-pleiocarpamine (18) into ( \pm )-normavacurine (16) via reduction of the ester and then $( \pm$ )-C-mavacurine $(\mathbf{2})$ by a methylation step.

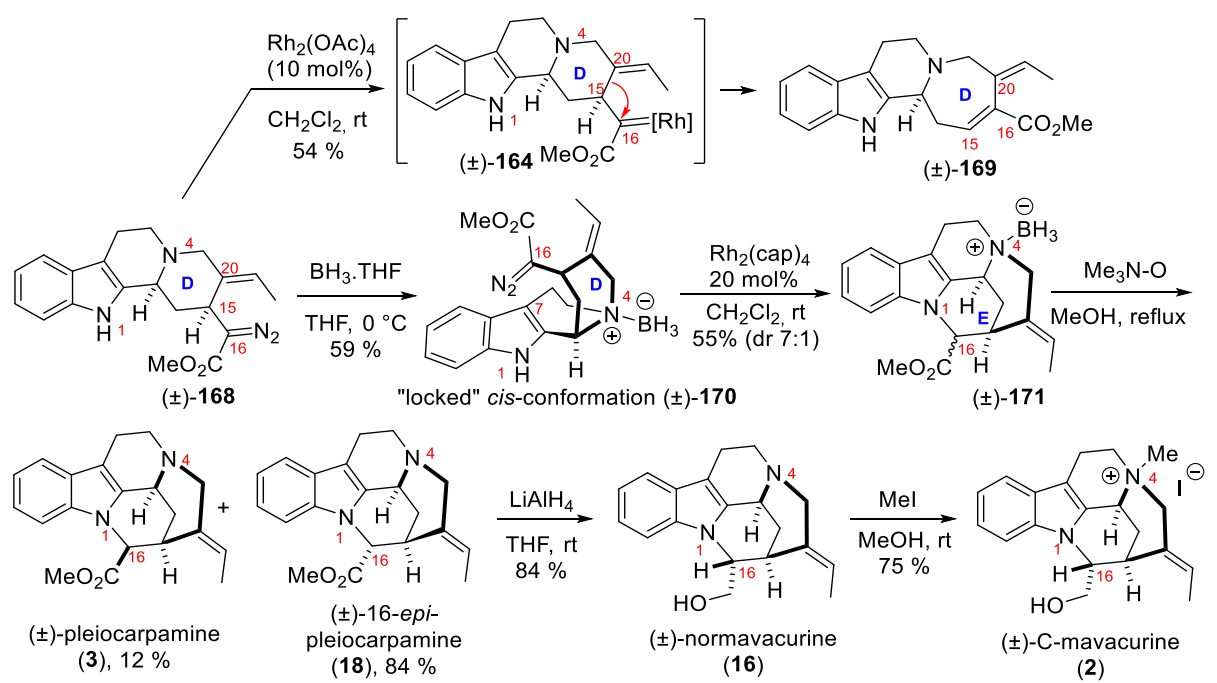

Scheme 45 Total synthesis of ( \pm )-pleiocarpamine, $( \pm)$-16-epi-pleiocarpamine, $( \pm)$-normavacurine and $( \pm)$-C-mavacurine

\section{Mavacurane-containing bis-indole alkaloids}




\subsection{Reactivity of pleiocarpamine}

The assembly of two indole alkaloids is a common feature in nature and in particular for monoterpene indole alkaloids (MIA). ${ }^{71}$ In this context, pleiocarpamine (3) is a major entry to highly complex bisindolic scaffolds. The highly strained caged-like skeleton of pleiocarpamine enhanced the nucleophilicity of the indole nucleus at the C7-position, leading to $\mathbf{1 7 2}$ which is electrophilic at C2 and can lead to $\mathbf{1 7 3}$ (Scheme 46). Thereby, it results in a high propensity of pleiocarpamine to add to other partners within the cells in a highly diastereoselective manner through its convex face. The mechanisms of the biosynthetic assemblies of all the bis-indoles alkaloids that we will present are only hypothesis.

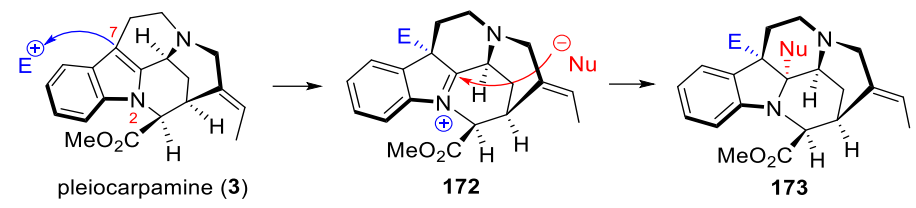

Scheme 46 Fundamental reactivity of pleiocarpamine

All the bis-indole alkaloids owning the mavacurane motif can be classified in different sub-families depending on the nature of the second MIA unit. Among all of them only a few have been synthesized by hemisynthesis.

\subsection{Macrolane-mavacurane bis-indoles}

The scaffold of the macrolane alkaloids is reactive and well suited to couple with other indole alkaloids including pleiocarpamine-related alkaloids (Scheme 47). ${ }^{2 \mathrm{~b}, 72}$

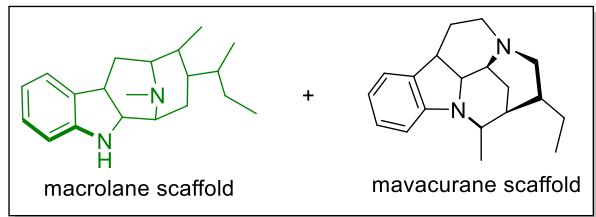

Scheme 47 Assembly of macrolane and mavacurane alkaloids

Villalstonine (4) was the first mavacurane-containing bis-indole alkaloid isolated in 1939 (Alstonia villosa Blume, Alstonia somersetensis F.M.Bailey, Alstonia macrophylla Wall. ex G.Don). ${ }^{73}$ However, its structure was elucidated years later in 1965 by chemical transformations ${ }^{74}$ and by X-ray analysis. ${ }^{75} \mathrm{It}$ proved to be the assembly product of pleiocarpamine (3) and macroline (174), a biosynthetic intermediate towards the macrolane alkaloids, with a tetrahydropyran ring between the indole of the former and the enone of the latter (Scheme 48). Several other natural congeners were isolated with different oxidation patterns with the presence of a 10-methoxy group on the macroline indole unit in $10^{\prime}$-methoxy-villalstonine (175) or a N4-oxide on the tertiary amine of the pleiocarpamine unit in villalstonine-N4-oxide (176), 10'-methoxy-villalstonine-N4-oxide (177) from Alstonia angustifolia. ${ }^{76}$ Villalstonidines A-C (178-180) differs in part from villalstonine at the C16 carbon (Alstonia angustifolia). ${ }^{76}$ Villalstonidine $\mathrm{B}(\mathbf{1 7 9})$ is an assemblage of macroline and 16 -hydroxymethylpleiocarpamine. Villalstonidines A (178) and C (180) display unusual oxidations at C16 with the presence of an $\alpha$-hydroxyester for villalstonidine $\mathrm{C}$ and a carbonyl at $\mathrm{C} 16$ resulting in a E-ring lactam for villalstonidine $\mathrm{A}$. The $\mathrm{C} 19-\mathrm{C} 20$ double bond have also been dihydroxylated for villalstonidine $\mathrm{A}$ (178), while villalstonidine $C(\mathbf{1 8 0})$ possesses an allylic alcohol at C18. Villalstonidines $D(\mathbf{1 8 1})$ and $E$ (182) are quaternized N4 amine and the latter is clearly an artefact of the isolation process with the reaction of villalstonine (4) with dichloromethane. ${ }^{77}$ Villalstonidine $F(\mathbf{1 8 3})$ is a demethylated version of villalstonine on the indolic nitrogen of the macroline part. ${ }^{78}$

Closely related to these compound, macrocarpamine $(\mathbf{1 8 5} \text {, Alstonia macrophylla })^{79}$ and its natural congeners $\quad\left[10^{\prime}\right.$-methoxy-macrocarpamine $\quad\left(\mathbf{1 8 6}\right.$, Alstonia angustifolia) ${ }^{76} \quad 10^{\prime}$-methoxymacrocarpamine- $\mathrm{N} 4$ oxide $(\mathbf{1 8 8}, \text { Alstonia angustifolia })^{76}$ and angustilongine $\mathrm{L}(\mathbf{1 8 7}$, Alstonia 
penangiana Sidiyasa) $]^{80}$ are composed of the anhydromacrosalhine-methine (184) and pleiocarpamine templates. They are linked by a single carbon bond between the terminal double bond of the macrolane part and the $\mathrm{C} 2$-indolic position of the mavacurane framework. Indeed, the pyrolytic cleavage of macrocarpamine (185) delivered anhydromacrosalhine-methine (184) and pleiocarpamine (3) monomers (not shown) as a proof of the biosynthetic origin of this indole natural product. ${ }^{79}$

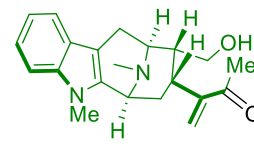

macroline (174)

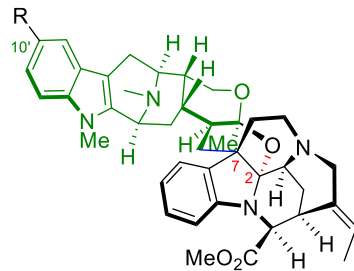

$\mathrm{R}=\mathrm{H}$, villalstonine $(\mathbf{4})$ $\mathrm{R}=\mathrm{OMe}, 10^{\prime}$-methoxyvillalstonine (175)

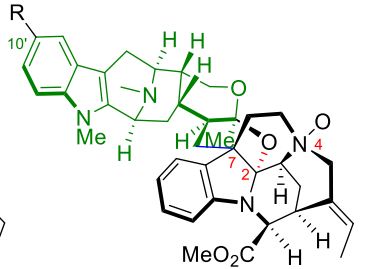

$\mathrm{R}=\mathrm{H}$, villalstonine- $\mathrm{N4}$-oxide (176) $\mathrm{R}=\mathrm{OMe}, 10^{\prime}$-methoxy-villalstonine N4-oxide (177)

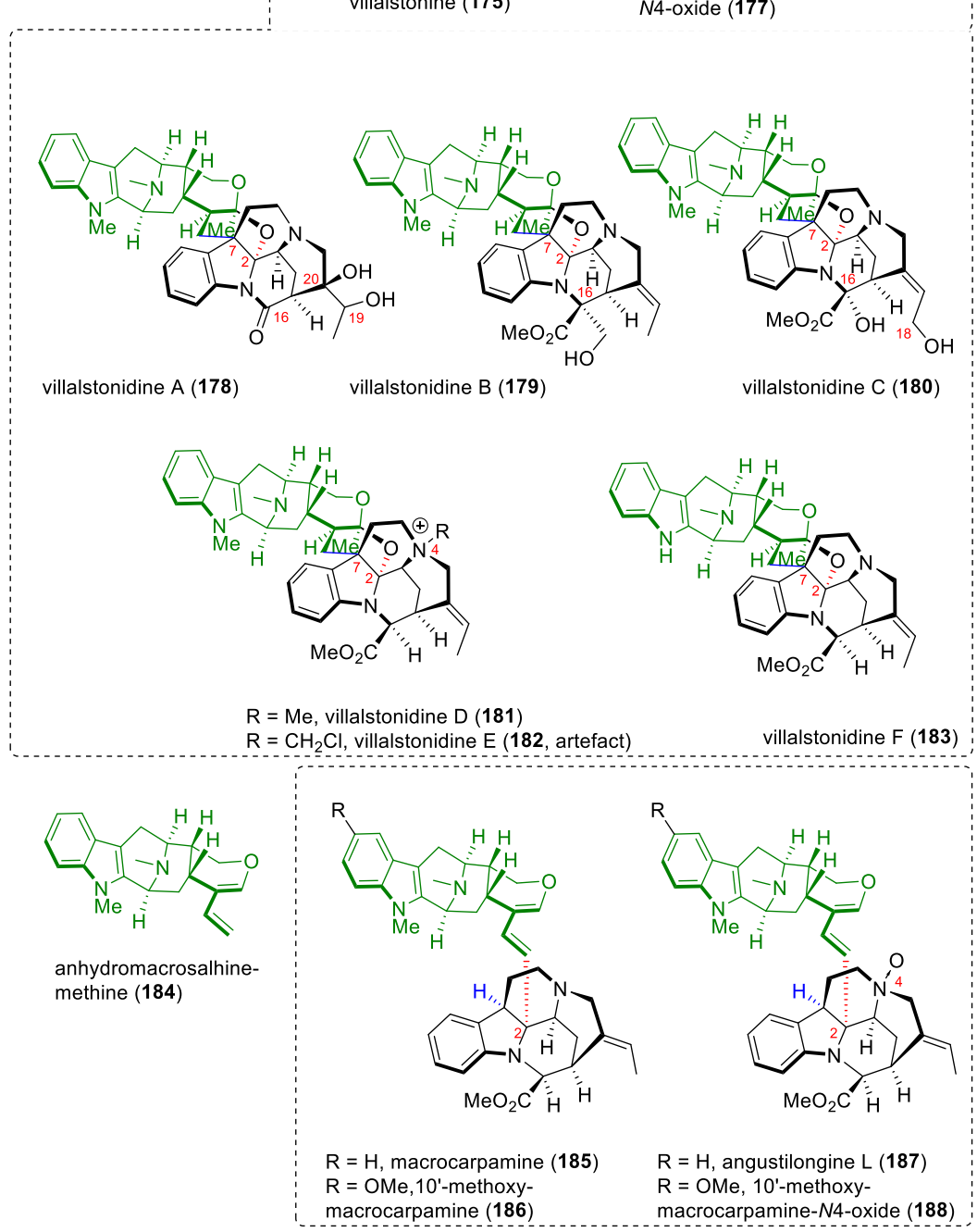

Scheme 48 Macrolane-mavacurane bis-indoles

From a biosynthetic point of view, villalstonine would be produced through the addition of the $\mathrm{C} 7$ nucleophilic enamine position of pleiocarpamine (3) onto the enone of macroline (174), followed by interception of the resulting C2-iminium (189) by the oxygen of the hemiketal formed by reaction of the ketone and alcohol of macroline to complete the formation of the tetrahydropyran ring (Scheme 49). Concerning macrocarpamine (185), the nucleophilic conjugated dienol ether part of anhydomacrosalhine-methine (184) would add to the highly electrophilic transient C2-iminium 190, 
produced by protonation at C7 of pleiocarpamine (3). Elimination of a proton from 191 would then restore the conjugated dienol ether of macrocarpamine (185).
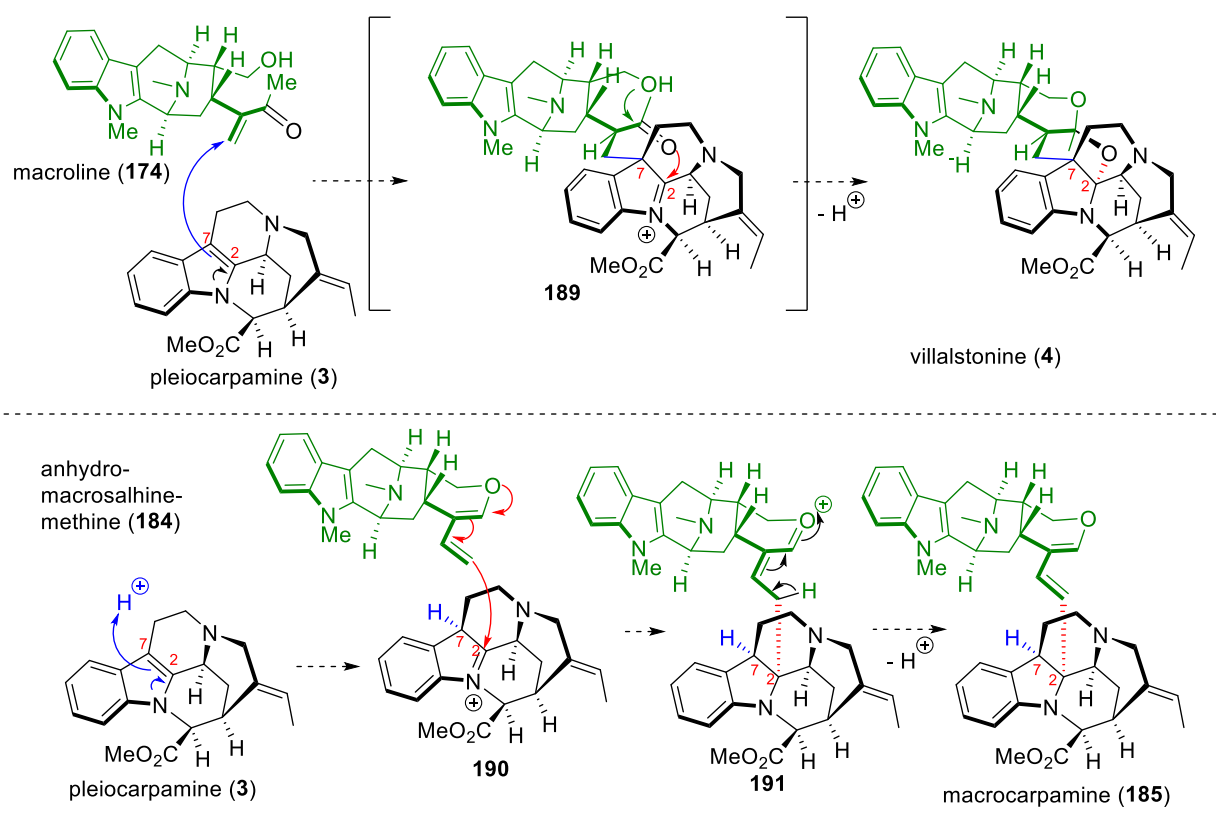

Scheme 49 Postulated biosynthesis of villastonine and macrocarpamine

These biosynthetic hypotheses were reinforced by the hemisynthesis of both villalstonine (4) and macrocarpamine (185) from pleiocarpamine (3) and macroline (174) or anhydromacrosalhine-methine (184) (Scheme 50).

Villalstonine (4) was first synthesized by Le Quesne and co-workers in 1972 via a biomimetic assemblage of the two monoterpene alkaloid units: natural pleiocarpamine (3) and macroline (174), obtained by degradation of villalstonine (4) itself, in diluted hydrochloric acid according the biosynthetic mechanism. ${ }^{81}$

Later on, Cook and co-workers reported a similar hemisynthesis of villalstonine (4) between natural pleiocarpamine (3) and the silyl-ether-containing last intermediate 192 of their total synthesis of macroline using similar acidic conditions in presence of fluoride ions (TBAF) to allow the in-situ deprotection of the primary alcohol. ${ }^{82}$

The same team also reported in 1996 the bioinspired hemisynthesis of macrocarpamine (185) from synthetic anhydromacrosalhine-methine $(\mathbf{1 8 4})^{83}$ and natural pleiocarpamine (3) in presence of dry hydrogen chloride according to the biosynthetic scenario. ${ }^{84}$ 

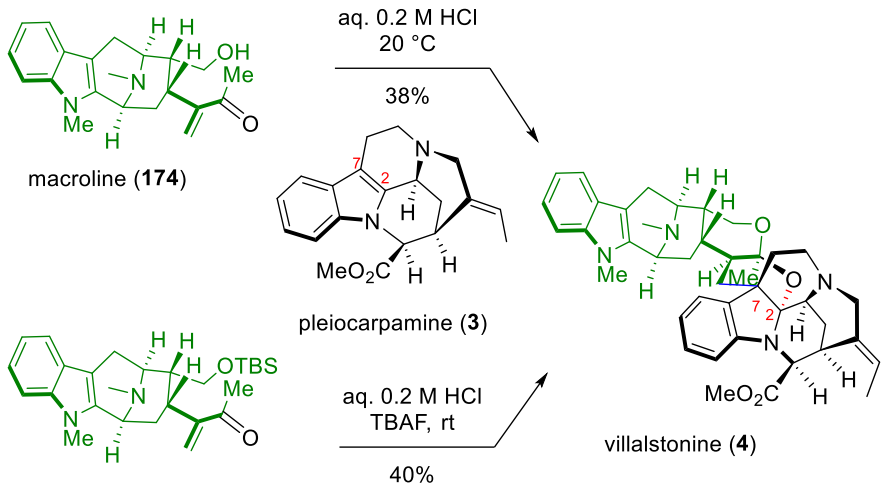

192
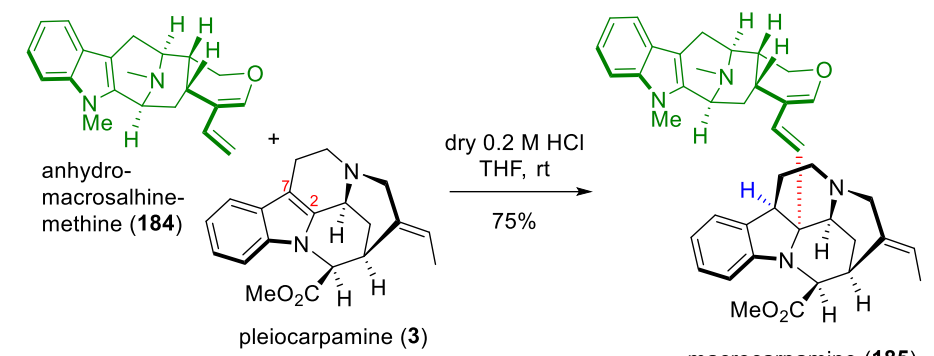

macrocarpamine (185)

Scheme 50 Biomimetic hemisynthesis of villalstonine and macrocarpamine by Le Quesne and Cook

\subsection{Sarpagane-mavacurane bis-indole}

The sarpagane skeleton ${ }^{2}$ is the biosynthetic precursor of the macrolane scaffold via N4methylation and C15'-C16' bond cleavage via Hoffmann reaction. Through a similar process, the C3'N4' bond of sarpagane 193 can also be cleaved to generate 16-epi-vobasine (194) or electrophilic intermediate 195 at C3 which can react with the C7-nucleophilic position of pleiocarpamine (Scheme 51). The resulting C2-iminium 196 could then be intercepted by the $N 1^{\prime}$ indolic nitrogen of the sarpagane unit leading to the unique indolo-pyrrolo-indoline motif of hunterizeyline $F(197) .{ }^{85}$
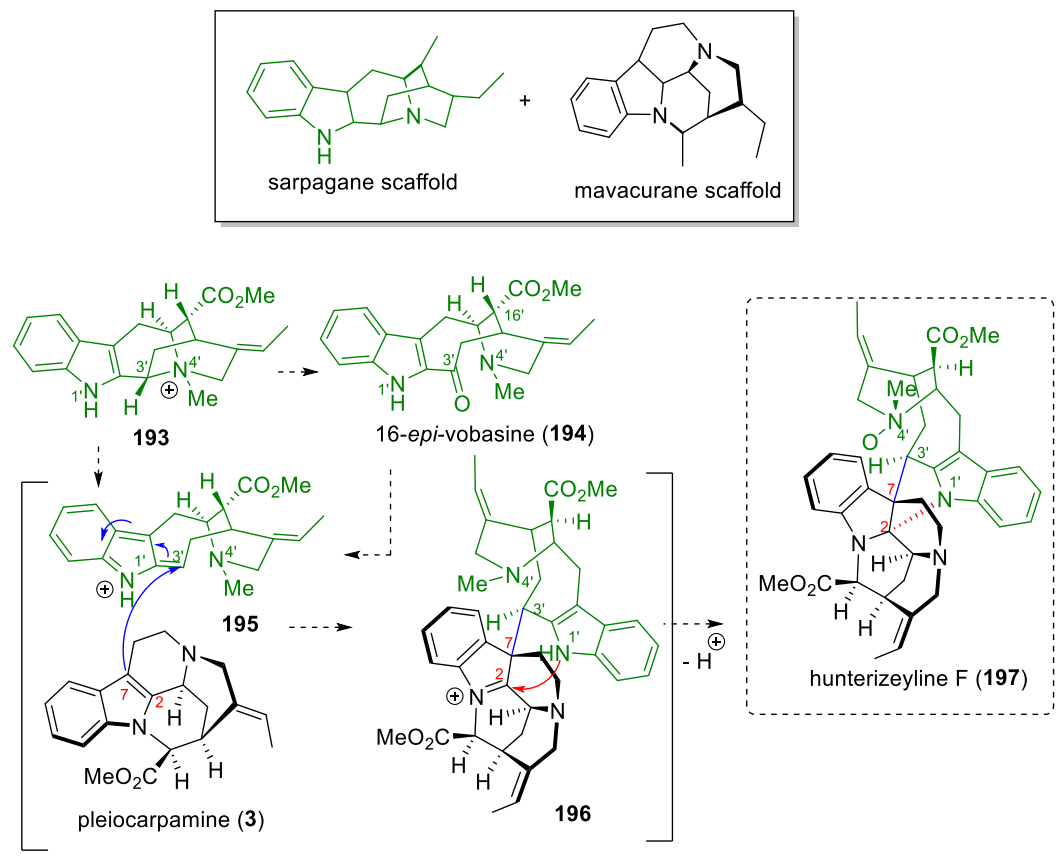

Scheme 51 Sarpagane-mavacurane bis-indole and its postulated biosynthesis

\subsection{Aspidospermane-mavacurane bis-indoles}


Aspidospermane alkaloids ${ }^{4,5}$ are also good partners of the mavacuranes to generate bis-indole alkaloids (Scheme 52).

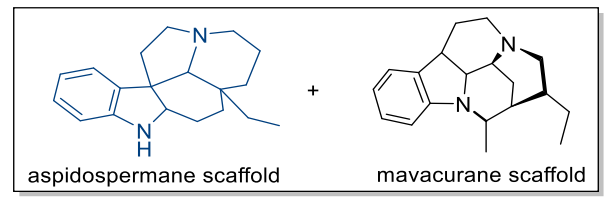

Scheme 52 Assembly of aspidospermane and mavacurane alkaloids

In several of them the aspidospermane unit is linked to the mavacurane unit via a methylene bridge between the $\mathrm{C} 7$ carbon of pleiocarpamine and the $\mathrm{N} 1^{\prime}$ indolic nitrogen of the aspidospermane unit with an additional bond between the $\mathrm{C} 2$ and $\mathrm{C}_{12}$ ' carbons to form a 6-membered ring (Scheme 53). Among them, pycnanthinine (6, Pleiocarpa pycnantha (Stapf) Pichon), whose structure was resolved in $1967,{ }^{86}$ is composed of dehydroaspidospermidine (198) and pleiocarpamine (3). ${ }^{7 \mathrm{~b}}$ Contortarine A (200, Tabernaemontana contorta Stapf) ${ }^{87}$ displays aspidofractinine (199) as the aspidosperman pseudomonomer. The structures of pycnanthine (Pleiocarpa pycnantha) ${ }^{88}$ and pleiomutinine (Pleiocarpa pycnantha $)^{13}$ for which the aspidospermane unit was originally misassigned, ${ }^{88}$ were revised in 1976 to 202 and 203 and possess a 19-epi-vindolininie (201) subunit. ${ }^{89}$ Pleiomutinine (203) is a saturated analog of pycnanthine (202). Epimers at both the pleiocarpamine (16-epi-pleiomutinine (204), Tabernaemontana contorta $)^{87}$ and vindolininine (19'-epi-pleiomutinine (205), Hunteria congolana Pichon) ${ }^{90}$ parts of pleiomutinine and $\mathrm{N}$-oxide derivatives (huncaniterines $\mathrm{A}$ (206) and $\mathrm{B}$ (207), Hunteria zeylanica (Retz.) Gardner ex Thwaites, Pleiocarpa pycnantha) ${ }^{37,91}$ are also known natural products.

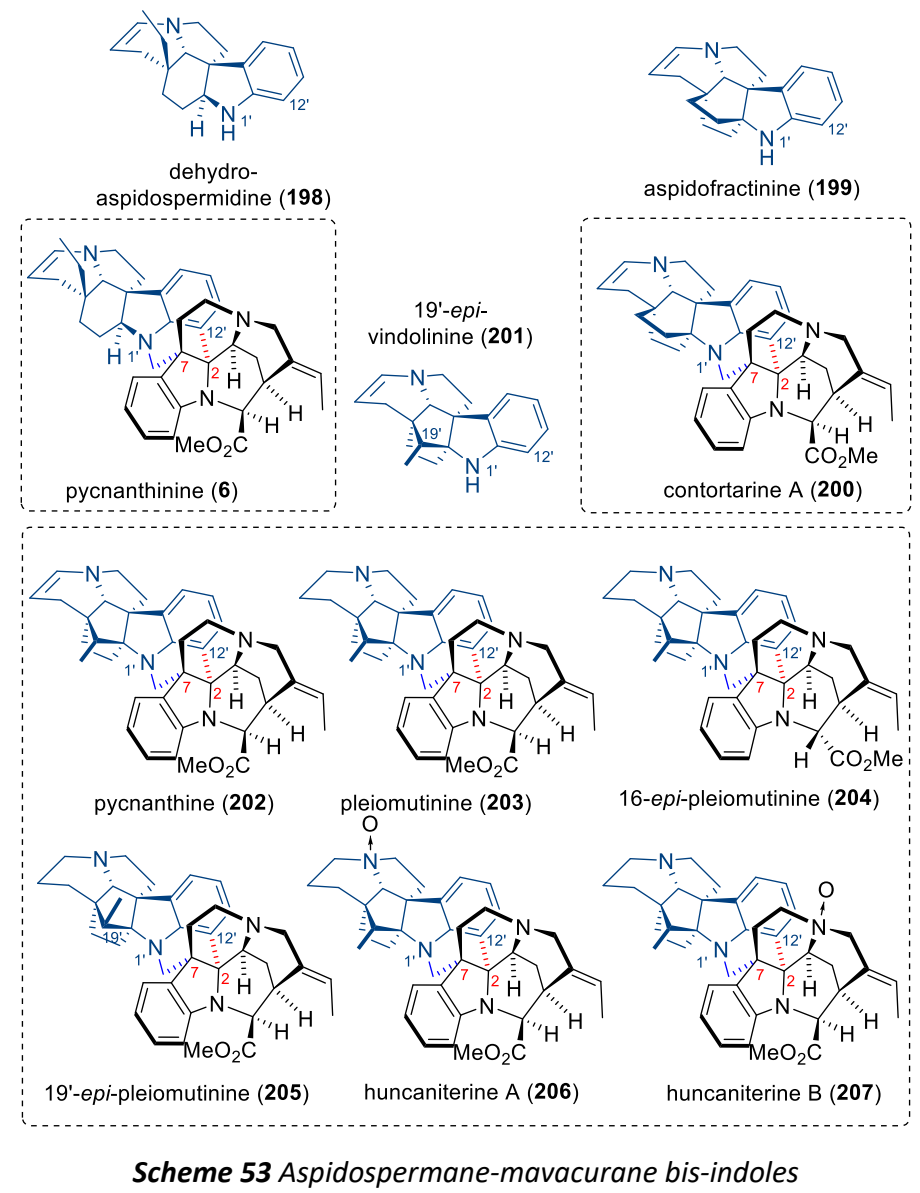

The extra carbon atom of the methylene bridge would be obtained biosynthetically from the condensation of formaldehyde with the aspidospermane alkaloid (198, 199 or 201). Mannich-type C7addition of pleiocarpamine (3) into the generated iminium 208 would then provide C2-iminium 209 
(Scheme 54). Finally, bis-indoles $\mathbf{6 , 2 0 0}$ or $\mathbf{2 0 2}$ would be obtained after trapping of iminium $\mathbf{2 0 9}$ via an aromatic electrophilic substitution at the $\mathrm{C}^{12}$ ' position of the aspidospermane part.

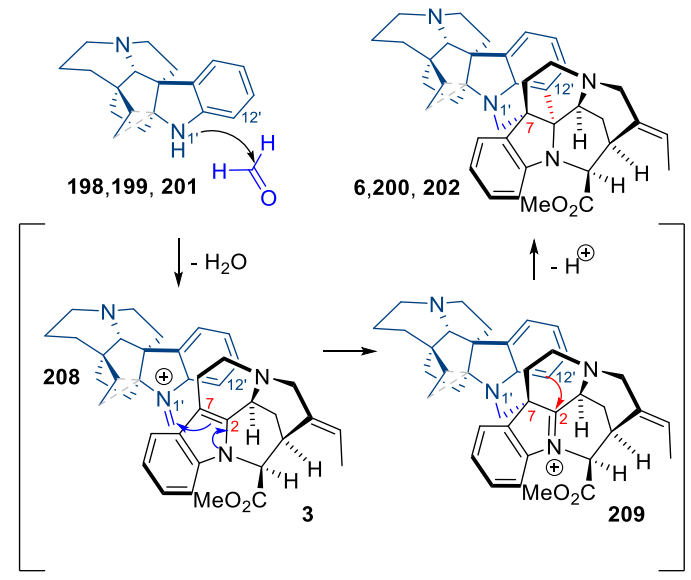

Scheme 54 Postulated biosynthesis of aspidospermane-mavacurane bis-indoles

Goniomedine B (210, Gonioma malagasy Markgr. \& Boiteau), arises biosynthetically from the attachment of pleiocarpamine with the help of a molecule of formaldehyde onto 11-hydroxyquebrachamine (214), which originate from a C3-C7 bond reduction of the aspidospermane skeleton (Scheme 55). ${ }^{92}$ However, unlike pycnanthinine (6), the two units are linked by a dihydropyrane motif. The ortho-hydroxymethylation of 11-hydroquebrachamine (214) would give, upon elimination, paraiminoquinomethide $\mathbf{2 1 5}$ which would be attacked by pleiocarpamine (3). The resulting C2-iminium 216 would be trapped by the hydroxyl group at the $\mathrm{C}^{11}$ ' position of quebrachamine leading to goniomedine B (210). It is believed that goniomedine A (211), goniomedine A $N$-oxide (212) and goniomedinone (213) are artefact produced during the isolation process via formation of $7^{\prime}$-hydroxyindolenine $\mathbf{2 1 7}$ on the quebrachamine part followed by trapping of the $\mathrm{C2}^{\prime}$-indolenine by the $\mathrm{N} 4^{\prime}$-tertiary amine. ${ }^{92,93}$

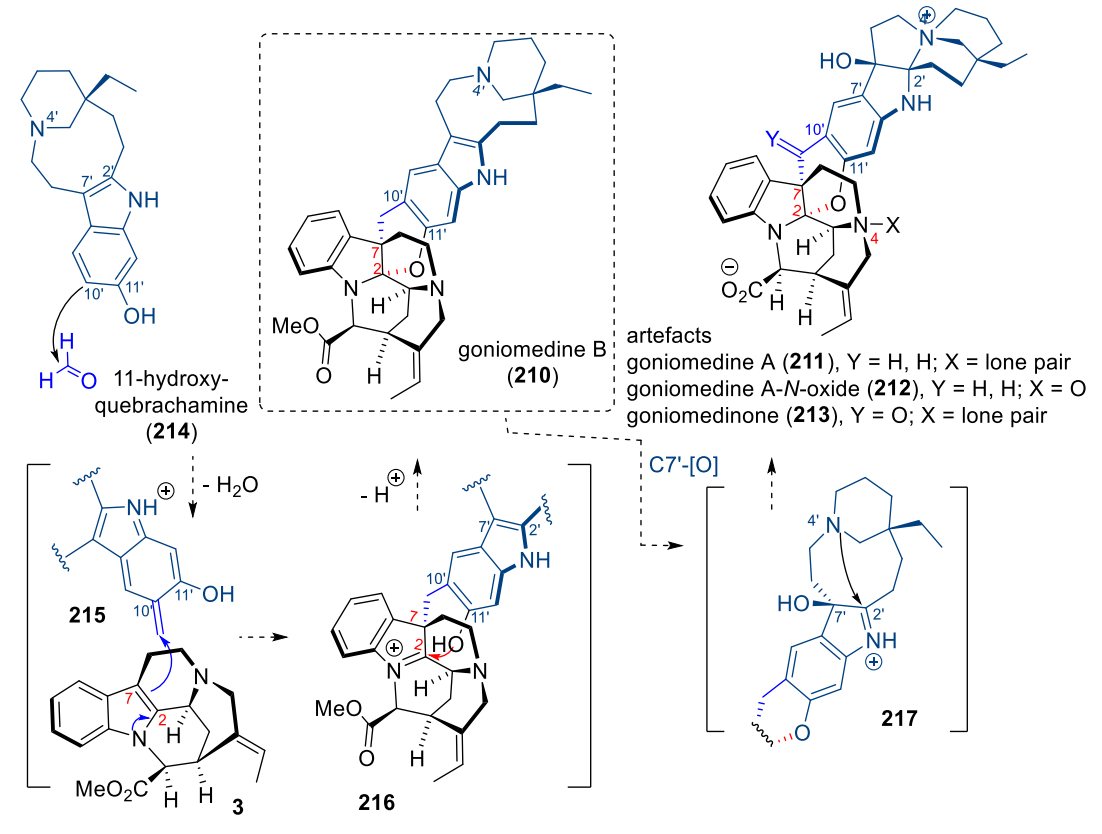

Scheme 55 Dihydropyran-containing aspidospermane-mavacurane bis-indoles

\subsection{Akuammilane-mavacurane bis-indoles}

The akuammilane alkaloids ${ }^{3}$ are probably the most important source of molecular diversity when assembled with pleiocarpamine (3) and the mavacuranes (Scheme 56). 


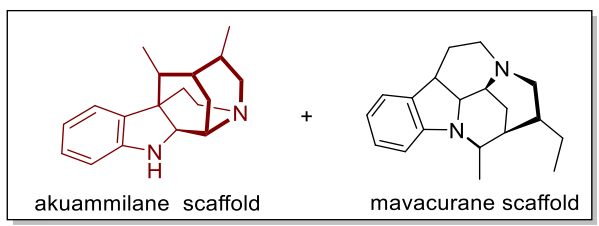

Scheme 56 Akuammilane-mavacurane bis-indoles

Pleiocorine (220, Alstonia deplanchei Van Heurk \& Müll.Arg.) ${ }^{94}$ and pleiocraline (223, Alstonia deplanchei) ${ }^{95}$ were the first akuammilane-mavacurane bis-indoles isolated (Scheme 57). They share a benzofuro[2,3-b]indoline link between the $\mathrm{C} 2-\mathrm{C} 7$ indolic carbons of pleiocarpamine and the benzene part of the akuammilane counterpart: 10-desmethyl-vincorine (218) for pleiocorine (220) or 1,10bisdesmethyl-vincorine (219) for N1'-desmethyl-pleiocorine (221, Alstonia odontophore Boiteau) ${ }^{96}$ and 10-hydroxy-cathafoline (222) for pleiocraline (223). The benzofuroindoline motif, also found in the emblematic marine natural product diazonamide $A,{ }^{97}$ should biosynthetically be the product of the oxidative coupling of the indole and phenol parts of respectively pleiocarpamine (3) and the akuammilane alkaloid via formation of a C-C bond, followed by the intramolecular trapping of the iminium 224 by the hydroxy group of the phenol.

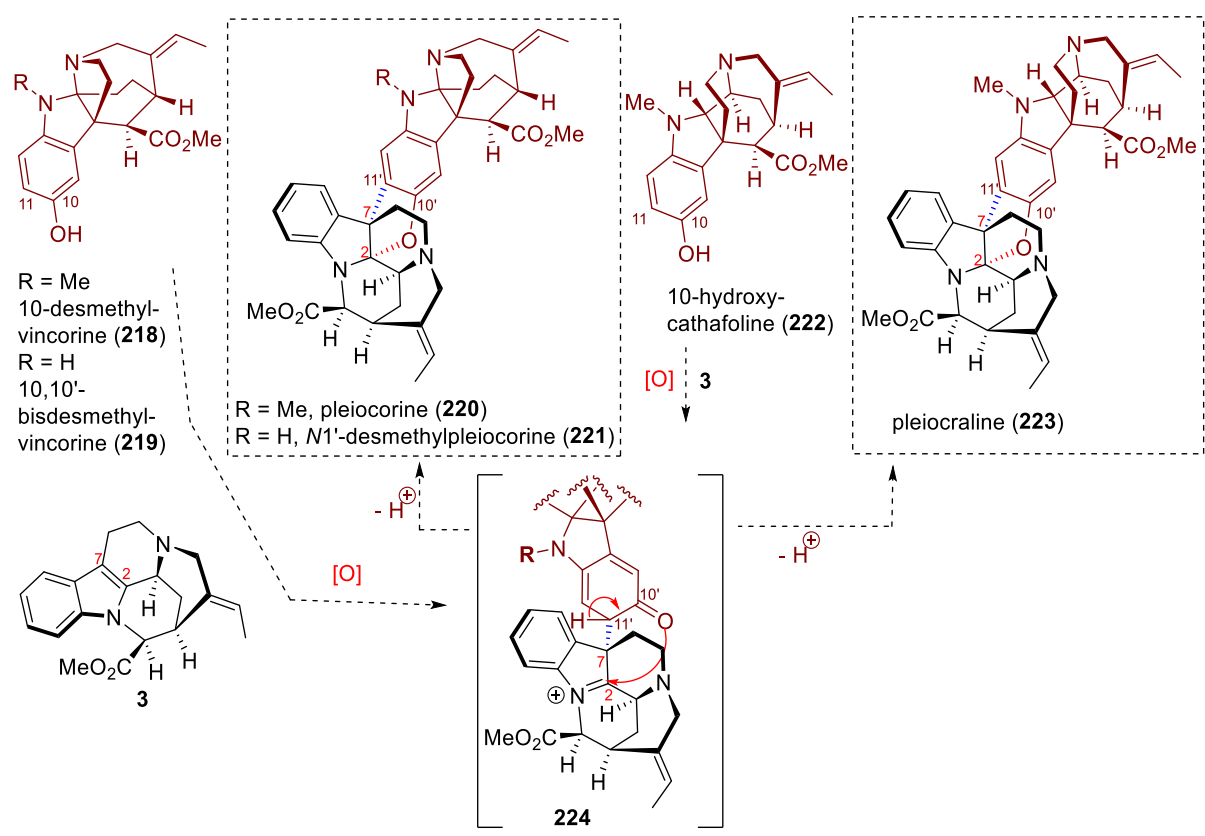

Scheme 57 Benzofuroindolines-containing akuammilane-mavacurane bis-indoles and their postulated biosynthesis

Plumocraline (225, Alstonia plumosa), ${ }^{23,98}$ isolated by Massiot and co-workers, features the union of pleiocarpamine (3) and cabucraline (226) which is closely related to the akuammilane unit of pleiocorine (220) (Scheme 58). However, in this case, the two units are linked by a single carbon-carbon bond between the $\mathrm{C} 2$-indolic position of pleiocarpamine (3) and the $\mathrm{C}^{\prime} \mathrm{O}^{\prime}$-benzenic-position of cabucraline (226). This was demonstrated by the recovery of both these two MIA upon hydrolysis of plumocraline (225) in dry methanol with hydrogen chloride. According to the postulated biosynthesis, 
this bond would result from the attack of the carbon in ortho of the methoxy group of cabucraline (226) to protonated pleiocarpamine 190.

Massiot and co-workers were able to do the biomimetic hemisynthesis of plumocraline (225) upon treatment of a pleiocarpamine (3) and cabucraline (226) with $2 \%$ hydrogen chloride in methanol. ${ }^{98}$

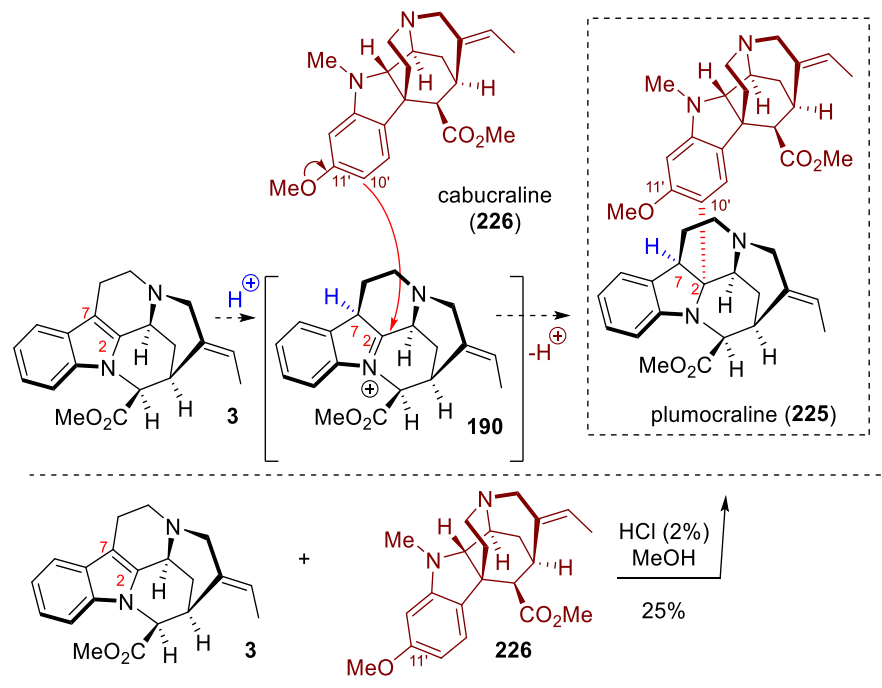

Scheme 58 Plumocraline, postulated biosynthesis and biomimetic hemisynthesis via C2-arylation of pleiocarpamine

In the hunzeylanines A-E (227-231, Hunteria zeylanica), pleiocarpamine (3) or 16-hydroxymethylpleiocarpamine (23) are connected to 11-hydroxy-10-deoxy-akuammine (232) via a dihydropyran ring between the $\mathrm{C2}-\mathrm{C} 7$ indolic carbons of the mavacurane and the phenol part of the akuammilane unit with the presence of a methylene bridge (Scheme 59). ${ }^{99}$ Hypothetically, condensation of the 11hydroxy-indole of $\mathbf{2 3 2}$ with formaldehyde may lead to para-iminoquinomethide $\mathbf{2 3 3}$ which would react with the nucleophilic indole of pleiocarpamine via $\mathbf{2 3 4}$ to furnish the hunzeylanines (227-231).
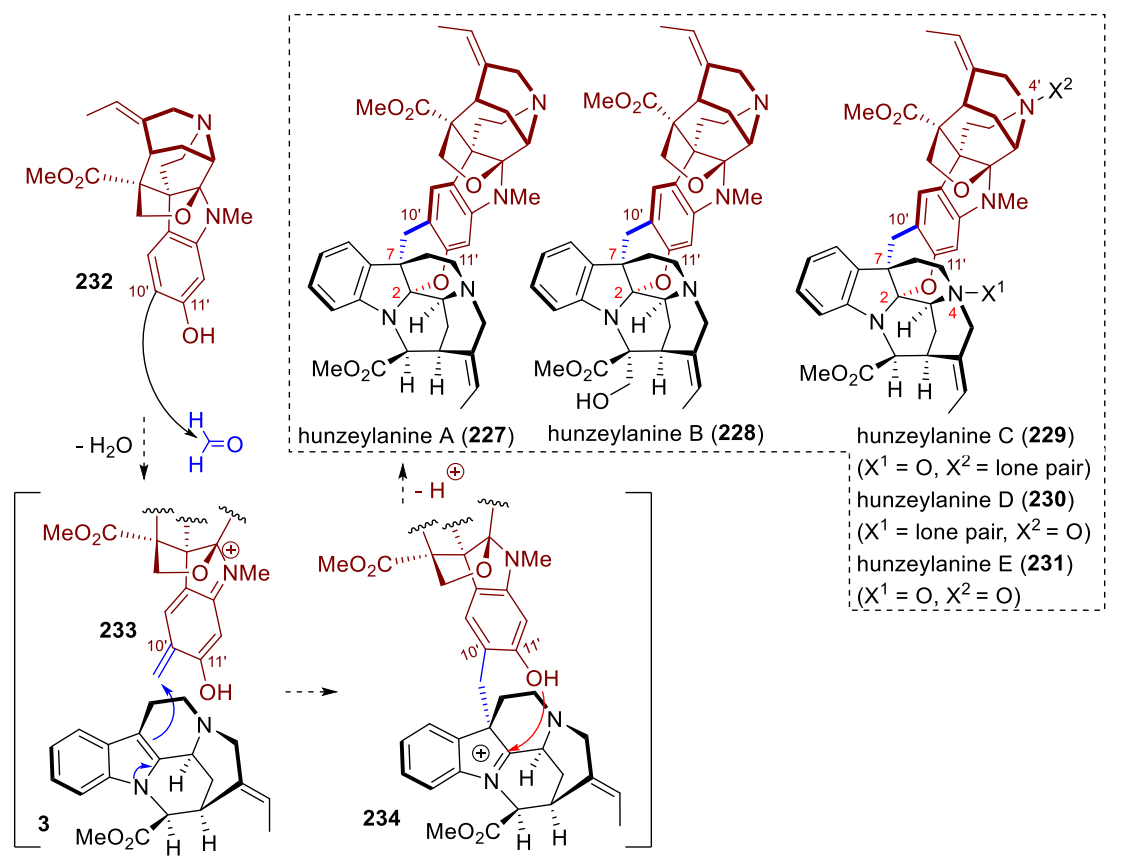

Scheme 59 Dihydropyran-containing akuammilane-mavacurane bis-indoles and their postulated biosynthesis

Ceylanine (235, Petchia ceylanica (Wight) Livera) is, to the best of our knowledge, the only mavacurane-containing bis-indole that is not linked by the indolic C2 and/or C7 position (Scheme 60). ${ }^{100}$ Instead, the mavacurane unit is connected to vincorine (236) via a $\mathrm{C} 10-\mathrm{C} 11^{\prime}$ bond between the benzene rings of the two MIA which should have been produced by an oxidative coupling in orthopositions of two oxygenated MIA. The mavacurane unit features an unusual lactone which should arise 
from the dihydroxylation of the $\mathrm{C} 19=\mathrm{C} 20$ double bond followed by cyclization with the $\mathrm{C} 22$ ester (237 to 238 to 239). Migration of the N4 tertiary amine to the C2-indolic position is also rare in the mavacurane series ( 240 to 241 to 242 to 243 ).

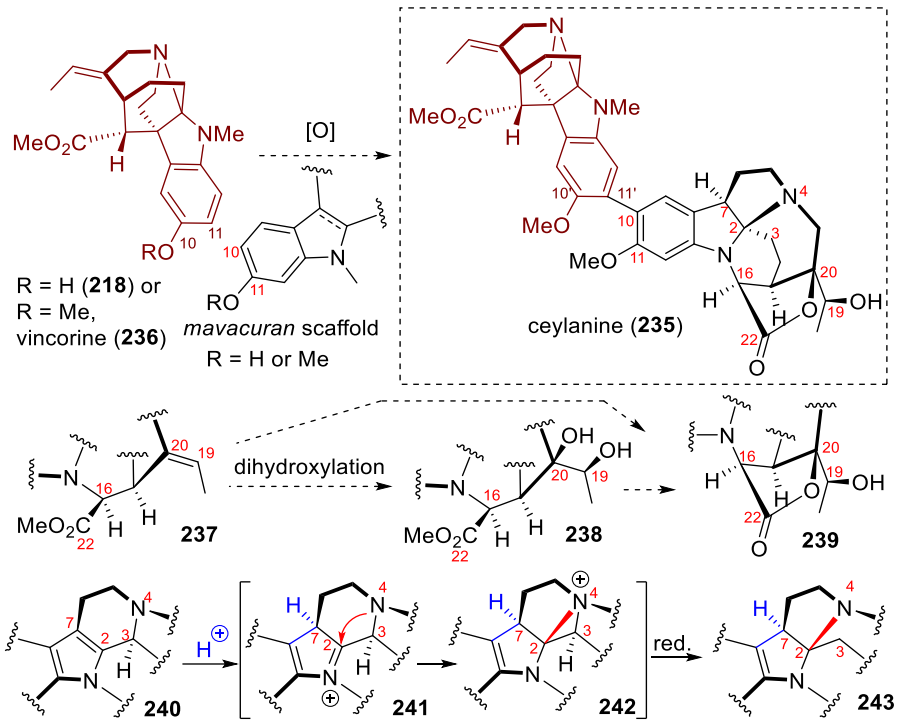

Scheme 60 Ceylanine and its postulated biosynthesis

\subsection{Adducts of mavacuranes with non-indolic species}

The reactive $\mathrm{C} 2=\mathrm{C} 7$ indolic double bond offers to pleiocarpamine the ability to not only react with a second MIA in plant but also with small non-indolic electrophilic reagents such as quinone-methidelike pyrone species or ortho-quinones (Scheme 61).

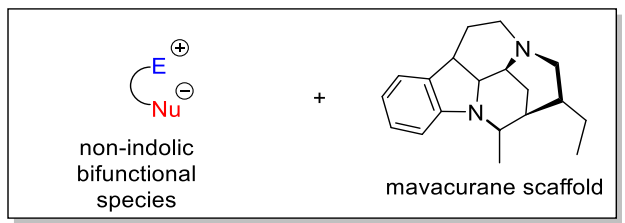

Scheme 61 Assembly of mavacurane alkaloids and non-indolic species

Pleiomaltinine (244, Alstonia angustifolia) is constituted of pleiocarpamine (3) associated to a pyrone motif via a dihydropyran linker (Scheme 62). ${ }^{25}$ This natural product may have biosynthetically originated from an oxidative coupling between pleiocarpamine (3) and maltol (245), a naturallyoccurring hydroxypyrone. ${ }^{25}$ Maltol (245) would be oxidized into conjugated diketone $\mathbf{2 4 7}$ which would be trapped by the enamine of pleiocarpamine via a 1,4-addition. Then iminium 248 would be intercepted via intramolecular addition of the hydroxy group on the pyrone to give pleiomaltinine.

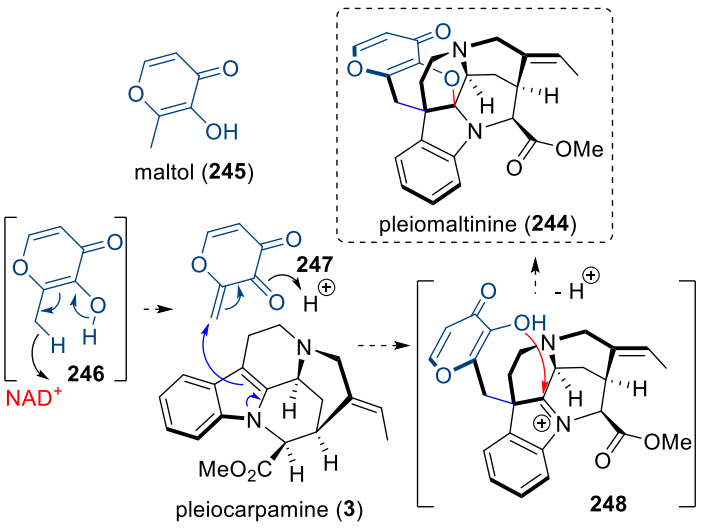

Scheme 62 Pleiomaltinine and its postulated biosynthesis 
In 2012, Porco and co-workers developed an indole-pyrone annulation for the hemisynthesis of pleiomaltinine (244). ${ }^{101}$ They unsuccessfully tried to form intermediate $\mathbf{2 4 7}$ by direct oxidation of maltol 245. Alternatively, protonated conjugated methylene diketone $\mathbf{2 5 5}$ could be generated through desilylation and expulsion of bromide from silyl ether derivative $\mathbf{2 5 0}$ of bromomaltol in presence of anhydrous hydrogen chloride via $\mathbf{2 5 2}$ and $\mathbf{2 5 3}$ to yield pyronopyranoindolines ( \pm )-251 (Scheme 63).

These conditions were then applied to natural pleiocarpamine (3) and pleiomaltinine (244) was then obtained in $51 \%$ yield as only one diastereomer due to the greater accessibility of the convex face of pleiocarpamine (3).

It should be noted that Porco and Jacobsen developed an enantioselective version of this pyroneindole annulation for which they used a chiral thiourea as catalyst in presence of an achiral Brønsted acid to form a chiral ion pair with the oxidopyrylium $\mathbf{2 5 4}$ to guide the stereoselective addition of the indole. $^{102}$
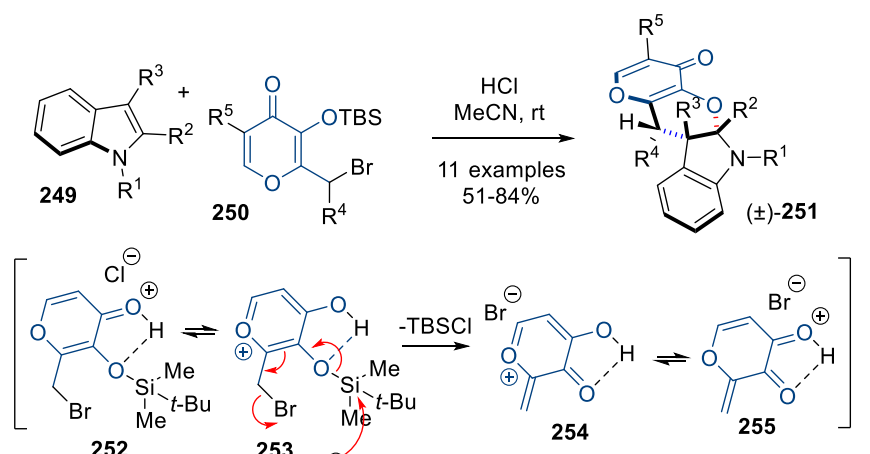

252

253
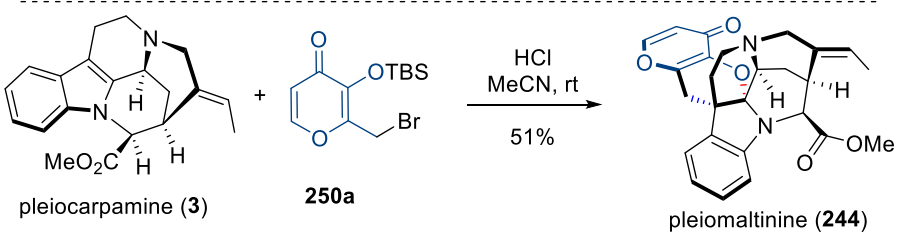

Scheme 63 Porco's indole-pyrone annulation and bioinspired hemisynthesis of pleiomaltinine

Bipleiophylline (5, Alstonia angustifolia), discovered in 2008, represents the mavacurane-mavacurane subfamily on its own (Scheme 64). ${ }^{103}$ It is the only known bisindole constituted of two pleiocarpamine units. However, these two monomers are not directly connected in contrast to most mavacuranecontaining bis-indole alkaloids. Those two units are separated to each other by an aromatic spacer. The latter obviously originates from pyrocatechuic acid (256, 2,3-dihydroxybenzoic acid) and is linked to the two pleiocarpamine halves with a dihydrofuran on one side and a $\delta$-lactone on the other side. Five years after the discovery of bipleiophylline (5), voacalgine A was isolated and proved to be the product of the union of pyrocatechuic acid and only one pleiocarpamine monomer. Its structure was originally attributed to $\mathbf{2 5 7}$ which possessed the dihydrofuran linkage. ${ }^{104}$ However, it was few years later reattributed to $\mathbf{2 5 8}$ which contains the $\delta$-lactone anchoring. ${ }^{105}$ 


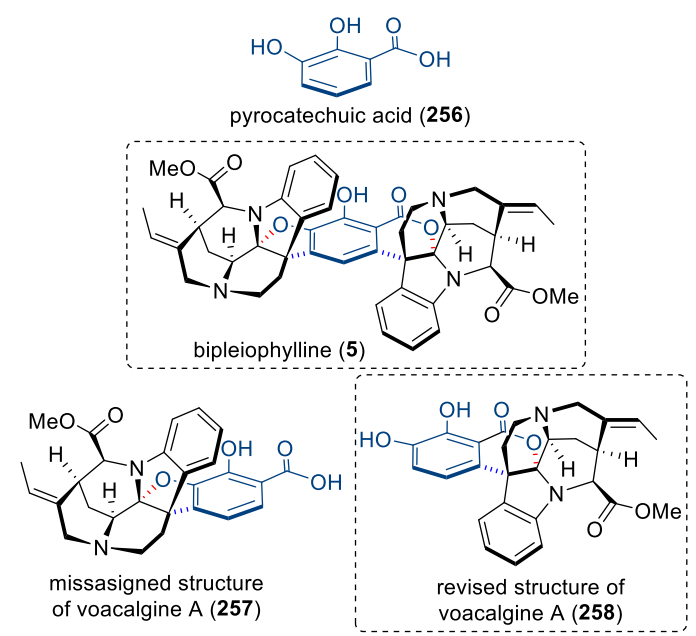

Scheme 64 Voacalgine A and bipleiophylline, a mavacurane-mavacurane bis-indole

Indeed, a common biosynthetic pathway could be proposed for bipleiophylline (5) and voacalgine A (258). In fact, this unified hypothesis was logically postulated by Kam and co-workers before the discovery of voacalgine A (Scheme 65). ${ }^{103}$ The catechol moiety of pyrocatechuic acid (256) would be oxidize into ortho-quinone (259) which would be the subject of a 1,4 conjugated addition of pleiocarpamine (3). The resulting iminium $\mathbf{2 6 0}$ would be intramolecularly trapped by the carboxylic acid leading to the $\delta$-lactone of voacalgine $A(\mathbf{2 5 8})$. Further oxidation of the catechol moiety of the latter would deliver another ortho-quinone $\mathbf{2 6 1}$ which would be involved in a 1,6 addition of a second unit of pleiocarpamine (3). Trapping of the resulting iminium $\mathbf{2 6 2}$ by one the hydroxy group of the catechol would eventually produce bipleiophylline (5).

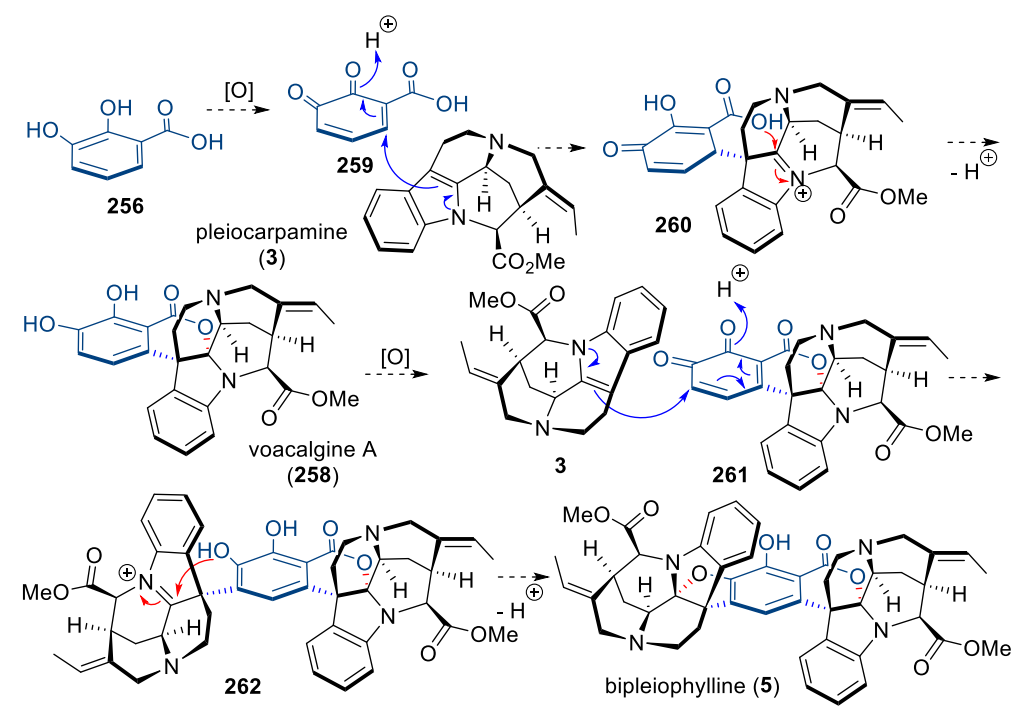

Scheme 65 Postulated unified biosynthesis of voacalgine A and bipleiophylline

An oxidative coupling was developed by Vincent and co-workers between truncated pleiocarpamine model substrates $( \pm)-263$ and $( \pm)$-137 and electron-rich phenol 264 with NIS via the formation of iodoindolenine intermediates (Scheme 66). This method yielded hexacyclic benzofuro[2,3-b]indolines ( \pm )265 and ( \pm )-266 related to the originally misassigned structure of heptacyclic voacalgine $A(257) .{ }^{106}$ However, these compounds are still similar to the other half of bipleiophylline (5). Unfortunately, this method was not applicable to catechols in lieu of phenols. 


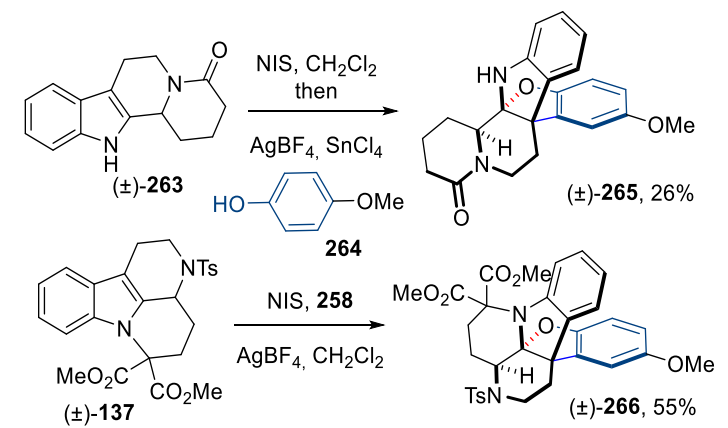

Scheme 66 Vincent's indole-phenol oxidative coupling leading to benzofuro[2,3-b]indolines related to bipleiophylline.

In order to access voacalgine A (258) and bipleiophylline (5), Poupon, Evanno, Vincent and co-workers developed bioinspired divergent oxidative couplings between indoles and 2,3-dihydrobenzoic acid derivatives (Scheme 67). ${ }^{105,107}$ Silver oxide in presence of formic acid was employed to oxidize the catechol into an ortho-quinone and the reactions presumably proceed according to the biosynthetic mechanism depicted in Scheme 64. 2,3-Dihydroxybenzoic acid 256 leaded to the formation of isochromano[3,4-b]indolenines $( \pm)$-267 which is found both in voacalgine $A(\mathbf{2 5 8})$ and bipleiophyline (5) while the methyl ester $\mathbf{2 6 8}$ delivered benzofuro[2,3-b]indolines ( \pm )-269 present in the other half of bipleiophylline (5). These two reactions demonstrated the feasibility to build the bipleiophyline skeleton. Therefore, applying this oxidative coupling to isochromano[3,4-b]indoline ( \pm )-267a as the catechol substrate and 2,3-dimethylindole 249a led to formation of the remaining benzofuro[2,3$b$ ]indoline of heptacyclic bipleiophylline model as a mixture of two diastereoisomers $( \pm)-\mathbf{2 7 0 a} / \mathbf{2 7 0 b}$. It was also possible to realize these two consecutive oxidative couplings in only one step from 2,3dihydroxybenzoic acid $\mathbf{2 5 6}$ and an excess of indole 249a. Of interest is the use of a catalytic amount of iron(II) phthalocyanine (FePc) in presence of $t$-butyl hydroperoxide instead of silver oxide to synthesize isochromano[3,4-b]indolines $( \pm)-\mathbf{2 6 7}$ as described by Chen and co-workers. ${ }^{108}$

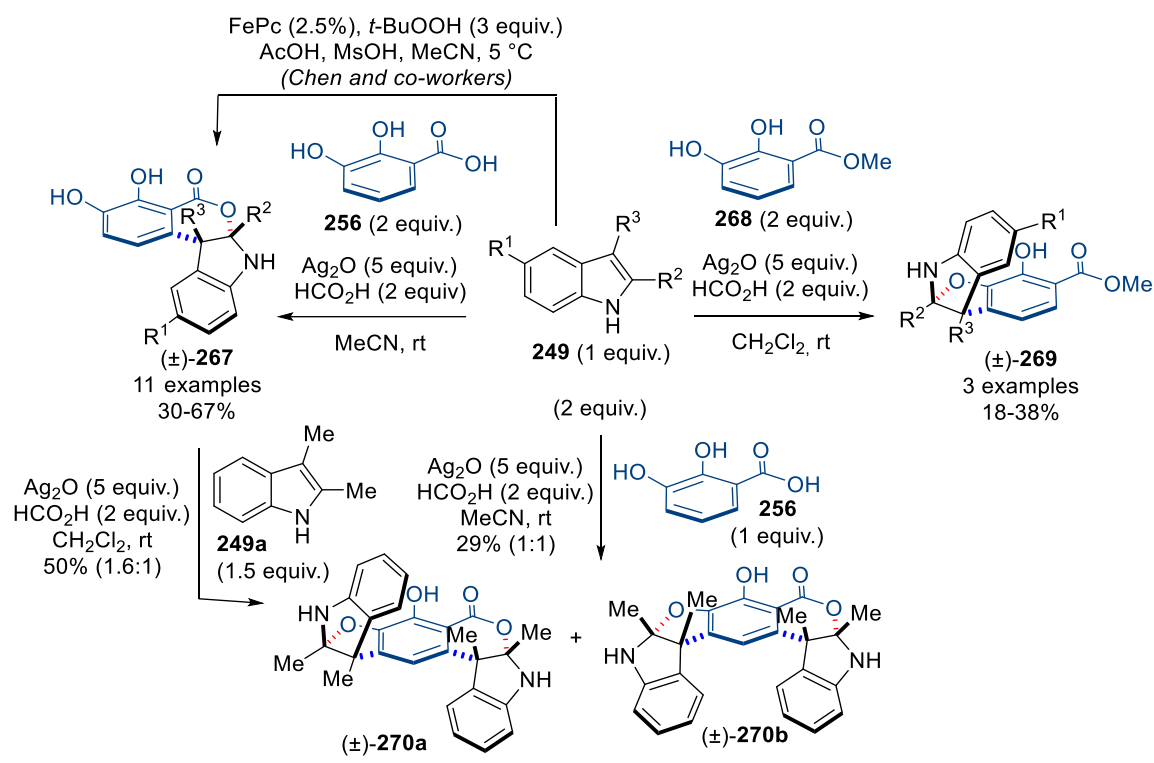

Scheme 67 Poupon, Evanno, Vincent's divergent oxidative couplings towards benzofuro[2,3-b]indolines and isochromano[3,4-b]indolines

The silver oxide-mediated divergent oxidative couplings were then applied to the hemisynthesis of voacalgine A (258) and bipleiophyline (5) from pleiocarpamine (3) isolated as a formic acid salt from Alstonia balansae (Scheme 68). ${ }^{105,107}$ A first oxidative coupling with pyrocatechuic acid (256) delivered voacalgine $A$ (258) in $21 \%$ yield. The latter was then reengaged with pleiocarpamine (3) in presence of silver oxide to assemble bipleiophylline (5) with a 3\% yield over the two steps. 


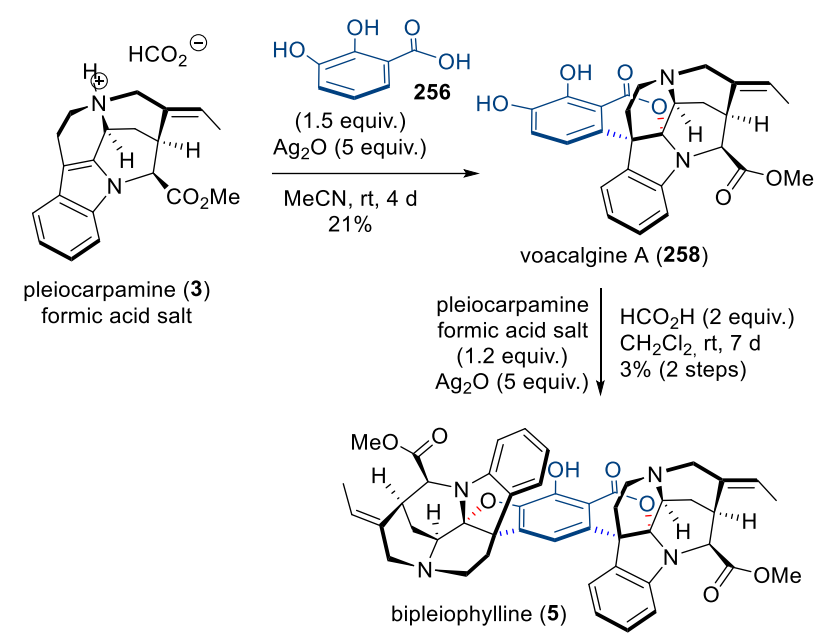

Scheme 68 Poupon, Evanno, Vincent's hemisynthesis of voacalgine A and bipleiophyline

\subsection{Comments upon "biosynthesis" of pleiocarpamine-based bis-indoles}

One may question the "real origin" of compounds as described in this section. Talking of biosynthetic origins of specialized metabolites, indeed, the enzymatic machinery dedicated to the building of, sometimes, such complex architectures has to be envisaged. Nevertheless, given the high propensity of pleiocarpamine to react (as a nucleophile for instance), the question of enzymatic control governing the formation of the above-mentioned alkaloids in living plants could be opened to debate but, needless to say, not answered at that time. The existence of discrete enzymes, more or less specifically dedicated to coupling the different partners, is for sure elusive when considering general rules of biosynthetic pathway evolution. For compounds isolated in trace amounts, some arguments may cast doubt about the involvement of DNA-encoded dedicated enzymes at the tail head of the biosynthetic pathways and can support (mostly)-non-enzymatic scenarios in the case of pleiocarpamine reactivity. Even if some bis-indoles such as villalstonine are described as a major compound, most of these alkaloids have been extracted in scarce to very scarce amounts from dried (and sometimes long shelfremaining periods) plant material (e.g. bipleiophylline: $2 \mathrm{mg} / \mathrm{kg}$; hunterizeyline $\mathrm{F}: 23 \mathrm{mg}$ from $6 \mathrm{~kg}$ ).

Note that the coupling reactions may all at first sight appear as thermodynamically favourable and are known to take place quite spontaneously (Michael-type additions, Mannich and related reactions etc.) and may be triggered under simple conditions (e.g. $\mathrm{pH}$ variations, biological transition metal ions etc.). Oxidation steps that may also provide reactive intermediates could conceivably be accomplished by promiscuous oxidases, in a way that from these last enzymatic driven steps, chemical spontaneity may provide a crucial driving force to attain astonishing high degrees of molecular complexity. These are typically the kind of situations that have been beautifully mastered in the course of bio-inspired syntheses from pleiocarpamine (see the examples of villalstonine, macrocarpamine, plumocraline, pleiomaltinine, voacalgine A or bipleiophylline). Establishing whether these intricated natural products exist in the living plants or whether in some cases they are formed during the drying process (e.g. disorganization of intracellular compartments, oxidative processes etc.) is also a remaining challenging issue. Some of these structures have been clearly demonstrated as extraction artefacts (e.g. goniomedine A arising an artefactual indolic oxidation). Interstingly, the usually observed good stereocontrol encountered in the course of the linking steps observed during the bio-inspired syntheses mentioned in this review, demonstrate that with or without the action of an enzyme: assembly steps are substrate-controlled. More generally, if and only existing in the living plants, the role of spontaneous metabolism (part of so-called "underground metabolism") is now well accepted as playing a key role in the emergence of future metabolic pathways and enzymes. ${ }^{109}$ The physiological roles of such compounds is clearly a challenging questions both in terms of evolution and chemical ecology. 


\section{Conclusion}

We reviewed the chemistry of the mavacurane subfamily of the monoterpene indole alkaloids. Its pentacyclic skeleton is characterized by a bond between the N1-indolic nitrogen and the methyl esterbearing $\mathrm{C} 16$ carbon of the corynanthe skeleton of geissoschizine, thus forming the $\mathrm{E}$ ring.

The biosynthetic hypotheses for the formation of this key bond lack clear mechanistic evidence and should foster intense efforts to understand the factors that govern the biosynthetic divergent formation of the pentacyclic mavacurane, akuammilane, excelsinidine or sarpagane alkaloids from the tetracyclic corynanthe scaffold. The conjunction of transcriptomic, proteomic and metabolomic studies will be the key to success, from the identification of gene candidates to the evaluation of enzyme promiscuity. ${ }^{110}$ Computational chemistry could also be helpful to evaluate the mechanistic plausibility of different biosynthetic scenarios. In the field of natural product chemistry, hyphenated pipelines of deep analytical methods (especially based on HPLC, UPLC/MS ${ }^{2}$ data) are now routinely used in the laboratories. ${ }^{111}$ Molecular networks accurately annotated by databases (a growing database of monoterpene indole alkaloids is now available), ${ }^{112}$ are good examples of the revolution that is on its way in the field to anticipate molecular complexity and novelty within targeted metabolomes.

Chemically speaking, due to these characteristic N1-C16 bond and E ring, the mavacurane skeleton adopts a hemispherical shape which enhances the nucleophilicity of its indole nucleus which is of importance for further biosynthetic transformation. For instance, pleiocarpamine, the most important member of the mavacuranes has the ability to assemble with several families of monoterpene alkaloids to form highly intricate bis-indole alkaloids. Very few of them (villalstonine (4), macrocarpamine (179), plumocraline (219), pleiomaltinine (238), voacalgine A (252) and bipleiophylline (5)) have been synthesize by chemists (Le Quesne, Cook, Massiot, Porco and Poupon-Evanno-Vincent) from natural pleiocarpamine (3) via biomimetic strategies.

On the other hand, the total synthesis of the mavacurane alkaloids is surprisingly a highly difficult endeavour. The formation of the N1-C16 bond and the E ring constitute a major synthetic challenge. So far, a few synthetic strategies have succeeded. Boekelheide discovered an aerobic based-mediated pinacol-type C-ring contraction and epoxide opening cascade to form the N1-C16 bond of spirooxindole-containing unnatural ( \pm )-19,20-dihydro-norfluorocurine (20) which could be converted to ( \pm )19,20-dihydro-normavacurine (22) via a reductive C-ring expansion. The group of Sakai achieved the hemisynthesis of 16-epi-pleiocarpamine (18) from geissoschizine (51) by forging the N1-C16 bond and $E$ ring by an intramolecular nucleophilic substitution of a C16-chloroester with prior opening of C/D rings junction to give more flexibility to the substrate. The group of Harley-Mason employed the same strategy to complete the total synthesis of ( \pm )-16-epi-pleiocarpamine (18), ( \pm )-16-epi-pleiocarpamine $\mathrm{N}$-oxide (26), ( \pm )-normavacurine (16) and ( \pm )- C-mavacurine (2). Nevertheless, they demonstrated that a related nucleophilic substitution without cleaving the $C / D$ rings junction could be achieved from a C16-primary mesylate lacking the methyl ester at $\mathrm{C} 16$ as well as the $\mathrm{C} 20$-exocyclic ethylidene. Poupon, Evanno and Vincent deployed a Ma's oxidative cyclization (KHMDS/ $/ \mathrm{I}_{2}$ ) of the complete geissoschizine framework. The key was the quaternization of the N4-tertiary amine into an ammonium to induce a cis-conformation in order to form the N1-C16 bond for the total synthesis of 16-epi-pleiocarpamine (18), 16-hydroxymethyl-pleiocarpamine (23) and taberdivarine $\mathrm{H}$ (24). Takayama used a metal carbenoid $\mathrm{N} 1-\mathrm{H}$ insertion from a 16-diazo-geissoschizine derivative to synthetize ( \pm )-pleiocarpamine (3), ( \pm )-16-epi-pleiocarpamine (18), ( \pm )-normavacurine (16) and ( \pm )-C-mavacurine (2) via locking the cis-conformation as a N4-aminoborane. The group of Bosch relied on a sharply different strategy in which the $\mathrm{E}$ ring and the N1-C16 bond were formed at an early stage via the annulation of an indolylacetate and an pyridinium salt. They were able to achieve the total synthesize of vinoxine (38) and then ( \pm )-2,7-dihydro-pleiocarpamine (19) via a late stage photocyclization step to construct the $\mathrm{C} 7-\mathrm{C} 6$ bond and the $\mathrm{C}$ ring.

\section{Conflict of interest}

There are no conflicts to declare. 


\section{Acknowledgements}

We gratefully acknowledge the ANR (ANR-15-CE29-0001; "Mount Indole") for a research grant. A.M. thanks the "Ministère de l'Enseignement Supérieur, de la Recherche et de l'Innovation " (MESRI) for her PhD fellowship. We are also grateful to Université Paris-Saclay and the CNRS for funding.

\section{Biography}

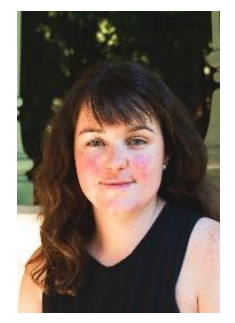

Audrey Mauger graduated with her Master degree in 2019 from Universite de Nantes (France) with a six-month internship at Paraza Pharma, Inc. (Montréal, Canada) with Dr. Vincent Albert and Dr. Stéphane Ciblat. She is now a PhD student under the supervision of Dr. Guillaume Vincent at the Institut de Chimie Moléculaire et des Matériaux d'Orsay (ICMMO) of Université Paris-Saclay (France) on the synthesis of mavacurane alkaloids.

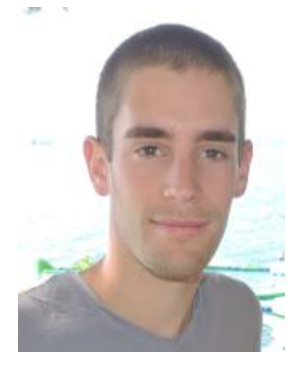

Maxime Jarret completed his Master degree in 2016 from Université de Nantes (France) with a oneyear internship at GSK (Les Ulis, France) with Dr. Nicolas George. Then, he continued his education under the supervision of Dr. Guillaume Vincent at Université Paris-Saclay (France), focusing on the total synthesis of monoterpene indole alkaloids, and received his PhD in 2019. In 2020, he joined the group of Prof. Alois Fürstner, at the Max-Planck-Institut für Kohlenforschung (Mülheim/Ruhr, Germany), as a postdoctoral associate. His research interest includes polyketide total synthesis. Since February 2021, he is a junior project manager in medicinal chemistry at NovAliX in Belgium.

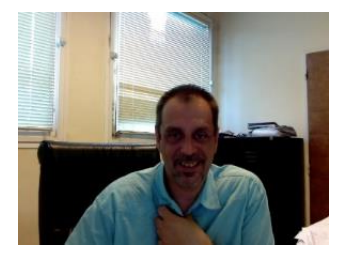

Cyrille Kouklovsky was born in Paris, France, and educated at Université Paris-Sud, Orsay (France). He defended his PhD in 1989 under the supervision of Prof. Y. Langlois (CNRS, Gif-Sur-Yvette, France), working on the cationic asymmetric Diels-Alder reaction. Then he moved to a postdoctoral position in Prof. Steven V. Ley's research group (University of Cambridge, UK), working on the total synthesis of rapamycin. In 1995, he was appointed as a CNRS research fellow at Université Paris-Sud working on asymmetric dipolar cycloaddition reactions and their synthetic applications. He was promoted as Professor of Chemistry in 2003 and he is currently the MSMT team leader at the Institut de Chimie Moléculaire et des Matériaux d'Orsay of Université Paris-Saclay. His research interests are in the field of synthetic methodology, asymmetric synthesis and peptide synthesis. He was president of the Organic Chemistry Division of the French Chemical Society from 2015 to 2019. 


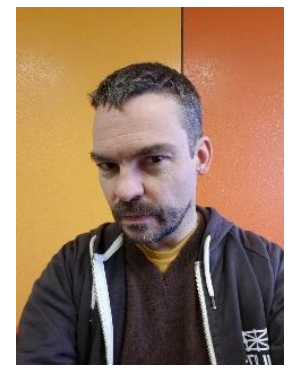

Erwan Poupon is a full professor of Natural Product Chemistry at Université Paris-Saclay (France). He obtained his PharmD from the University of Rennes in 1996 and his PhD from Paris-Descartes University in 2000 under the guidance of Pr Henri-Philippe Husson and Dr. Nicole Kunesh. After a postdoctoral period in the group of Pr Emmanuel Theodorakis (University of California in San Diego, USA), he joined the faculty at Paris-Sud University. He is particularly interested in biomimetic strategies in total synthesis and in understanding the intimate mechanisms involved in the biosynthetic pathways of specialized metabolites. Other interests include the discovery of new natural products from plants, marine invertebrates and micro-organisms as well as natural product-based drug design.

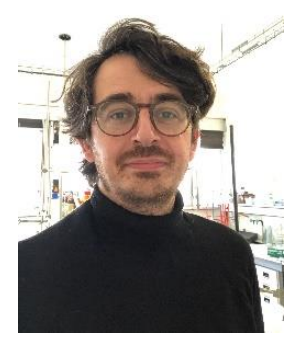

Laurent Evanno received his PhD degree in 2007 from Université Pierre et Marie Curie, Paris (France), working on total synthesis under the supervision of Dr Bastien Nay at the 'Muséum National d'Histoire Naturelle'. He then undertook postdoctoral research with Professor Petri Pihko at Helsinki University of Technology - TKK (Finland) in 2008 and with Professor Janine Cossy at ESPCl - Paris Tech (France) in 2009. Since 2010, he has been an assistant professor at Paris-Saclay University (France) and his research interests encompass biomimetic synthesis.

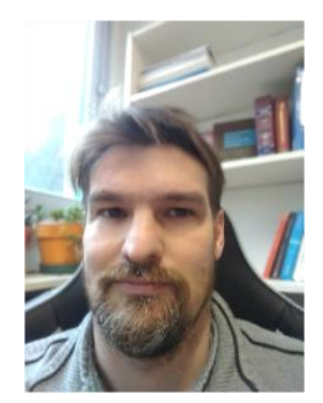

Guillaume Vincent graduated in 2002 from CPE Lyon (Ecole Supérieure de Chimie, Physique, Electronique de Lyon, France) with a one-year internship at Dupont Pharma (Wilmington, DE, USA) with Dr. Patrick Y. S. Lam. He obtained his Master (2002) and PhD (2005) degrees from Université Claude Bernard Lyon-1 (France) with Prof. Marco A. Ciufolini. After two postdoctoral experiences with Prof. Robert M. Williams at Colorado State University (USA) and with Prof. Louis Fensterbank and Prof. Max Malacria at Université Pierre et Marie Curie Paris-6 (France), he was recruited as a CNRS researcher in 2007 ("Chargé de Recherche" and then "Directeur de Recherche" since 2019) at the Institut de Chimie Moléculaire et des Matériaux d'Orsay (ICMMO) of Université Paris-Sud which is now 
Université Paris-Saclay (France). He obtained in 2018, the Jean-Marie Lehn Prize (Advanced Researcher Prize) from the Organic Chemistry Division of the French Chemical Society.

\section{References}

1.a) R. B. Herbert, in Chemistry of Heterocyclic Compounds, ed. J. E. Saxton, John Wiley \& Sons, Inc., 1983, pp. 1-46; b) S. E. O'Connor and J. J. Maresh, Nat. Prod. Rep., 2006, 23, 532-547; c) A. I. Scott, Acc. Chem. Res., 1970, 3, 151-157; d) L. F. Szabó, Molecules, 2008, 13, 1875-1896.

2.a) F. Wu, P. Kerčmar, C. Zhang and J. Stöckigt, in The Alkaloids: Chemistry and Biology, ed. H.-J. Knölker, Academic Press, 2016, vol. 76, pp. 1-61; b) O. A. Namjoshi and J. M. Cook, in The Alkaloids: Chemistry and Biology, ed. H.-J. Knölker, Academic Press, 2016, vol. 76, pp. 63-169.

3.a) G. L. Adams and A. B. Smith, in The Alkaloids: Chemistry and Biology, ed. H.-J. Knölker, Academic Press, 2016, vol. 76, pp. 171-257; b) R. Eckermann and T. Gaich, Synthesis, 2013, 45, 2813-2823; c) J. M. Smith, J. Moreno, B. W. Boal and N. K. Garg, Angew. Chem. Int. Ed., 2015, 54, 400-412.

4.J. M. Saya, E. Ruijter and R. V. A. Orru, Chem. - Eur. J., 2019, 25, 8916-8935.

5.J. M. Lopchuk, in Progress in Heterocyclic Chemistry, eds. G. W. Gribble and J. A. Joule, Elsevier, 2011, vol. 23, pp. 1-25.

6.a) T. Wieland and H. Merz, Chem. Ber., 1952, 85, 731-743; for reviews on alkaloids from calabash curare: b) A. R. Battersby and H. F. Hodson, in The Alkaloids: Chemistry and Physiology, ed. R. H. F. Manske, Academic Press, 1965, vol. 8, pp. 515579; c) P. Karrer, J. Pharm. Pharmacol., 1956, 8, 161-184.

7.H. Schmid and P. Karrer, Helv. Chim. Acta, 1947, 30, 2081-2091.

8.a) H. Bickel, E. Giesbrecht, J. Kebrle, H. Schmid and P. Karrer, Helv. Chim. Acta, 1954, 37, 553-565; b) H. Bickel, H. Schmid and P. Karrer, Helv. Chim. Acta, 1955, 38, 649-669.

9.H. Fritz, T. W. U. Mitarbeit and E. Besch, Justus Liebigs Ann. Chem., 1958, 611, 268-276.

10. H. Asmis, E. Bächli, E. Giesbrecht, J. Kebrle, H. Schmid and P. Karrer, Helv. Chim. Acta, 1954, 37, 1968-1973.

11. J. Penelle, M. Tits, P. Christen, J. Molgo, V. Brandt, M. Frédérich and L. Angenot, Phytochemistry, 2000, 53, 10571066.

12. a) H. Rapoport, R. J. Windgassen, N. A. Hughes and T. P. Onak, J. Am. Chem. Soc., 1960, 82, 4404-4414; b) J. QuetinLeclercq, G. Dive, C. Delaude, R. Warin, R. Bassleer and L. Angenot, Phytochemistry, 1994, 35, 533-536.

13. W. G. Kump and H. Schmid, Helv. Chim. Acta, 1961, 44, 1503-1516.

14. M. F. Bartlett, R. Sklar, A. F. Smith and W. I. Taylor, J. Org. Chem., 1963, 28, 2197-2199.

15. M. Hesse, W. V. Philipsborn, D. Schumann, G. Spiteller, M. Spiteller-Friedmann, W. I. Taylor, H. Schmid and P. Karrer, Helv. Chim. Acta, 1964, 47, 878-911.

16. a) G. Massiot, P. Thépenier, M.-J. Jacquier, L. Le Men-Olivier and C. Delaude, Heterocycles, 1989, 29, 1435; b) G. Massiot, P. Thepenier, M.-J. Jacquier, L. Le Men-Olivier and C. Delaude, Phytochemistry, 1992, 31, 2873-2876.

17. a) N. Langlois, L. Diatta and R. Z. Andriamialisoa, Phytochemistry, 1979, 18, 467-471; b) F. Ladhar, M. Damak, A. Ahond, C. Poupat, P. Potier and C. Moretti, J. Nat. Prod., 1981, 44, 459-465; c) B.-J. Zhang, J.-M. Yan, Z.-K. Wu, Y.-P. Liu, M.F. Bao, G.-G. Cheng, X.-D. Luo, X.-H. Cai and Y. Li, Helv. Chim. Acta, 2013, 96, 2288-2298.

18. D. E. Burke, G. A. Cook, J. M. Cook, K. G. Haller, H. A. Lazar and P. W. Le Quesne, Phytochemistry, 1973, 12, 14671474.

19. a) C. Kan, J.-R. Deverre, T. Sevenet, J.-C. Quirion and H.-P. Husson, Nat. Prod. Lett., 1995, 7, 275-281; b) T.-S. Kam, G. Subramaniam and W. Chen, Phytochemistry, 1999, 51, 159-169; c) T.-S. Kam and Y.-M. Choo, Phytochemistry, 2004, 65, 2119-2122; d) G. Subramaniam, O. Hiraku, M. Hayashi, T. Koyano, K. Komiyama and T.-S. Kam, J. Nat. Prod., 2008, 71, 5357; e) B.-J. Zhang, C. Liu, M.-F. Bao, X.-H. Zhong, L. Ni, J. Wu and X.-H. Cai, Tetrahedron, 2017, 73, 5821-5826.

20. B.-J. Zhang, X.-F. Teng, M.-F. Bao, X.-H. Zhong, L. Ni and X.-H. Cai, Phytochemistry, 2015, 120, 46-52.

21. a) Z. M. Khan, M. Hesse and H. Schmid, Helv. Chim. Acta, 1965, 48, 1957-1965; b) R. H. Burnell, A. Chapelle and M. F. Khalil, Can. J. Chem., 1974, 52, 2327-2330; c) T. Zeng, X.-Y. Wu, S.-X. Yang, W.-C. Lai, S.-D. Shi, Q. Zou, Y. Liu and L.-M. Li, J. Nat. Prod., 2017, 80, 864-871.

22. Z. Votický, L. Dolejš and E. Grossmann, Collect. Czechoslov. Chem. Commun., 1979, 44, 123-127.

23. M. J. Jacquier, J. Vercauteren, G. Massiot, L. Le Men-Olivier, J. Pussett and T. Sevenet, Phytochemistry, 1982, 21, 2973-2977.

24. S.-J. Tan, J.-L. Lim, Y.-Y. Low, K.-S. Sim, S.-H. Lim and T.-S. Kam, J. Nat. Prod., 2014, 77, 2068-2080.

25. S.-J. Tan, Y.-M. Choo, N. F. Thomas, W. T. Robinson, K. Komiyama and T.-S. Kam, Tetrahedron, 2010, 66, 7799-7806.

26. a) B. A. Akinloye and W. E. Court, Phytochemistry, 1980, 19, 307-311; b) B. A. Akinloye and W. E. Court, Phytochemistry, 1980, 19, 2741-2745.

27. Kh. T. Il'yasova, V. M. Malikov and S. Yu. Yunusov, Chem. Nat. Compd., 1970, 6, 728-729.

28. M. R. Yagudaev, M. M. Khalmirzaev and S. Yu. Yunusov, Chem. Nat. Compd., 1983, 19, 454-458.

29. L. Liu, Y.-Y. Chen, X.-J. Qin, B. Wang, Q. Jin, Y.-P. Liu and X.-D. Luo, Fitoterapia, 2015, 105, 160-164.

30. Atta-ur-Rahman and S. Khanum, Heterocycles, 1987, 26, 2125-2128.

31. a) H. Schmid, J. Kebrle and P. Karrer, Helv. Chim. Acta, 1952, 35, 1864-1879; b) E. Bächli, C. Vamvacas, H. Schmid and P. Karrer, Helv. Chim. Acta, 1957, 40, 1167-1187; c) H. Asmis, H. Schmid and P. Karrer, Helv. Chim. Acta, 1954, 37, 19831992.

32. a) R. Kaschnitz and G. Spiteller, Monatshefte Für Chem., 1965, 96, 909-921; b) M. Bashir, Planta Med., 1983, 49, 124-125. 
33. J. Mokrý, I. Kompiš and G. Spiteller, Collect. Czechoslov. Chem. Commun., 1967, 32, 2523-2531.

34. a) Z. Votický, E. Grossmann, J. Tomko, G. Massiot, A. Ahond and P. Potier, Tetrahedron Lett., 1974, 15, 3923-3926;

b) Z. Votický, E. Grossmann and P. Potier, Collect. Czechoslov. Chem. Commun., 1977, 42, 548-552.

35. M. Pinar, M. Hanaoka, M. Hesse and H. Schmid, Helv. Chim. Acta, 1971, 54, 15-43.

36. M. Pinar, M. Hesse and H. Schmid, Helv. Chim. Acta, 1973, 56, 2719-2722.

37. J. T. Ndongo, J. N. Mbing, A. Monteillier, M. F. Tala, M. Rütten, D. Mombers, M. Cuendet, D. E. Pegnyemb, B. Dittrich and H. Laatsch, J. Nat. Prod., 2018, 81, 1193-1202.

38. a) J. Stöckigt, J. Chem. Soc. Chem. Commun., 1978, 1097-1099; b) I. Gerasimenko, Y. Sheludko, X. Ma and J. Stöckigt, Eur. J. Biochem., 2002, 269, 2204-2213.

39. E. Wenkert and B. Wickberg, J. Am. Chem. Soc., 1965, 87, 1580-1589.

40. T.-T. T. Dang, J. Franke, I. S. T. Carqueijeiro, C. Langley, V. Courdavault and S. E. O'Connor, Nat. Chem. Biol., 2018, 14, 760-763.

41. L. Zhang, C.-J. Zhang, D.-B. Zhang, J. Wen, X.-W. Zhao, Y. Li and K. Gao, Tetrahedron Lett., 2014, 55, $1815-1817$.

42. H. Takayama, T. Watanabe, H. Seki, N. Aimi and S. Sakai, Tetrahedron Lett., 1992, 33, 6831-6834.

43. R. Eckermann and T. Gaich, Chem. - Eur. J., 2016, 22, 5749-5755.

44. a) J.-L. Pousset, J. Poisson, L. Olivier, J. Le Men and M.-M. Janot, C. R. Acad. Sci., 1965, 261, 5538; b) S. Benayad, K. Ahamada, G. Lewin, L. Evanno and E. Poupon, Eur. J. Org. Chem., 2016, 1494-1499; c) E. C. Tatsis, I. Carqueijeiro, T. D. de Bernonville, J. Franke, T.-T. T. Dang, A. Oudin, A. Lanoue, F. Lafontaine, A. K. Stavrinides, M. Clastre, V. Courdavault and S. E. O'Connor, Nat. Commun., 2017, 8, 316.

45. G. Hugel, D. Royer, L. Le Men-Olivier, B. Richard, M.-J. Jacquier and J. Lévy, J. Org. Chem., 1997, 62, $578-583$.

46. O. N. Tolkachev, V. G. Korobko, T. A. Shapiro and N. A. Preobrazhenskii, Chem. Heterocycl. Compd., 1967, 3, 241243.

47. a) W. Benson and E. Winterfeldt, Angew. Chem. Int. Ed. Engl., 1979, 18, 862-863; b) E. Winterfeldt and W. Benson, Heterocycles, 1981, 15, 935-941; c) C. Bohlmann, R. Bohlmann, E. G. Rivera, C. Vogel, M. D. Manandhar and E. Winterfeldt, Liebigs Ann. Chem., 1985, 1752-1763; d) M.-L. Bennasar, J.-M. Jiménez, B. A. Sufi and J. Bosch, Tetrahedron Lett., 1996, 37, 9105-9106; e) M.-L. Bennasar, B. Vidal, B. A. Sufi and J. Bosch, Chem. Commun., 1998, 2639-2640; f) M.-L. Bennasar, J.-M. Jiménez, B. Vidal, B. A. Sufi and J. Bosch, J. Org. Chem., 1999, 64, 9605-9612.

48. a) G. Rackur, M. Stahl, M. Walkowiak and E. Winterfeldt, Chem. Ber., 1976, 109, 3817-3824; b) H. Takayama, M. Morikawa, M. Kitajima, S. Sakai and N. Aimi, Nat. Prod. Lett., 1995, 7, 81-84; c) M. -L. Bennasar, E. Zulaica, B. A. Sufi and J. Bosch, Tetrahedron, 1996, 52, 8601-8610; d) V. B. Birman and V. H. Rawal, J. Org. Chem., 1998, 63, 9146-9147.

49. D. D. O'Rell, F. G. H. Lee and V. Boekelheide, J. Am. Chem. Soc., 1972, 94, 3205-3212.

50. a) S. Sakai and N. Shinma, Heterocycles, 1976, 4, 985-988; b) S. Sakai and N. Shinma, Yakugaku Zasshi, 1978, 98, 950-964.

51. S. Sakai, A. Kubo, K. Katano, N. Shinma and K. Sasago, Yakugaku Zasshi, 1973, 93, 1165-1182.

52. a) T. Koike, H. Takayama and S. Sakai, Chem. Pharm. Bull. (Tokyo), 1991, 39, 1677-1681; b) S. Sakai and N. Shinma, Chem. Pharm. Bull. (Tokyo), 1974, 22, 3013-3016.

53. M. J. Calverley, B. J. Banks and J. Harley-Mason, Tetrahedron Lett., 1981, 22, 1635-1638.

54. B. J. Banks, M. J. Calverley, P. D. Edwards and J. Harley-Mason, Tetrahedron Lett., 1981, 22, 1631-1634.

55. M. J. Calverley, J. Harley-Mason, S. A. Quarrie and P. D. Edwards, Tetrahedron, 1981, 37, 1547-1556.

56. J. Bosch, M.-L. Bennasar, E. Zulaica and M. Feliz, Tetrahedron Lett., 1984, 25, 3119-3122.

57. M.-L. Bennasar, E. Zulaica, J.-M. Jimenez and J. Bosch, Tetrahedron Letters, 1990, 31, 747-750.

58. M.-L. Bennasar, E. Zulaica, Y. Alonso, B. Vidal, J. T. Vázquez and J. Bosch, Tetrahedron Asymmetry, 2002, 13, 95-106.

59. J.-M. Jiménez, E. Zulaica, M.-L. Bennasar and J. Bosch, J. Chem. Soc. Chem. Commun., 1993, 732-733.

60. M.-L. Bennasar, E. Zulaica, J.-M. Jimenez and J. Bosch, J. Org. Chem., 1993, 58, 7756-7767.

61. P. J. Gritsch, C. Leitner, M. Pfaffenbach and T. Gaich, Angew. Chem. Int. Ed., 2014, 53, 1208-1217.

62. W. Ren, N. Tappin, Q. Wang and J. Zhu, Synlett, 2013, 24, 1941-1944.

63. a) W. Zi, Z. Zuo and D. Ma, Acc. Chem. Res., 2015, 48, 702-711; b) W. Zi, W. Xie and D. Ma, J. Am. Chem. Soc., 2012, 134, 9126-9129; c) M. Teng, W. Zi and D. Ma, Angew. Chem. Int. Ed., 2014, 53, 1814-1817; d) M. Teng, W. Zi and D. Ma, Angew. Chem. Int. Ed., 2014, 53, 1814-1817; f) R. Andres, Q. Wang and J. Zhu, J. Am. Chem. Soc., 2020, 142, 14276-14285.

64. M. Jarret, A. Tap, C. Kouklovsky, E. Poupon, L. Evanno and G. Vincent, Angew. Chem. Int. Ed., 2018, 57, 1229412298.

65. M. Jarret, A. Tap, V. Turpin, N. Denizot, C. Kouklovsky, E. Poupon, L. Evanno and G. Vincent, Eur. J. Org. Chem., 2020, 6340-6351.

66. S. F. Martin, K. X. Chen and C. T. Eary, Org. Lett., 1999, 1, 79-82.

67. S. Yu, O. M. Berner and J. M. Cook, J. Am. Chem. Soc., 2000, 122, 7827-7828.

68. M. Jarret, V. Turpin, A. Tap, J.-F. Gallard, C. Kouklovsky, E. Poupon, G. Vincent and L. Evanno, Angew. Chem. Int. Ed., 2019, 58, 9861-9865.

69. M. Jarret, H. Abou-Hamdan, C. Kouklovsky, E. Poupon, L. Evanno and G. Vincent, Org. Lett., 2021, doi:10.1021/acs.orglett.1c00018.

70. K. Sato, N. Kogure, M. Kitajima and H. Takayama, Org. Lett., 2019, 21, 3342-3345.

71. a) T.-S. Kam and Y.-M. Choo, in The Alkaloids: Chemistry and Biology, ed. G. A. Cordell, Academic Press, 2006, vol. 63, pp. 181-337; b) K. S. Ryan and C. L. Drennan, Chem. Biol., 2009, 16, 351-364; c) C. G. L. Veale and M. T. Davies-Coleman, in The Alkaloids: Chemistry and Biology, ed. H.-J. Knölker, Academic Press, 2014, vol. 73, pp. 1-64; d) M. Sato, S. Kishimoto, 
H. Noguchi and K. Watanabe, in Comprehensive Natural Products III, eds. H.-W. (Ben) Liu and T. P. Begley, Elsevier, Oxford, 2020, pp. 467-485.

72. M. T. Rahman, V. V. N. P. B. Tiruveedhula and J. M. Cook, Molecules, 2016, 21, 1525.

73. T. M. Sharp, J. Chem. Soc., 1934, 1227-1232.

74. a) M. Hesse, H. Hürzeler, C. W. Gemenden, B. S. Joshi, W. I. Taylor and H. Schmid, Helv. Chim. Acta, 1965, 48, 689704; b) G. Neukomm, E. Kletzhäundler and M. Hesse, Helv. Chim. Acta, 1981, 64, 90-96; c) M. Hesse, F. Bodmer, C. W. Gemenden, B. S. Joshi, W. I. Taylor and H. Schmid, Helv. Chim. Acta, 1966, 49, 1173-1182.

75. C. E. Nordman and S. K. Kumra, J. Am. Chem. Soc., 1965, 87, 2059-2060.

76. K. Ghedira, M. Zeches-Hanrot, B. Richard, G. Massiot, L. Le Men-Olivier, T. Sevenet and S. H. Goh, Phytochemistry, 1988, 27, 3955-3962.

77. S.-J. Tan, K.-H. Lim, G. Subramaniam and T.-S. Kam, Phytochemistry, 2013, 85, 194-202.

78. S.-H. Lim, Y.-Y. Low, G. Subramaniam, Z. Abdullah, N. F. Thomas and T.-S. Kam, Phytochemistry, 2013, 87, $148-156$.

79. F. Mayerl and M. Hesse, Helv. Chim. Acta, 1978, 61, 337-351.

80. J. S.-Y. Yeap, H. M. Saad, C.-H. Tan, K.-S. Sim, S.-H. Lim, Y.-Y. Low and T.-S. Kam, J. Nat. Prod., 2019, 82, 3121-3132.

81. a) D.E. Burke and P. W. le Quesne, J. Chem. Soc. Chem. Commun., 1972, 678; b) D. E. Burke, J. M. Cook and P. W. Le Quesne, J. Am. Chem. Soc., 1973, 95, 546-552.

82. a) Y. Bi, J. M. Cook and P. W. Le Quesne, Tetrahedron Lett., 1994, 35, 3877-3878; b) Y. Bi, L.-H. Zhang, L. K. Hamaker and J. M. Cook, J. Am. Chem. Soc., 1994, 116, 9027-9041.

83. T. Gan and J. M. Cook, Tetrahedron Lett., 1996, 37, 5033-5036.

84. a) T. Gan and J. M. Cook, Tetrahedron Lett., 1996, 37, 5037-5038; b) T. Gan and J. M. Cook, J. Org. Chem., 1998, 63, $1478-1483$.

85. M.-F. Bao, C.-X. Zeng, Y.-P. Liu, B.-J. Zhang, L. Ni, X.-D. Luo and X.-H. Cai, J. Nat. Prod., 2017, 80, 790-797.

86. A. A. Gorman and H. Schmid, Monatshefte Für Chem., 1967, 98, 1554-1566.

87. J. T. Ndongo, J. N. Mbing, M. F. Tala, A. Monteillier, D. E. Pegnyemb, M. Cuendet and H. Laatsch, Phytochemistry, 2017, 144, 189-196.

88. A. A. Gorman, N. J. Dastoor, M. Hesse, W. von Philipsborn, U. Renner and H. Schmid, Helv. Chim. Acta, 1969, 52, 33-55.

89. P. Rasoanaivo and G. Lukacs, J. Org. Chem., 1976, 41, 376-378.

90. J. Vercauteren, G. Massiot, L. LeMen-Olivier, J. Lévy and C. Delaude, Bull Soc Chim Fr, 1982, 9-10, $291-296$.

91. H. Morita, K. Mohamad, T. Suzuki, Y. Baba, K. Zaima, Y. Matsuno, Y. Hirasawa, M. Ropi Mukhtar, K. Awang and A. Hamid A. Hadi, Heterocycles, 2007, 74, 969.

92. M. A. Beniddir, M.-T. Martin, M.-E. Tran Huu Dau, P. Grellier, P. Rasoanaivo, F. Guéritte and M. Litaudon, Org. Lett., 2012, 14, 4162-4165.

93. M. A. Beniddir, M.-T. Martin, M.-E. Tran Huu Dau, P. Rasoanaivo, F. Guéritte and M. Litaudon, Tetrahedron Lett., 2013, 54, 2115-2119.

94. B. C. Das, J. P. Cosson, G. Lukacs and P. Potier, Tetrahedron Lett., 1974, 15, 4299-4302.

$95 . \quad$ B. C. Das, J. P. Cosson and G. Lukacs, J. Org. Chem., 1977, 42, 2785-2786.

96. J. Vercauteren, G. Massiot, T. Sevenet, J. Lévy, L. Le Men-Olivier and J. Le Men, Phytochemistry, 1979, 18, 17291731.

97. M. Lachia and C. J. Moody, Nat. Prod. Rep., 2008, 25, 227-253.

98. G. Massiot, J. Vercauteren, M. J. Jacquier, J. Lévy and L. Le Men-Olivier, C. R. Acad. Sci. Paris Sér. 2, 1981, 292, 191194.

99. J. Zhang, M.-F. Yuan, S.-T. Li, C.-C. Sang, M.-F. Chen, Y.-L. Ao, Z.-W. Li, J. Xie, W.-C. Ye and X.-Q. Zhang, J. Org. Chem., 2020, 85, 10884-10890.

100. Atta-ur-Rahman, A. Pervin, Anjun Muzaffar, K. Tuley Dayanada de Silva and W. Susil Jayalath Silva, Heterocycles, 1988, 27, 2051.

101. R. E. Ziegler, S.-J. Tan, T.-S. Kam and J. A. Porco, Angew. Chem. Int. Ed., 2012, 51, 9348-9351.

102. C. S. Yeung, R. E. Ziegler, J. A. Porco and E. N. Jacobsen, J. Am. Chem. Soc., 2014, 136, 13614-13617.

103. T.-S. Kam, S.-J. Tan, S.-W. Ng and K. Komiyama, Org. Lett., 2008, 10, 3749-3752.

104. Y. Hirasawa, H. Arai, A. Rahman, I. Kusumawati, N. C. Zaini, O. Shirota and H. Morita, Tetrahedron, 2013, 69, 1086910875.

105. D. Lachkar, N. Denizot, G. Bernadat, K. Ahamada, M. A. Beniddir, V. Dumontet, J.-F. Gallard, R. Guillot, K. Leblanc, E. O. N'nang, V. Turpin, C. Kouklovsky, E. Poupon, L. Evanno and G. Vincent, Nat. Chem., 2017, 9, 793-798.

106. (a) N. Denizot, A. Pouilhès, M. Cucca, R. Beaud, R. Guillot, C. Kouklovsky and G. Vincent, Org. Lett., 2014, 16, 57525755; (b) N. Denizot, R. Guillot, C. Kouklovsky and G. Vincent, Synthesis, 2018, 50, 4823-4828.

107. N. Denizot, D. Lachkar, C. Kouklovsky, E. Poupon, L. Evanno and G. Vincent, Synthesis, 2018, 50, 4229-4242.

108. J. Ye, Y. Lin, Q. Liu, D. Xu, F. Wu, B. Liu, Y. Gao and H. Chen, Org. Lett., 2018, 20, 5457-5460.

109. L. Noda-Garcia, W. Liebermeister and D. S. Tawfik, Annu. Rev. Biochem., 2018, 87, 187-216.

110. (a) T. Dugé de Bernonville, N. Papon, M. Clastre, S. E. O'Connor and V. Courdavault, Trends Pharmacol. Sci., 2020, 41, 142-146; (b) J. J. J. van der Hooft, H. Mohimani, A. Bauermeister, P. C. Dorrestein, K. R. Duncan and M. H. Medema, Chem. Soc. Rev., 2020, 49, 3297-3314.

111. A. E. F. Ramos, L. Evanno, E. Poupon, P. Champy and M. A. Beniddir, Nat. Prod. Rep., 2019, 36, 960-980. 
112. A. E. Fox Ramos, P. Le Pogam, C. Fox Alcover, E. Otogo N’Nang, G. Cauchie, H. Hazni, K. Awang, D. Bréard, A. M. Echavarren, M. Frédérich, T. Gaslonde, M. Girardot, R. Grougnet, M. S. Kirillova, M. Kritsanida, C. Lémus, A.-M. Le Ray, G. Lewin, M. Litaudon, L. Mambu, S. Michel, F. M. Miloserdov, M. E. Muratore, P. Richomme-Peniguel, F. Roussi, L. Evanno, E. Poupon, P. Champy and M. A. Beniddir, Sci. Data, 2019, 6, 15. 